Florida International University FIU Digital Commons

$11-14-2013$

\title{
Investigating the In Vitro Oxidative Folding Pathways of Bovine Pancreatic Trypsin Inhibitor (BPTI)
}

Yingsong Wang

ywang020@fiu.edu

DOI: $10.25148 /$ etd.FI13121203

Follow this and additional works at: https://digitalcommons.fiu.edu/etd

Part of the Biochemistry Commons, and the Other Chemistry Commons

\section{Recommended Citation}

Wang, Yingsong, "Investigating the In Vitro Oxidative Folding Pathways of Bovine Pancreatic Trypsin Inhibitor (BPTI)" (2013). FIU Electronic Theses and Dissertations. 1029.

https://digitalcommons.fiu.edu/etd/1029 


\title{
FLORIDA INTERNATIONAL UNIVERSITY
}

Miami, Florida

\section{INVESTIGATING THE IN VITRO OXIDATIVE FOLDING PATHWAYS OF BOVINE PANCREATIC TRYPSIN INHIBITOR (BPTI)}

\author{
A dissertation submitted in partial fulfillment of \\ the requirements for the degree of \\ DOCTOR OF PHILOSOPHY \\ in \\ CHEMISTRY \\ by \\ Yingsong Wang
}

2013 
To: Dean Kenneth G. Furton

College of Arts and Sciences

This dissertation, written by Yingsong Wang, and entitled Investigating the In Vitro Oxidative Folding Pathways of Bovine Pancreatic Trypsin Inhibitor (BPTI), having been approved in respect to style and intellectual content, is referred to you for judgment.

We have read this dissertation and recommend that it be approved.

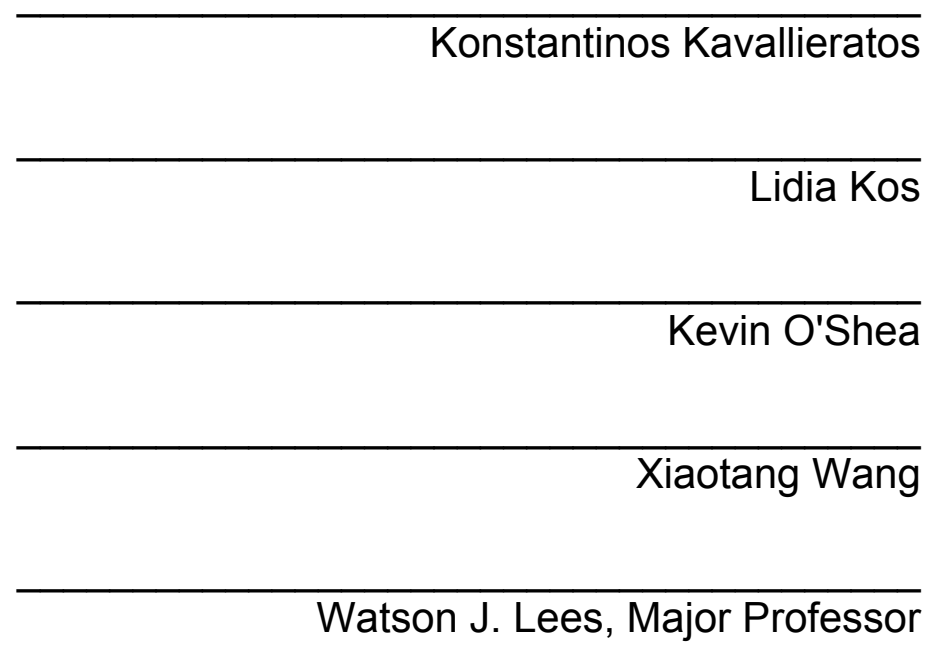

Date of Defense: November 14, 2013

The dissertation of Yingsong Wang is approved.

$\begin{array}{r}\text { Dean Kenneth G. Furton } \\ \text { College of Arts and Sciences } \\ \hline \begin{array}{r}\text { Dean Lakshmi N. Reddi } \\ \text { University Graduate School }\end{array}\end{array}$

Florida International University, 2013 
(C) Copyright 2013 by Yingsong Wang

All rights reserved. 


\section{DEDICATION}

I dedicate this dissertation to my wife, my parents and every family member. Only with their understanding, encouragement and support, I could complete this work. 


\section{ACKNOWLEDGMENTS}

After five years graduate studying in FIU, I successfully completed my chemistry Ph. D. degree. However, it is unimaginable to achieve this achievement without many people's help. I would like to express my appreciation and thanks to you all. First and foremost, I am so grateful to have Dr. Watson J. Lees to be my research advisor. His insightful thoughts and advices benefit me a lot in my academics and researches. I sincerely appreciate him for his guidance, patience and encouragement when I have any difficulties in my life. Meanwhile, I would like to thank my committee members, Dr. Konstantinos Kavallieratos, Dr. Lidia Kos, Dr. Kevin O'Shea and Dr. Xiaotang Wang, for their generosity in their time and suggestions.

I would like to thank all members in Dr. Lees' group: Xi Chen, Changjun Fan, Nadezhda Islamova, Ram Marahatta, and Amar Patel. I also appreciate Hanzhuo Fu, Yong Liang and all my friends and colleagues in FIU for their kindness and help. Finally, I acknowledge Department of Chemistry and Biochemistry at Florida International University for offering me the opportunity to work as a teaching assistant and thank the lab coordinators I worked with. 
ABSTRACT OF THE DISSERTATION

INVESTIGATING THE IN VITRO OXIDATIVE FOLDING PATHWAYS OF

BOVINE PANCREATIC TRYPSIN INHIBITOR (BPTI)

\author{
by
}

Yingsong Wang

Florida International University, 2013

Miami, Florida

\title{
Professor Watson J. Lees, Major Professor
}

The oxidative folding pathway of the disulfide containing protein bovine pancreatic trypsin inhibitor (BPTI) was one of the first to be elucidated and has served as a basis for understanding the folding pathways of other proteins. During the oxidative folding of reduced BPTI, two intermediates $\left(\mathrm{N}^{\prime}\right.$ and $\left.\mathrm{N}^{*}\right)$ accumulate in significant amounts and act as kinetic traps. Both $\mathrm{N}^{\prime}$ and $\mathrm{N}^{*}$ bury their two remaining free thiols in their hydrophobic cores, which inhibits further oxidation. Historically, the rate limiting step was considered to be the intramolecular rearrangements of $\mathrm{N}^{\prime}$ and $\mathrm{N}^{*}$ to another intermediate with two free thiols, $\mathrm{N}^{\mathrm{SH}}$. The two free thiols in $\mathrm{N}^{\mathrm{SH}}$ are solvent-exposed and easily oxidized to a disulfide, producing native protein $(\mathrm{N})$. Nevertheless, our research using reduced $\mathrm{BPTI}$ indicated that the folding rate of $\mathrm{N}^{*}$ to $\mathrm{N}$ was proportional to the concentration of added glutathione disulfide (GSSG), inconsistent with the slow intramolecular rearrangement of $\mathrm{N}^{*}$ to $\mathrm{N}^{\mathrm{SH}}$. To confirm our initial results, the intermediate $\mathrm{N}^{*}$ was purified and refolded in the presence of GSSG. The conversion of $\mathrm{N}^{*}$ to $\mathrm{N}$ was dependent upon the disulfide concentration and singly 
mixed disulfide $\mathrm{N}^{*}(\mathrm{SG})$ was observed during folding. These results emphasize that the folding of $\mathrm{N}^{*}$ can proceed via a growth type pathway, direct oxidation of the two remaining thiols in $\mathrm{N}^{*}$ by an exogenous small molecule disulfide, such as GSSG, to form N. Folding of reduced BPTI via $\mathrm{N}^{*}$ was performed under changing concentrations of GSSG and GSH as a function of time. The folding was improved dramatically in terms of rate and yield.

Aromatic disulfides and thiols have been demonstrated to improve the folding efficiency of disulfide containing proteins including ribonuclease A (RNase A) and lysozyme. Herein, $\mathrm{N}^{*}$ and $\mathrm{N}^{\prime}$ were refolded in the presence of aromatic disulfides. Folding of the two kinetic traps with aromatic disulfides indicated that folding proceed via a growth type pathway. The singly and doubly mixed disulfide intermediates were observed during most folding reactions. The oxidative folding of reduced BPTI with aromatic disulfides and thiols were also investigated. Reduced BPTI can be folded to disulfide intermediates rapidly. 


\section{TABLE OF CONTENTS}

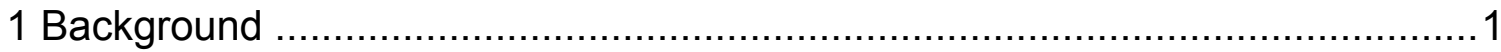

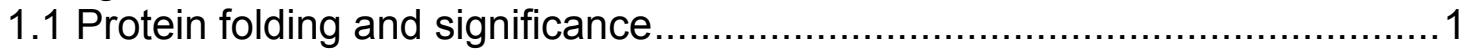

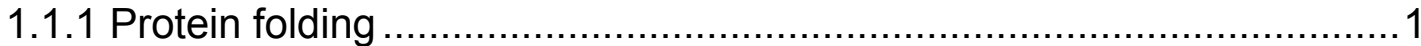

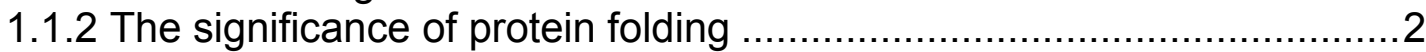

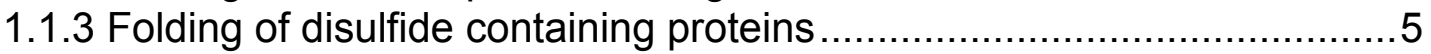

1.2 Disulfide bond formation and protein oxidative folding pathways.................6

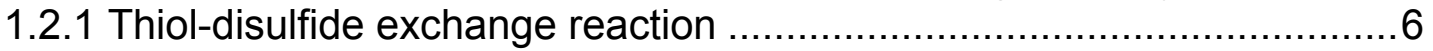

1.2.2 Traditional thiols and disulfides used for disulfide bond formation..........8

1.2.3 Oxidative folding of ribonuclease $A($ RNase A) ................................10

1.2.4 Generic pathways of oxidative folding ….......................................12

1.3 Early models of the oxidative folding of bovine pancreatic trypsin inhibitor

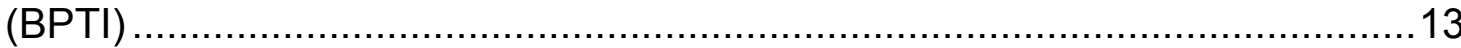

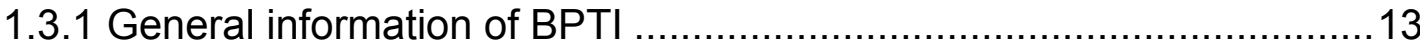

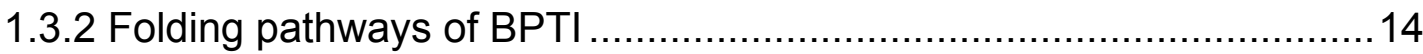

1.4 Recent developments on oxidative folding of BPTI...............................22

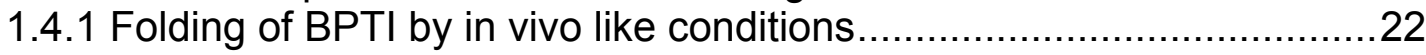

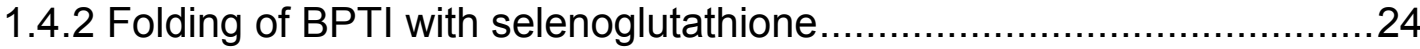

1.5 Folding of protein with protein disulfide isomerase (PDI) .......................27

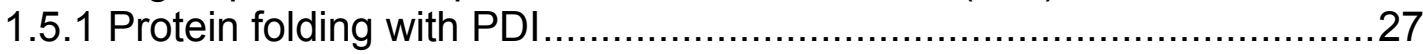

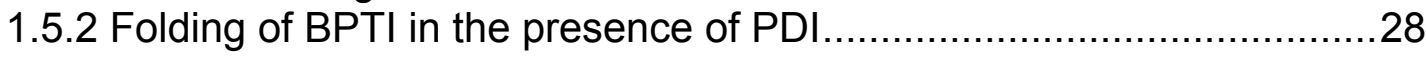

1.6 Protein folding with small aromatic molecules.......................................29

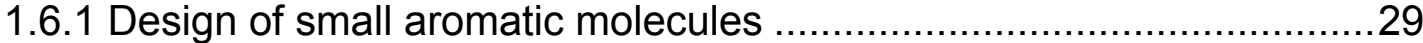

1.6.2 Aromatic monothiols and disulfides containing different functional

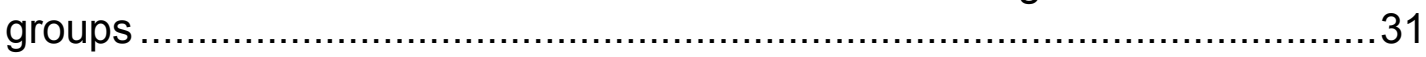

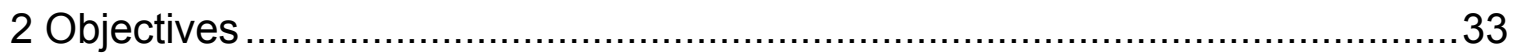

2.1 Production of pure reduced BPTI and folding intermediates $\mathrm{N}^{*}, \mathrm{~N}^{\prime}, \mathrm{N}^{\prime}(\mathrm{SG})_{2}$,

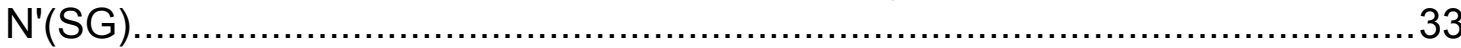

2.2 Kinetic study of the oxidative folding of intermediates $\mathrm{N}^{*}, \mathrm{~N}^{\prime}, \mathrm{N}^{\prime}(\mathrm{SG})_{2}, \mathrm{~N}^{\prime}(\mathrm{SG})$ and reduced BPTI with GSSG and GSH

2.3 Oxidative folding of BPTI with small molecule aromatic disulfides and thiols

3 Production of kinetic traps accumulated during the oxidative folding of BPTI ..35

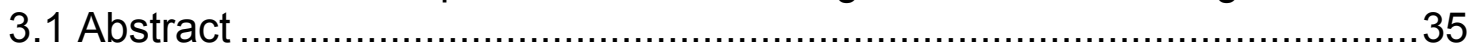

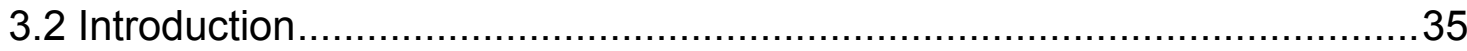

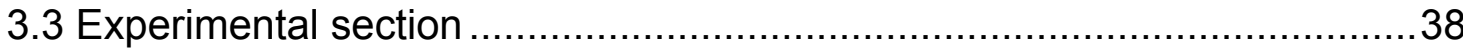

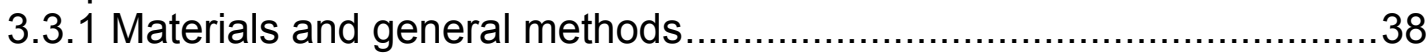

3.3.2 Preparation and purification of reduced BPTI .....................................39

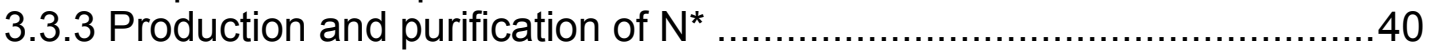

3.3.4 Preparation and purification of $\mathrm{N}^{\prime}$................................................. 42 


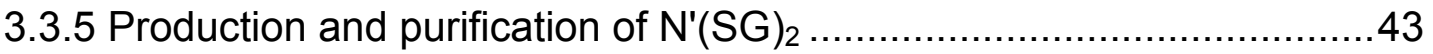

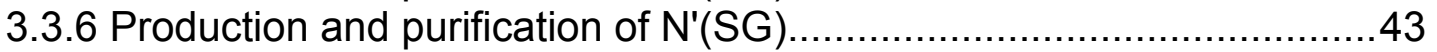

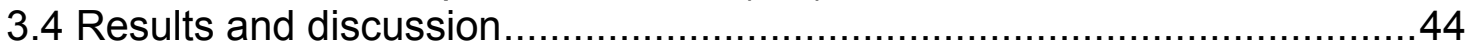

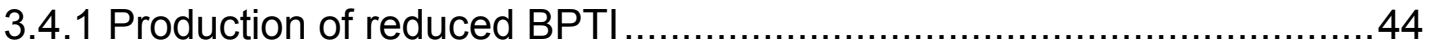

3.4.2 Production of kinetic trap $\mathrm{N}^{*}$ from reduced BPTI .............................45

3.4.3 Production of kinetic trap N' from reduced BPTI ..............................48

3.4.4 Production of kinetic trap N'(SG) $)_{2}$ from reduced $\mathrm{BPTI}$......................50

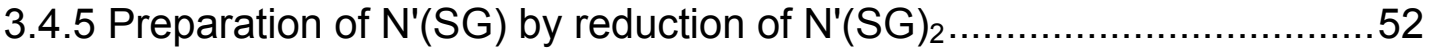

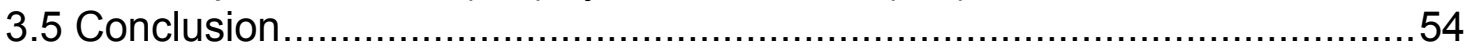

4 Kinetic study of the oxidative folding of intermediates $\mathrm{N}^{*}, \mathrm{~N}^{\prime}, \mathrm{N}^{\prime}(\mathrm{SG})_{2}, \mathrm{~N}^{\prime}(\mathrm{SG})$

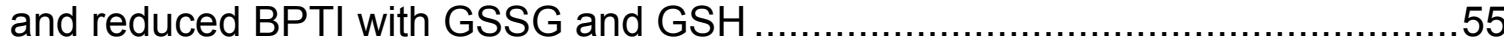

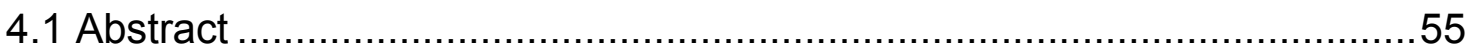

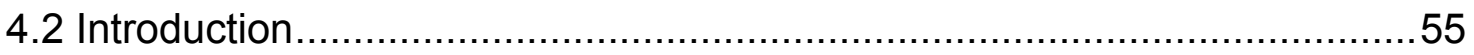

4.3 Experimental section .................................................................5

4.3.1 Determination of rate constants for the reaction of $\mathrm{N}^{*}, \mathrm{~N}^{\prime}$ and $\mathrm{N}^{\prime}(\mathrm{SG})$

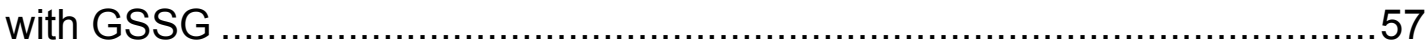

4.3.2 Determination of rate constants for the reduction of $\mathrm{N}^{*}, \mathrm{~N}^{\prime}, \mathrm{N}^{\prime}(\mathrm{SG})$ and

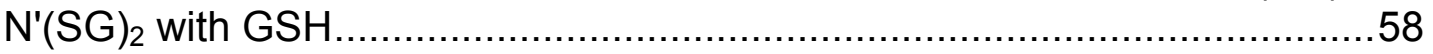

4.3.3 Folding of reduced BPTI by optimizing concentration of GSSG and

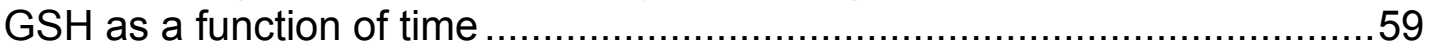

4.4 Results and discussion.............................................................59

4.4.1 Determination of rate constants for the reaction of $\mathrm{N}^{*}, \mathrm{~N}^{\prime}$ and $\mathrm{N}^{\prime}(\mathrm{SG})$

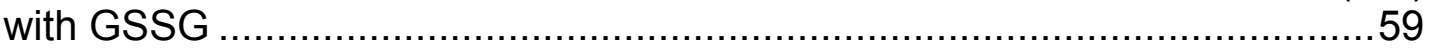

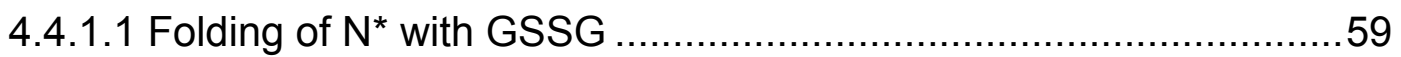

4.4.1.2 Folding of $\mathrm{N}^{\prime}$ in the buffer alone and GSSG ............................64

4.4.1.3 Folding of $\mathrm{N}^{\prime}(\mathrm{SG})$ in the buffer alone and GSSG .......................67

4.4.2 Determination of rate constants for the reduction of $\mathrm{N}^{*}, \mathrm{~N}^{\prime}, \mathrm{N}^{\prime}(\mathrm{SG})$ and

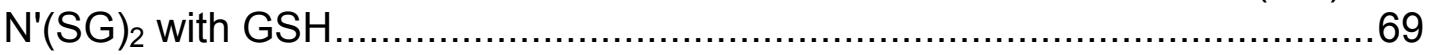

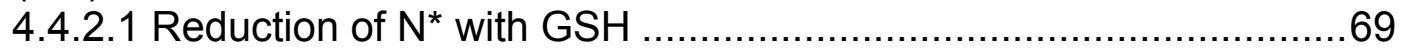

4.4.2.2 Reduction of N' with GSH ................................................ 70

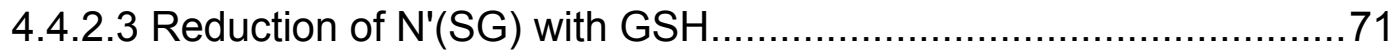

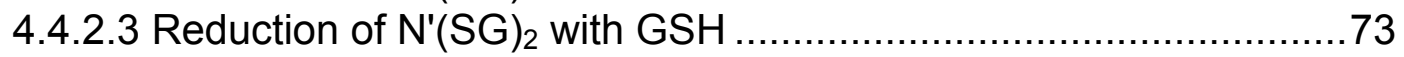

4.4.3 Folding of reduced BPTI by optimizing concentration of GSSG and

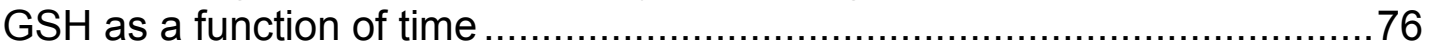

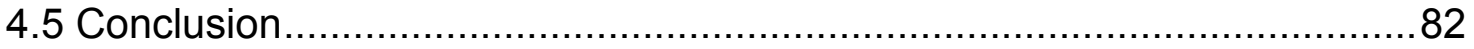

5 Oxidative folding of BPTI with small molecule aromatic disulfides and thiols ...83

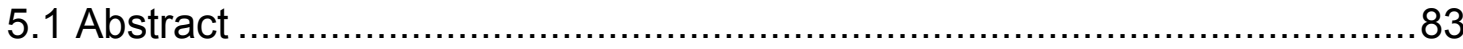

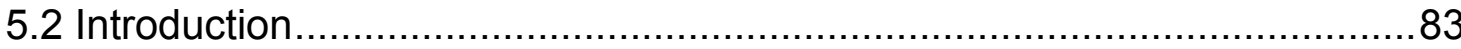

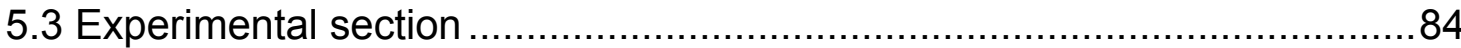

5.3.1 Kinetic study of oxidative folding of kinetic trap $\mathrm{N}^{*}$ with aromatic

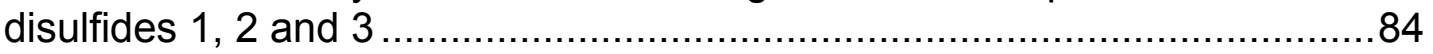

5.3.1.1 Folding of $\mathrm{N}^{*}$ with aromatic disulfide $1 \ldots \ldots \ldots \ldots \ldots \ldots \ldots \ldots \ldots \ldots \ldots . . . . . . . . \ldots 4$

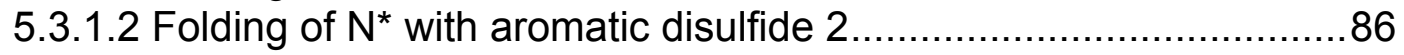


5.3.1.3 Folding of $\mathrm{N}^{*}$ with aromatic disulfide 3

5.3.2 Kinetic study of oxidative folding of kinetic trap $\mathrm{N}^{\prime}$ with aromatic

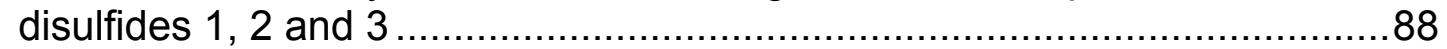

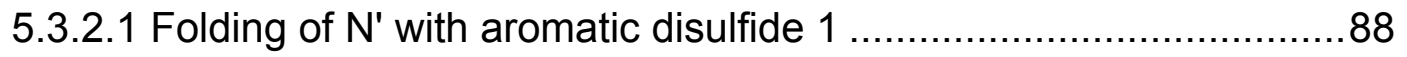

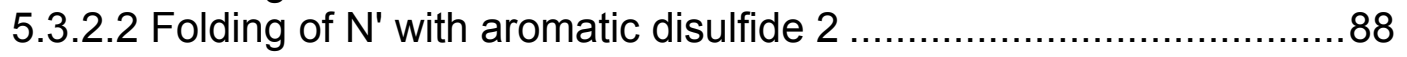

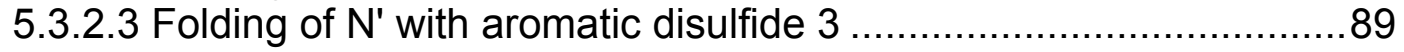

5.3.3 Oxidative folding of reduced BPTI with aromatic disulfides 1, 2 and 389

5.4 Results and discussion.................................................................... 90

5.4.1 Kinetic study of oxidative folding of kinetic trap $\mathrm{N}^{*}$ with aromatic

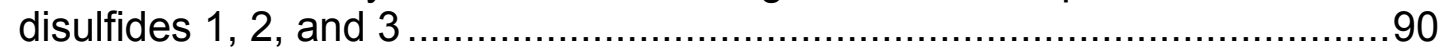

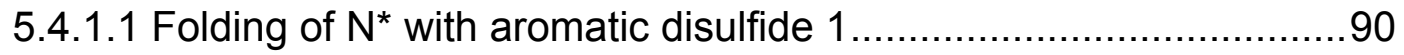

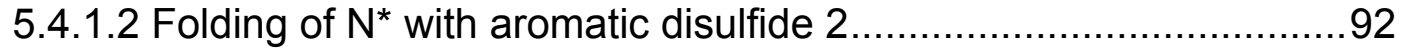

5.4.1.2 Folding of $\mathrm{N}^{*}$ with aromatic disulfide 3....................................95

5.4.2 Kinetic study of oxidative folding of kinetic trap $\mathrm{N}^{\prime}$ with aromatic

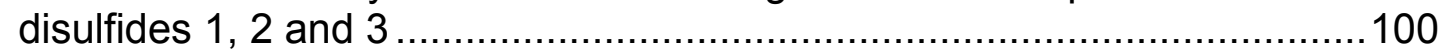

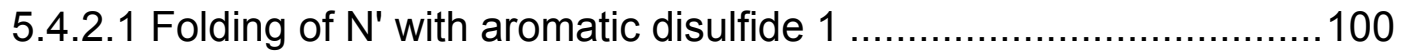

5.4.2.2 Folding of $\mathrm{N}^{\prime}$ with aromatic disulfide 2 .....................................101

5.4.2.2 Folding of $\mathrm{N}^{\prime}$ with aromatic disulfide 3 ....................................101

5.4.3 Oxidative folding of reduced BPTI with aromatic disulfides 1, 2 and 3

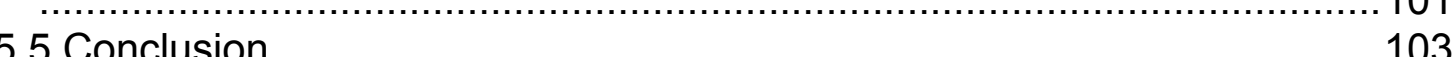

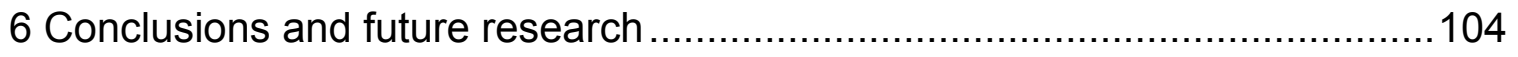

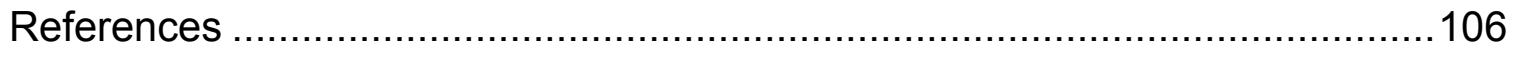

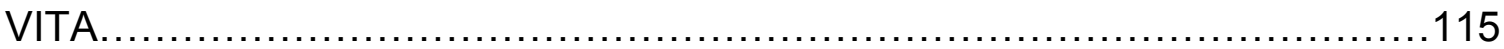




\section{LIST OF FIGURES}

FIGURE

PAGE

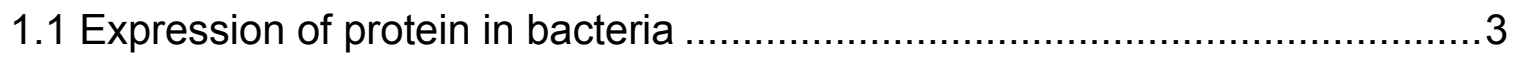

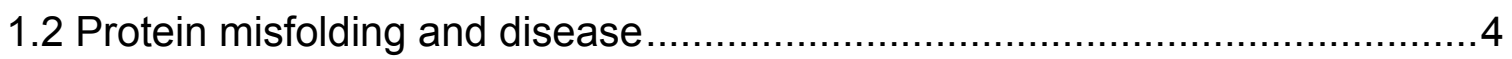

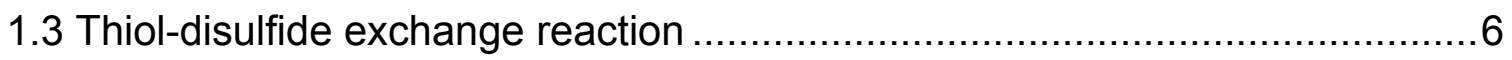

1.4 Intramolecular formation of a protein disulfide bond via a rearrangement type pathway

1.5 Intermolecular formation of a protein disulfide bond via a growth type pathway

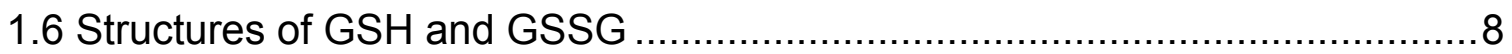

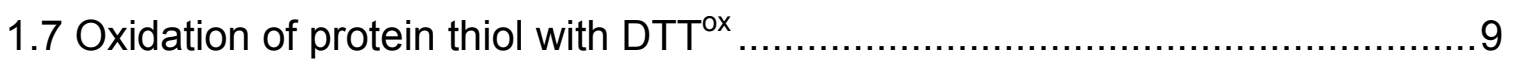

1.8 Structure of bovine pancreatic ribonuclease A (RNase A) .........................11

1.9 Kinetic model of the oxidative folding of RNase A .................................11

1.10 Generic folding pathways of a typical disulfide contacting protein ..............13

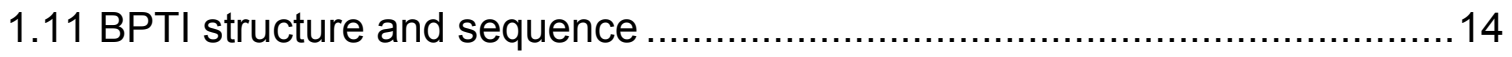

1.12 Three stages of BPTI folding with native disulfide bond ..........................15

1.13 Oxidative folding of BPTI via a rearrangement type pathway ....................17

1.14 Oxidative folding of BPTI via both rearrangement and growth type pathways 18

1.15 The pathway of unfolding and refolding of BPTI reported by Creighton ......19

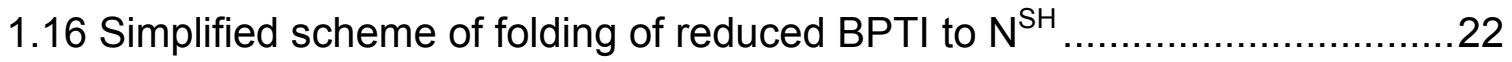

1.17 Modeling of folding of reduced BPTI to native protein ..............................24

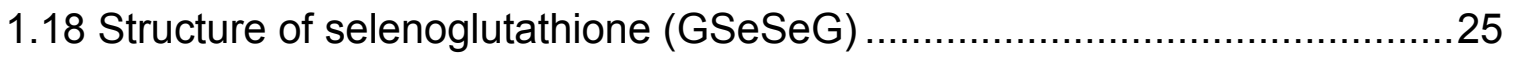

1.19 Oxidation of the active site of PDI to form a 14-membered disulfide ring....27 
1.20 Disulfide isomerization catalyzed by aromatic thiol

1.21 Aromatic disulfide catalyzed oxidative folding of a protein via a growth type pathway

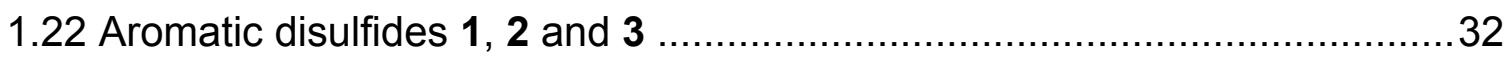

3.1 Folding of reduced BPTI with $5 \mathrm{mM}$ GSSG and $5 \mathrm{mM} \mathrm{GSH} \ldots \ldots \ldots \ldots \ldots \ldots \ldots \ldots$

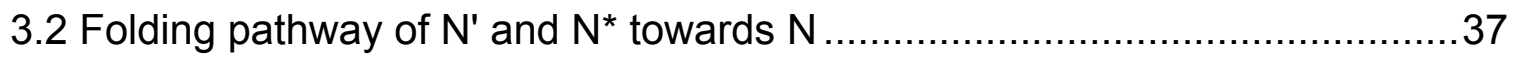

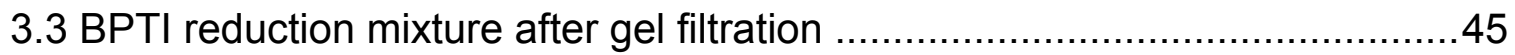

3.4 Reduced BPTI after purification by RP-HPLC .........................................

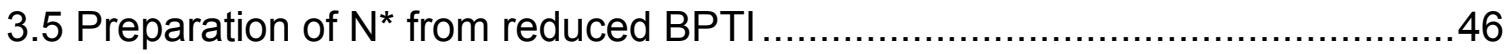

3.6 Separation of $\mathrm{N}^{*}$ on a Vydac C18 semi-preparative column ......................47

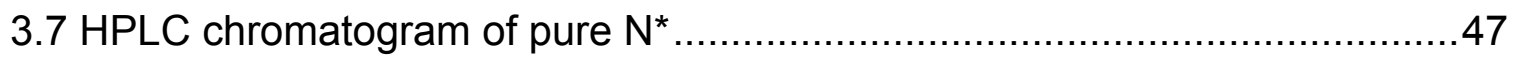

3.8 Reaction of reduced BPTI with $0.5 \mathrm{mM} \mathrm{GSSG}$ and $5 \mathrm{mM} \mathrm{GSH}$ after $15 \mathrm{~min} 48$

3.9 Separation of N' on C18 semi-preparative column ................................49

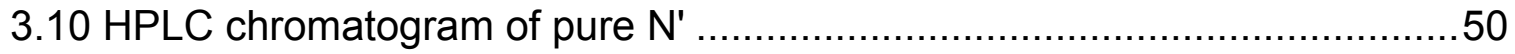

3.11 Reaction of reduced BPTI with $20 \mathrm{mM} \mathrm{GSSG}$ after $6 \mathrm{~h}$...........................51

3.12 Separation of $\mathrm{N}^{\prime}(\mathrm{SG})_{2}$ on a C18 semi-preparative column ......................51

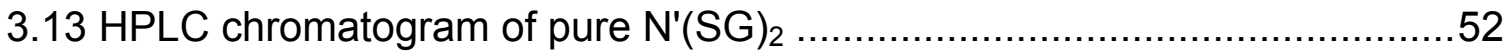

3.14 Reduction of $\mathrm{N}^{\prime}(\mathrm{SG})_{2}$ with $10 \mathrm{mM}$ GSH after $6 \mathrm{~min} \ldots \ldots \ldots \ldots \ldots \ldots \ldots \ldots \ldots \ldots . . . . . . . . . \ldots \ldots$

3.15 Separation of $\mathrm{N}^{\prime}(\mathrm{SG})$ on a C18 semi-preparative column ........................53

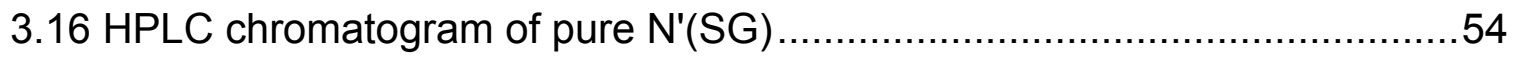

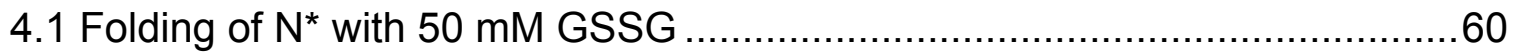

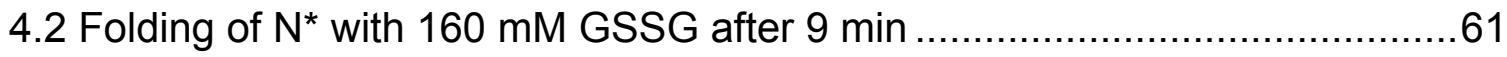

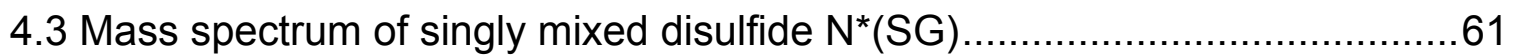




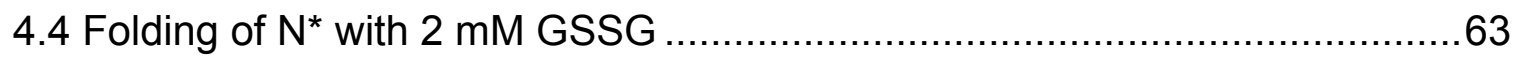

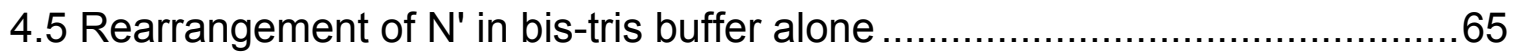

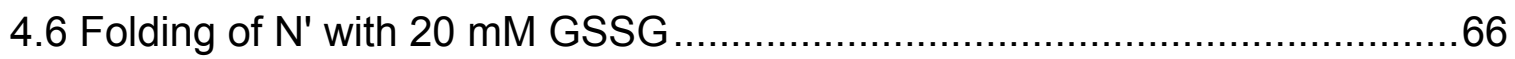

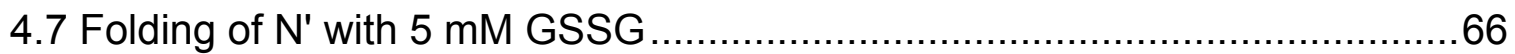

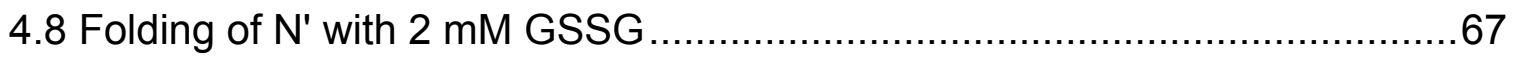

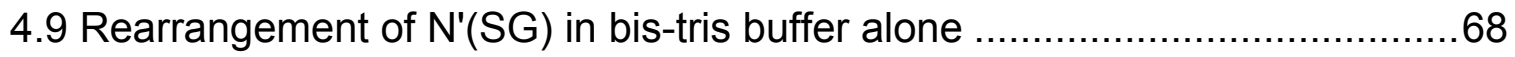

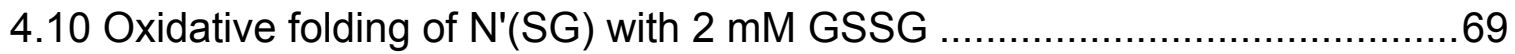

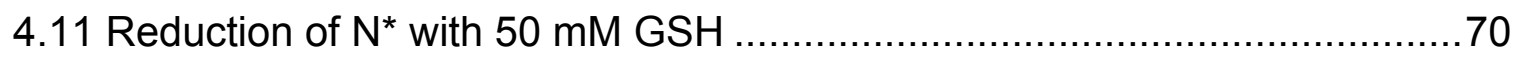

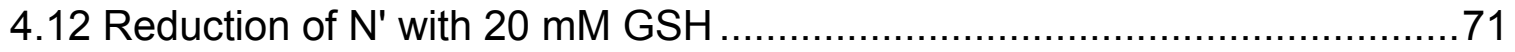

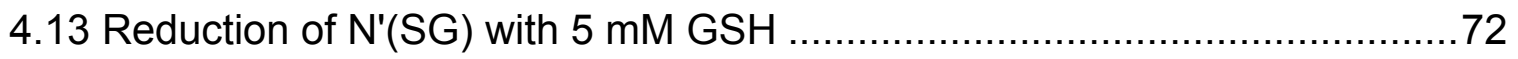

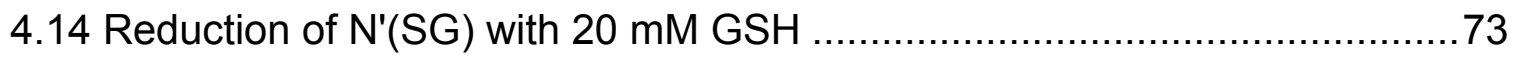

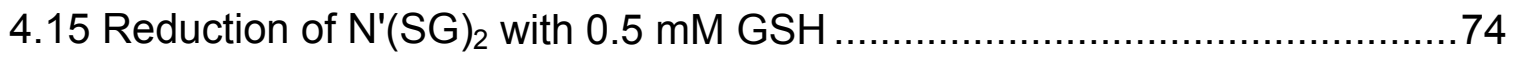

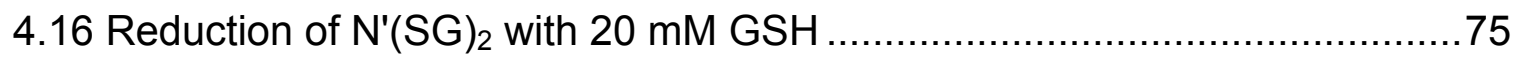

4.17 Both oxidation and reduction rate constants involving all the kinetic traps..76

4.18 Folding of reduced BPTI with $15 \mathrm{mM}$ GSH and $30 \mathrm{mM}$ GSSG under

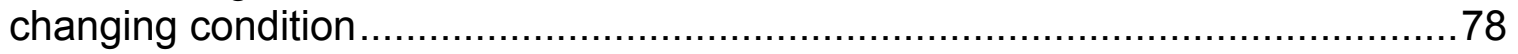

4.19 Folding of reduced BPTI with changing condition ...................................80

4.20 Folding of reduced BPTI with $50 \mathrm{mM}$ GSSG and $35 \mathrm{mM} \mathrm{GSH}$ under

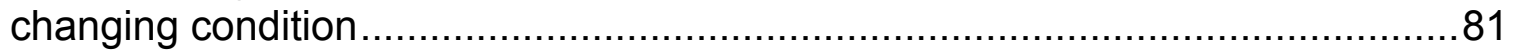

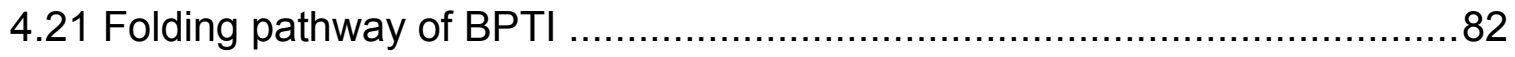

5.1 Aromatic disulfide 1, 2 and 3, and the corresponding thiols, 4, 5 and $6 \ldots \ldots . .84$

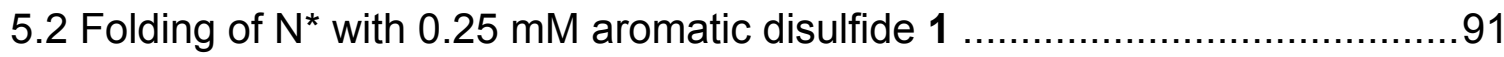

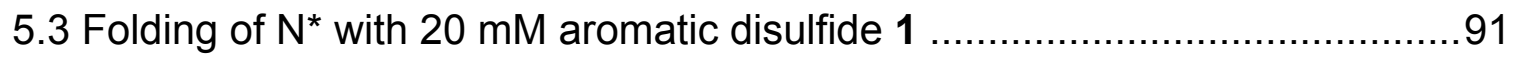

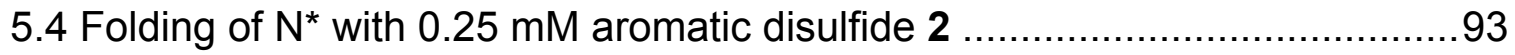


5.5 Two intermediates observed during reaction of $\mathrm{N}^{*}$ with $0.25 \mathrm{mM}$ aromatic disulfide 2 293

5.6 Mass spectrum of $\mathrm{N}^{*}(\mathrm{SAr})$ formed during the reaction of $\mathrm{N}^{*}$ with aromatic disulfide 2

5.7 Oxidative folding of $\mathrm{N}^{*}$ with $0.125 \mathrm{mM}$ aromatic disulfide 3 96

5.8 Mass spectrum of singly mixed disulfide formed during the reaction of $\mathrm{N}^{*}$ with aromatic disulfide 3 .

5.9 Folding of $\mathrm{N}^{*}$ with aromatic disulfide via a growth type pathway, $\operatorname{ArSSAr}$ refers to aromatic disulfide 1, 2 and 3

5.10 Oxidative folding of reduced BPTI with $0.25 \mathrm{mM}$ aromatic disulfide 1 at $\mathrm{pH}$ 7.3 102 


\section{Chapter 1}

\section{Background}

\subsection{Protein folding and significance}

\subsubsection{Protein folding}

Proteins are fundamental components of all living systems, and are essential for almost all biological functions, such as immune protection, catalysis, and transport. ${ }^{1}$ The diversity of protein functions is attributed to variations in the structure, size and composition of each protein. ${ }^{1,2}$ Proteins are composed of 20 amino acids. As the basic units of proteins, amino acids are linked together with peptide bonds. The sequence of this linear polypeptide chain is referred to as a protein's primary structure. ${ }^{1}$ Secondary structure occurs when the backbone of a polypeptide chain adopts a regular and spatially organized structure, such as an alpha helix or beta sheet. ${ }^{1}$ Tertiary structure refers to the three-dimensional folded conformation of the polypeptide chain including the spatial arrangement of side chains and disulfide bonds. ${ }^{1}$ The spatial arrangement of polypeptide chains in proteins with more than one chain defines quaternary structure. The conversion of an initially unstructured and unfolded polypeptide chain to its characteristic and functional three-dimensional structure is termed protein folding. ${ }^{3}$

Protein folding is a self-assembling process, in which the hydrophobic side chains of amino acids condense together. ${ }^{4}$ Normally for cytosolic proteins, the side chains of hydrophobic amino acids are buried inside of the protein while the side chains of polar and charged amino acids are exposed on the protein's 
surface. Non-covalent forces including hydrophobic interaction and van der Waals force, and covalent disulfide bonds contribute to the stability of the native protein. ${ }^{5}$ Protein folding is usually fast and mainly determined by the protein's primary structure and the cellular milieu. ${ }^{6,7}$ Folding reaction occurs spontaneously under suitable conditions and directs the protein's conformation towards a free energy minimum. The folding intermediates that accumulate during protein folding are thermodynamically favorable. However, any change in the amino acid sequence of the protein, the secondary and/or tertiary structure of the protein, and cellular milieu may lead to protein misfolding. ${ }^{8}$ Understanding of protein folding pathway has a potential to prevent the accumulation of misfolded proteins which can be malfunction and harmful to biological systems.

\subsubsection{The significance of protein folding}

The efficient production of recombinant proteins in bacteria is important because one third of all recombinant therapeutic proteins are produced in bacteria. ${ }^{9}$ However, the expression of engineered proteins in bacteria is limited by the bacteria's ability to perform posttranslational modifications and to form native disulfide bonds. ${ }^{10}$ Disulfide containing proteins expressed in bacteria usually accumulate as inactive precipitates, which are known as inclusion bodies. Efforts to minimize the formation of inclusion bodies have been investigated, such as co-expression of the target protein in the presence of chaperones and foldases, cultivating the cells at lower temperature, and adding solubilizer. ${ }^{11,12}$ However, the formation of inclusion bodies can be advantageous in the expression of many recombinant proteins. The production of proteins as inclusion 
bodies can prevent proteins from proteolytic degradation and can minimize the toxic effect to the host bacteria. The inclusion bodies, which are stable and relatively homogeneous, can be easily separated and stored for long period.

To recover the biologically active protein, the inclusion bodies are isolated and the protein within is resolubillized and refolded in vitro (Fig. 1.1). ${ }^{12,13}$ The inclusion bodies are separated from soluble components by microfiltration or lowspeed centrifugation. ${ }^{14}$ The collected inclusion bodies are resolubilized using a denaturant, such as guanidinium chloride $(\mathrm{GdmCl})$ or urea. $^{15}$ The solubilized protein is then refolded in vitro to recover its bioactivity. However, the in vitro folding of disulfide containing proteins can be slow and low yielding. The formation of misfolded disulfide bonds and accumulation of kinetically preferred intermediates inhibits the in vitro folding of disulfide containing proteins. An efficient in vitro folding of disulfide containing proteins becomes significant to improve the protein production.
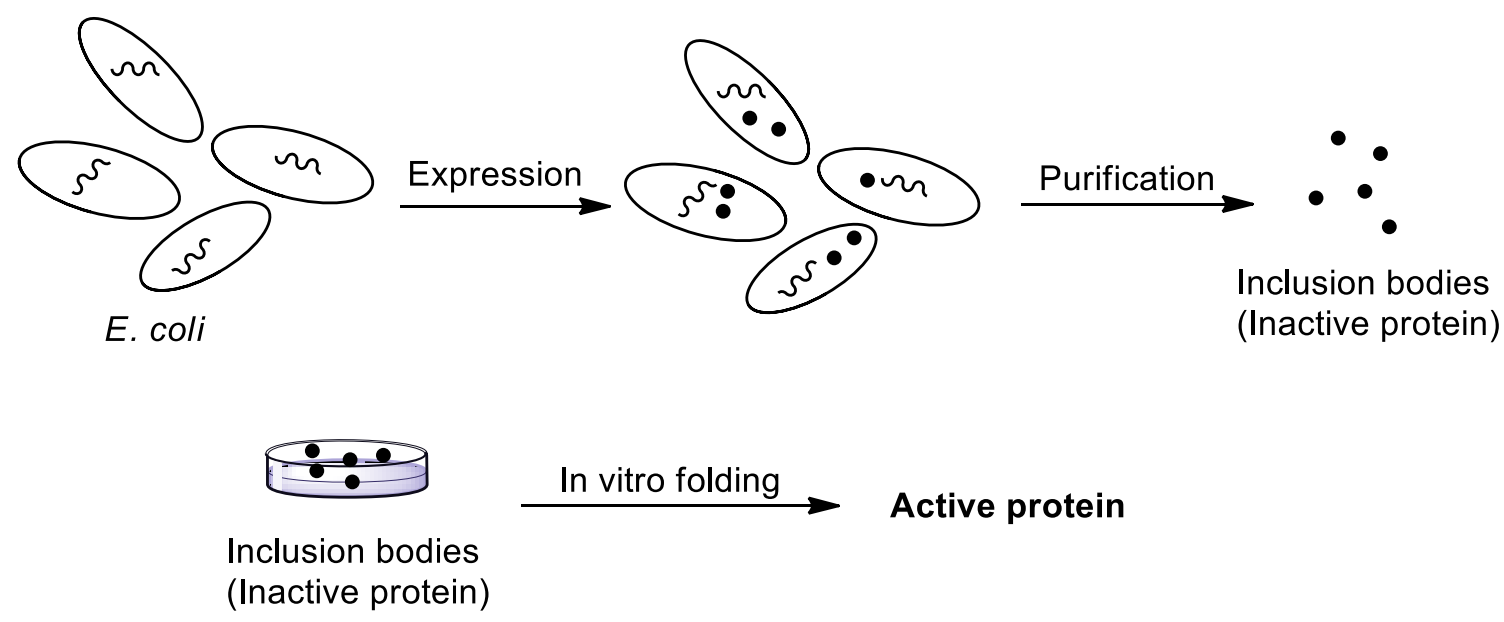

Fig. 1.1 Expression of protein in bacteria 
The biological function of a protein is directly linked with its native structure. Recently, a number of fatal diseases associated with aggregates of misfolded proteins are grouped in protein conformational disorders (PCDs). ${ }^{16-20}$ Diverse diseases including Alzheimer's disease (AD), Parkinson disease (PD) and mad cow disease belong to PCDs. The common feature of PCDs is the conformational change of a normal protein leading to misfolded protein. The misfolded protein tends to deposit as protein aggregates. As a result, the misfolded protein loses its biological function and even promotes toxic effects (Fig 1.2) ${ }^{20,21}$ The cause of PCDs is that these proteins are able to achieve not only one but multiple thermally stable conformations. ${ }^{20}$ Considering the cause of PCDs, the inhibition of formation and destabilization of misfolded proteins will minimize the deposit of protein aggregates. Herein, understanding the protein folding mechanism has the potential to minimize the formation and accumulation of misfolded proteins and slow the progression of these diseases.

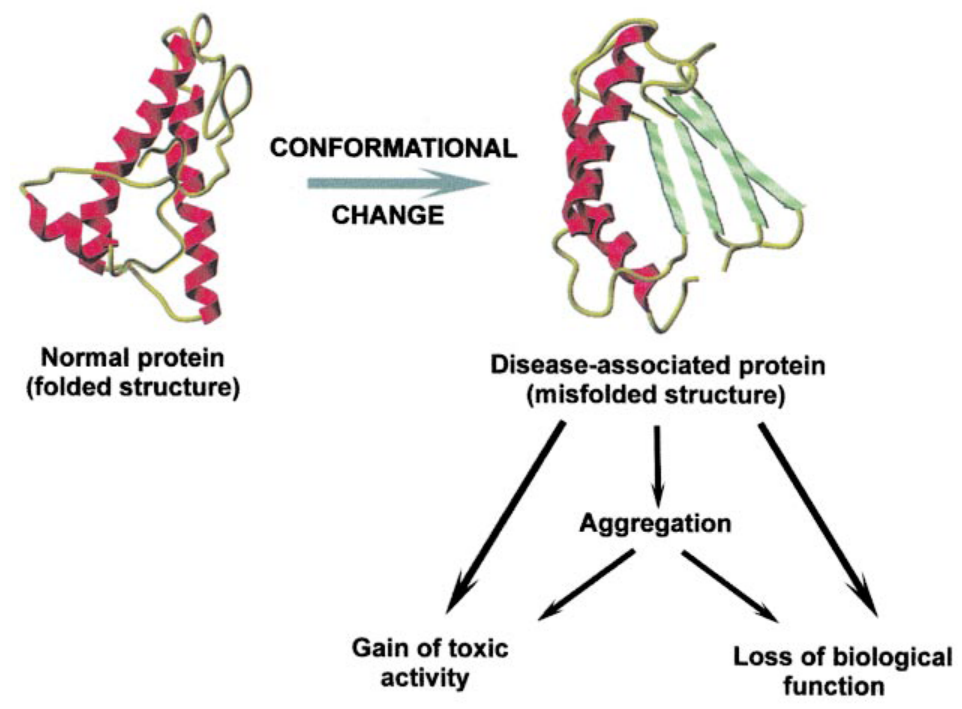

Fig. 1.2 Protein misfolding and disease 


\subsubsection{Folding of disulfide containing proteins}

To elucidate protein folding mechanism and pathways, many investigators have examined conformational folding and oxidative protein folding. Conformational folding focuses on the spontaneously renaturation process of denatured protein to native protein upon adjustment of denaturant concentration, $\mathrm{pH}$ or temperature. ${ }^{6,22,23}$ However, intermediates during conformational folding are difficult to characterize because the folding intermediates are transient and cannot be trapped and isolated. ${ }^{24}$ Another limitation of conformational folding is that the denatured protein may contain locally folded structure. ${ }^{25-31}$ As a result, conformational folding studies may only reflect part of the folding pathway. The early folding mechanism starting from the fully unfolded state is neglected. Proteins without disulfide bonds are mainly investigated by conformational folding.

Oxidative folding relies on identification and characterization of protein folding intermediates containing thiols/disulfide bonds. ${ }^{32,33} \mathrm{~A}$ disulfide bond is formed between two cysteine residues. Disulfide bonds stabilize the protein conformation by lowering the entropy of the unfolded protein. ${ }^{34,35}$ Oxidative folding of disulfide containing proteins involves the regeneration of native disulfide bonds and restoration of native conformation. Most folding reactions are so fast that folding intermediates exist only transiently. The trapping and isolation of folding intermediates becomes the bottleneck during folding studies. Disulfide intermediates can be trapped by inhibiting the reactivity of free thiols. The

commonly used methods are iodoacetamide alkylation and acid quenching. ${ }^{36-38}$ The partitioning of folding intermediates and the folding rates in many cases can 
be controlled experimentally by varying the concentration of redox reagents. Disulfide bonds containing proteins continue to be the only well know folding paradigm for studying the protein folding pathway.

\subsection{Disulfide bond formation and protein oxidative folding pathways}

\subsubsection{Thiol-disulfide exchange reaction}

Disulfide bonds maintain the protein's structure and stability in many pharmaceutical and extracellular proteins. A disulfide bond is formed via a thioldisulfide exchange reaction which involves a thiolate anion and a disulfide species (Fig. 1.3). ${ }^{39,40} \mathrm{~A}$ thiolate anion attacks a disulfide bond resulting in the formation of a new disulfide bond by releasing another thiolate anion. The process of forming and breaking of disulfide bonds is a redox reaction, in which thiolate anion acts as an electron donor and disulfide bond acts as an electron acceptor. The thiol-disulfide exchange reaction rate is highly affected by the accessibilities of either the thiol or disulfide. ${ }^{41}$

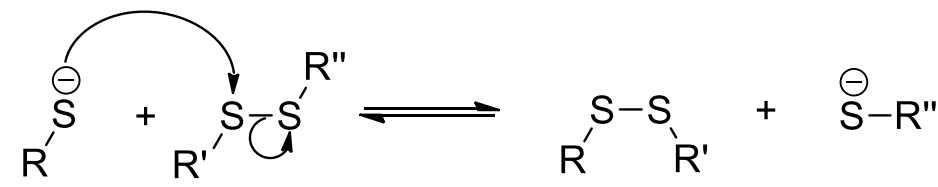

$\begin{array}{llll}\text { Thiolate anion } 1 & \text { Disulfide } 1 & \text { Disulfide } 2 & \text { Thiolate anion } 2\end{array}$

Fig. 1.3 Thiol-disulfide exchange reaction

Thiol-disulfide exchange reactions can take place either intra- or intermolecularly. In the intramolecular reaction, the protein disulfide bond is attacked by a thiolate anion of a cysteine residue within the same protein molecule. As a result, a new disulfide bond is formed but the number of disulfide bonds in the protein remains the same. The formation of a disulfide bond by this 
intramolecular process is known as disulfide reshuffling or as a rearrangement type pathway during protein folding (Fig. 1.4). The intermolecular mechanism involves a protein thiolate anion and an exogenous disulfide species. The protein thiolate anion attacks the exogenous disulfide bond resulting in the formation of a mixed disulfide bond. A mixed disulfide bond is then attacked by another protein thiolate anion leading to the formation of a new protein disulfide bond. The total number of disulfide bonds within the protein molecule increases (Fig. 1.5). This intermolecular mechanism corresponds to a growth type pathway during protein folding.

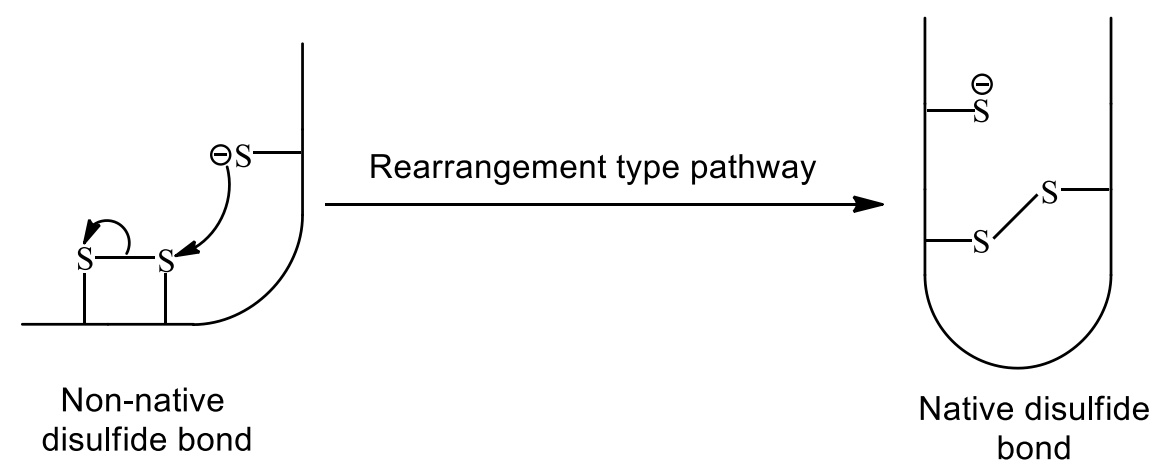

Fig. 1.4 Intramolecular formation of a protein disulfide bond via a rearrangement type pathway 


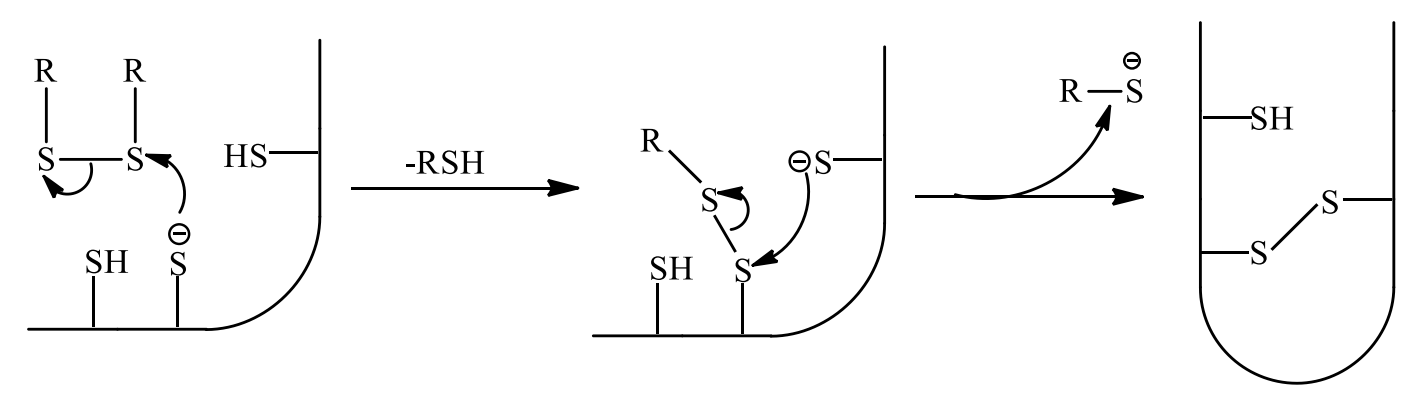

Growth type pathway

Fig. 1.5 Intermolecular formation of a protein disulfide bond via a growth type pathway

\subsubsection{Traditional thiols and disulfides used for disulfide bond formation}

The traditional thiols and disulfides used for oxidative folding of proteins are glutathione (GSH) and glutathione disulfide (GSSG), and reduced dithiothreitol (DTT ${ }^{\text {red }}$ ) and oxidized dithiothreitol (DTT $\left.{ }^{\text {ox }}\right){ }^{41,42}$ Both $\mathrm{GSH}$ and GSSG are found in vivo where they are proposed to catalyze the reduction and formation of disulfide bond respectively (Fig. 1.6). ${ }^{43}$<smiles>N[C@@H](CCC(=O)N[C@@H](CS)C(=O)NCC(=O)O)C(=O)O</smiles>

Glutathione (GSH)<smiles>N[C@@H](CCC(=O)N[C@@H](CSSC[C@H](NC(=O)CC[C@H](N)C(=O)O)C(=O)NCC(=O)O)C(=O)NCC(=O)O)C(=O)O</smiles>

Glutathione disulfide (GSSG)

Fig. 1.6 Structures of GSH and GSSG

The DTT ${ }^{\text {red }}$ is a very strong reducing reagent and the oxidized form DTT ${ }^{\text {ox }}$ is traditionally used to investigate the oxidative folding of disulfide containing proteins. ${ }^{44}$ The oxidation of a protein thiol with DTT $^{\text {ox }}$ proceeds via a thiol- 
disulfide exchange reaction as shown in Fig. 1.7. The protein thiolate anion attacks the disulfide of DTT ${ }^{\text {ox }}$ resulting in the formation of a mixed disulfide bond. However, the mixed disulfide bond is rapidly reduced by another thiolate anion in either DTT or the protein molecule as shown by route (a) or (b) in Fig. 1.7 respectively. Usually, the thiolate anion in DTT is more reactive than those in the protein, which results in the rapid ring closure to form DTT ${ }^{\text {ox }}$. The advantage of oxidative protein folding with $\mathrm{DTT}^{\mathrm{ox}}$ is that no mixed disulfide intermediates accumulate during folding.
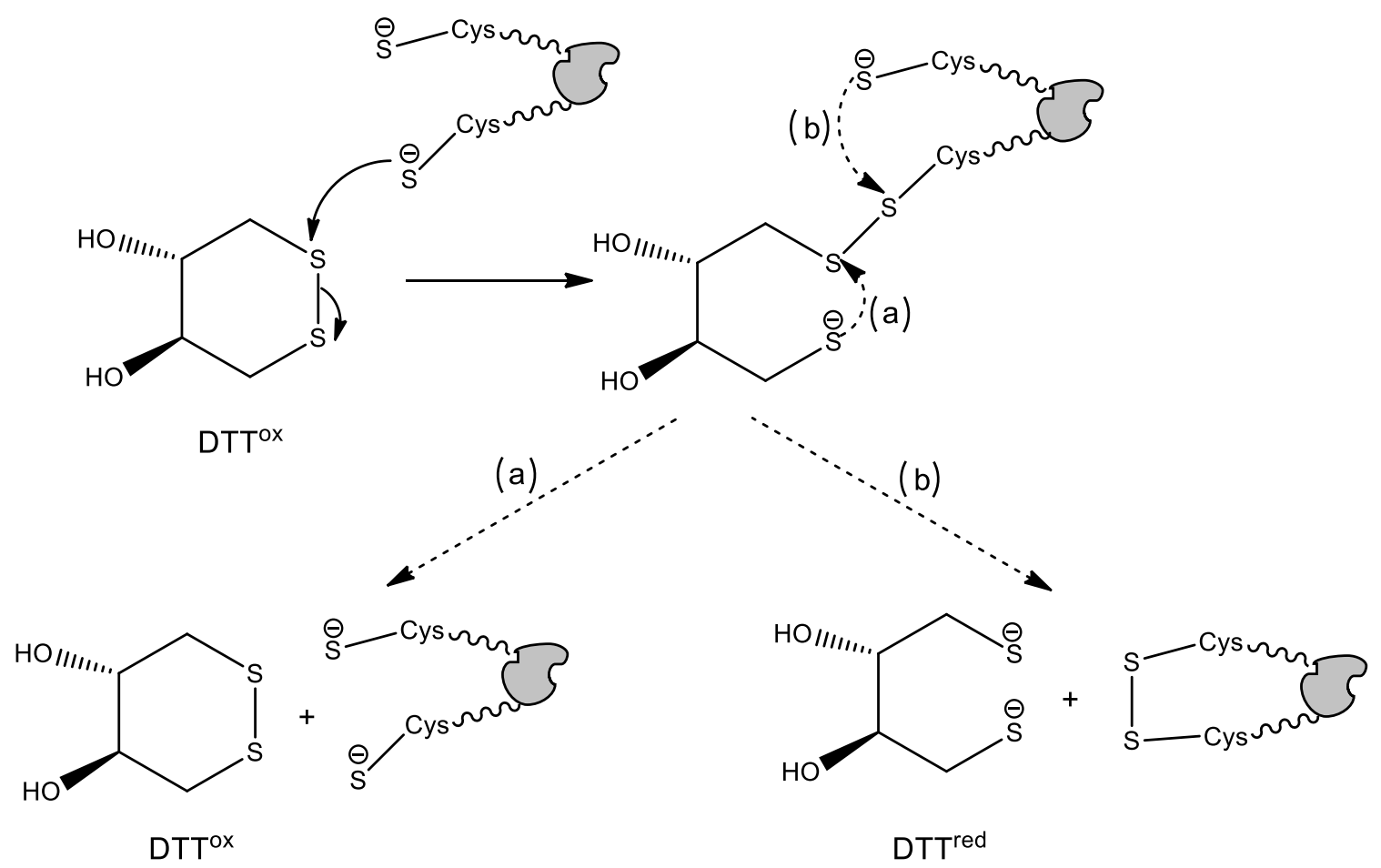

Fig. 1.7 Oxidation of protein thiol with DTT ${ }^{\text {ox: }}$ (a) Mixed disulfide bond is reduced by thiolate anion in DTT; (b) Mixed disulfide bond is reduced by protein thiolate anion. 


\subsubsection{Oxidative folding of ribonuclease $A$ (RNase $A$ )}

Ribonuclease A (RNase A) contains 124 amino acid residues and four disulfide bonds between Cys26 and Cys84, Cys40 and Cys95, Cys65 and Cys72, and Cys58 and Cys110 (Fig. 1.8). ${ }^{32}$ Folding of RNase A has been extensively studied by Scheraga et al. and the folding pathway is characterized by the disulfide intermediates. ${ }^{32,45-51}$ The intermediate with all native disulfide bonds except one is referred to as a des species. For instance, des[40-95] contains three native disulfide bonds but lacks the last native disulfide bond [40-95]. The term des only emphasizes the covalent property of protein intermediates. To characterize the conformational state of folding intermediates, a des species is further illustrated by des $u$ and des $_{N}$ to demonstrate its unfolded and folded states, respectively. Disulfide species with $n$ disulfide bonds, which are rearranging rapidly amongst themselves, are referred to as $n S$. The conformations of $n S$ species are flexible and usually unstructured because of the rapid rearrangement feature. For example, the folding intermediates $1 \mathrm{~S}$ contain one disulfide bond and rearrange intramolecularly. Disulfide intermediates $n S$ are a mixture of $n$ disulfide intermediates and are classified as one group because kinetically, they are equivalent as a consequence of the rapid rearrangement characteristics. The reduced protein, in which all disulfide bonds are reduced, is denoted as $\mathrm{R}$. The disulfide intermediates with all disulfide bonds except $\mathrm{N}$ are $4 \mathrm{~S}$ of RNase $\mathrm{A}$, are oxidized completely but lacking the native conformation because of nonnative disulfide bond combination. 


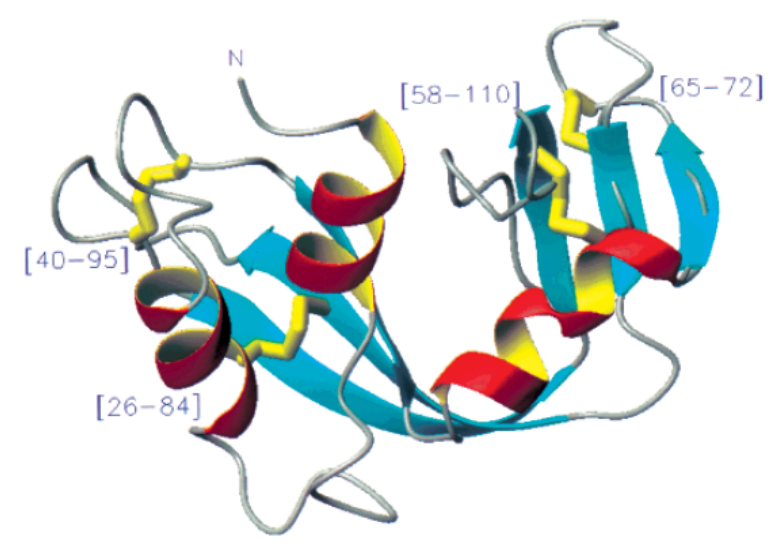

Fig. 1.8 Structure of bovine pancreatic ribonuclease A (RNase A)

Initially, oxidative folding of reduced RNase $\mathrm{A}$ to $\mathrm{N}$ experiences the formation of unstructured $1 \mathrm{~S}, 2 \mathrm{~S}, 3 \mathrm{~S}$ and $4 \mathrm{~S}$ ensembles (Fig. 1.9). ${ }^{32}$ The recovery of native protein from the unstructured ensembles is achieved via reshuffling of the unstructured $3 S$ species to two structured des species, des[4095] and des[65-72], also called $3 S^{*}$ species. Both $3 S^{*}$ species have the two remaining thiols exposed to solvent and can be readily oxidatized to native protein. The conversion of des[40-95] to $\mathrm{N}$ is the major folding pathway $(\sim 80 \%)$ during the regeneration of native protein from reduced RNase A. A minor pathway is the oxidation of $2 \mathrm{~S}$ to $3 S^{*}$ (less than $5 \%$ ).

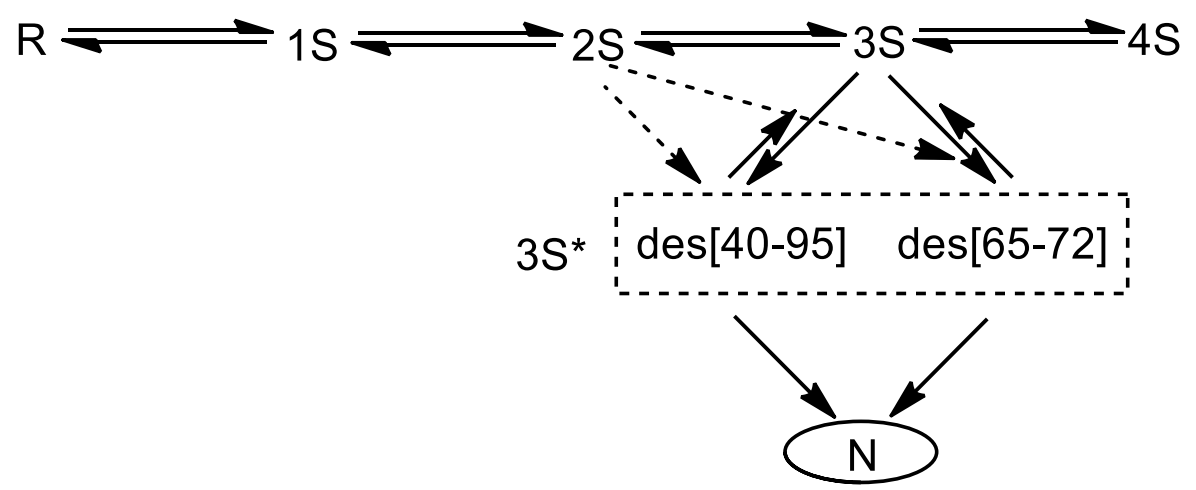

unstructured ensembles

structured intermediates

Fig. 1.9 Kinetic model of the oxidative folding of RNase A 
The oxidative folding of RNase A mainly relies on the formation of the two $3 S^{*}$ species. ${ }^{52-55}$ The reshuffling of $3 S$ to $3 S^{*}$ becomes the rate determining step during folding. ${ }^{56,57}$ The three native disulfide bonds in the $3 S^{*}$ species are inaccessible to be reduced or reshuffle because of the native like conformation. The remaining two thiols in $3 S^{*}$ are exposed to solvent, resulting in their rapid oxidation to form the last remaining native disulfide bond. The des[58-110] and des[26-84] are metastable species, which have both disulfide bonds and remaining thiols buried. The two metastable species, des[58-110] and des[26-84], only reshuffles to $3 S$ species instead of being oxidized to native protein.

\subsubsection{Generic pathways of oxidative folding}

On the basis of the oxidative folding of several proteins, Scheraga et al. proposed generic folding pathways for the oxidative folding of disulfide containing proteins. Generic folding pathways are based on the formation of des species, which are assumed to be the only productive disulfide intermediates (Fig. 1.10). ${ }^{32}$ In pathway I, the des species are unfolded and denoted as desu. The desu are in rapid equilibrium with these $n S$ unstructured ensembles via intramolecular rearrangement. The direct oxidation of des $u$ to an unfolded protein with all native disulfide bonds $(U)$ which folds conformationally to $\mathrm{N}$ become the rate determining step in pathway I. The pathways II to IV involve the folded intermediates $\operatorname{des}_{\mathrm{N}}$. The pathway II was considered as the most productive route because the des species have their disulfide bonds buried while the remaining thiols groups are exposed to solvent. The rate determining step in pathway II is the oxidation or rearrangement of unstructured precursors to the $\operatorname{des}_{\mathrm{N}}$ 
intermediates. The des species involved in pathway III and IV are metastable intermediates which protect their thiols and/or disulfide bonds in the hydrophobic core. In pathway III, the metastable species unfolds locally to facilitate the direct oxidation of the remaining thiols to native disulfide bond. However, the metastable des species in pathway IV prefers to reshuffle by opening its native like conformation. As a result, rearrangement of the metastable des species to unstructured $n S$ precursors becomes the rate determining step in pathway IV.

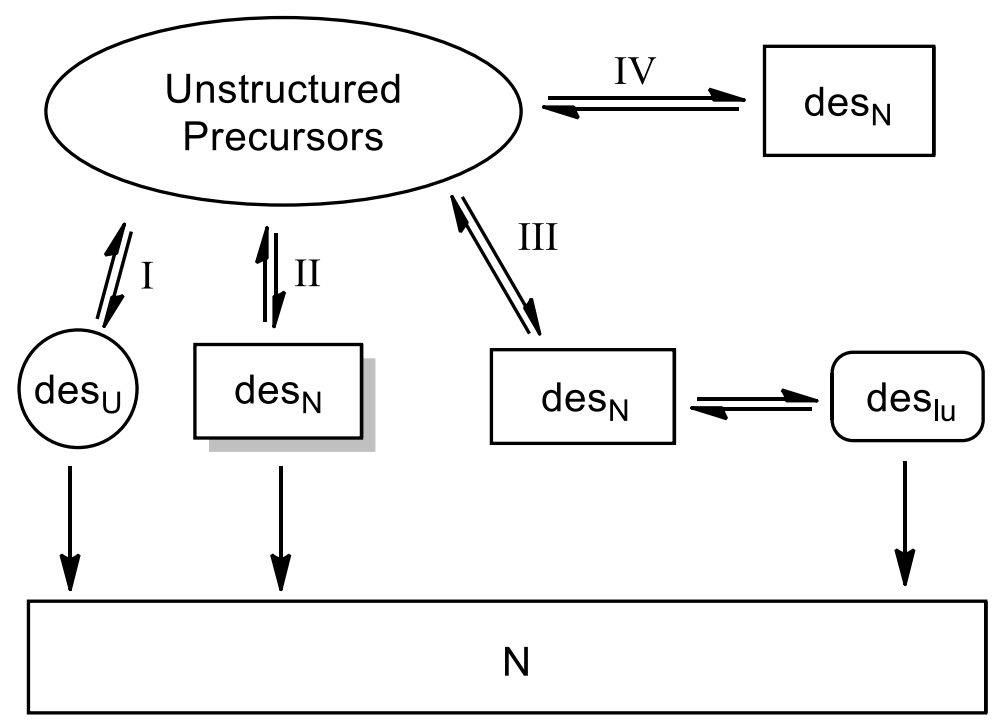

Fig. 1.10 Generic folding pathways of a typical disulfide contacting protein

\subsection{Early models of the oxidative folding of bovine pancreatic trypsin inhibitor (BPTI)}

\subsubsection{General information of BPTI}

Bovine pancreatic trypsin inhibitor (BPTI) has been studied extensively in terms of biological function, protein conformation and its folding pathway. ${ }^{38,58-64}$ Historically, BPTI was isolated from bovine pancreas or lung and sold by Bayer as a drug to inhibit serine proteases during heart and liver surgery. As a small 
globular protein, BPTI consists of 58 amino acid residues with a molecular weight of $6512 \mathrm{Da}$. The protein structure was determined by X-ray crystallography and NMR spectroscopy. ${ }^{65,66}$ The native state contains a small hydrophobic core which stabilizes the protein by minimizing the hydrophobic side-chains exposed to water. Three disulfide bonds between Cys5 and Cys55, Cys14 and Cys38, and Cys30 and Cys51 stabilize the characteristic three dimensional structure (Fig. 1.11). ${ }^{67}$ Native BPTI unfolds spontaneously when the three disulfide bonds are broken. As a disulfide containing protein, BPTI was one of the first to have its protein folding pathway elucidated and served as a basis for understanding the folding pathways of other proteins.
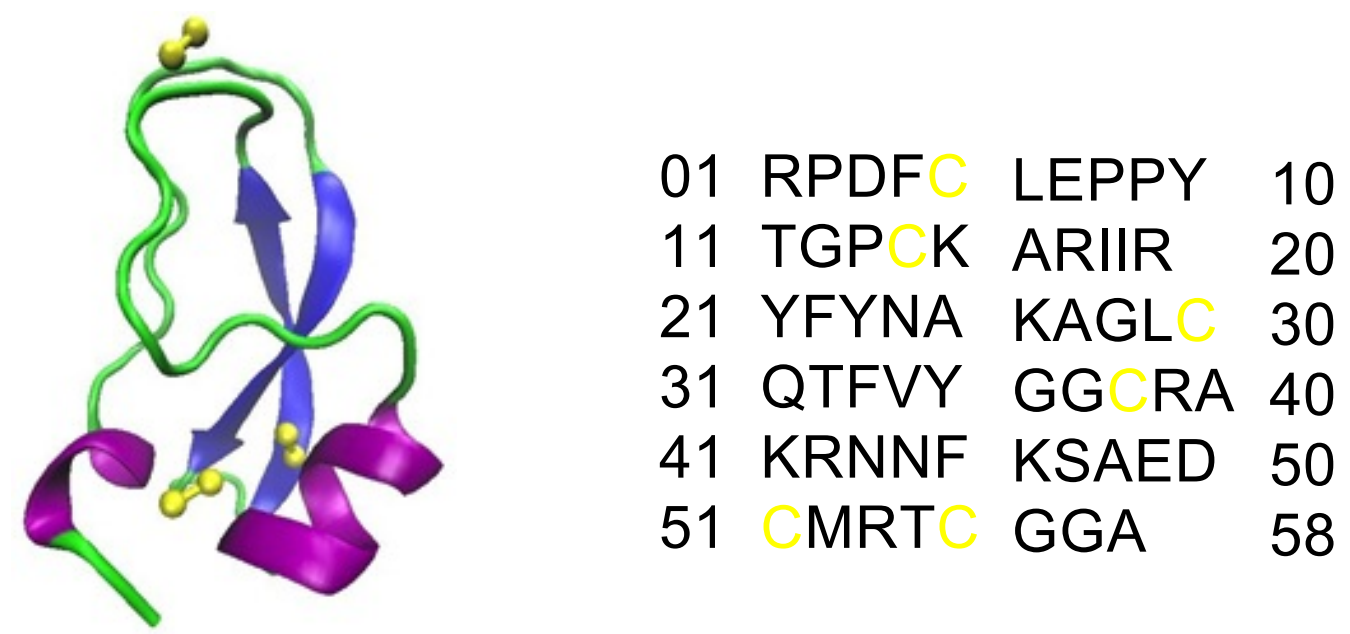

Fig. 1.11 BPTI structure and sequence with the cysteine residues indicated in yellow, from PDB6PTI

\subsubsection{Folding pathways of BPTI}

The oxidative folding pathway of BPTI is followed by characterizing folding intermediates that accumulate during conversion of the unfolded state to the native state. ${ }^{38,58}$ The protein folding pathway is complicated by the fact that six 
cysteine residues can form up to 75 possible intermediates with the combination of different disulfides and thiols. The order or lack thereof in which these disulfide bonds are formed reveals the folding pathway. The folding of BPTI proceeds through several native-like intermediates which have one or two native disulfides (Fig. 1.12) ${ }^{68}$ The mechanism of BPTI folding has been investigated both in vitro and in vivo. During in vitro folding, reduced BPTI is traditionally refolded in the presence of exogenous disulfides, such as oxidized dithiothreitol $\left(\mathrm{DTT}^{\mathrm{ox}}\right)$ or glutathione disulfide (GSSG). The appearance of disulfide species with time is monitored to help determine the folding pathways.

a) [30-51]

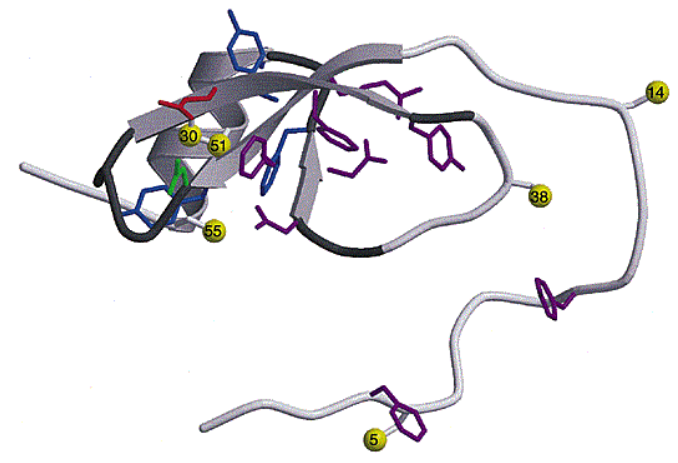

b) $[30-51 ; 5-55]$

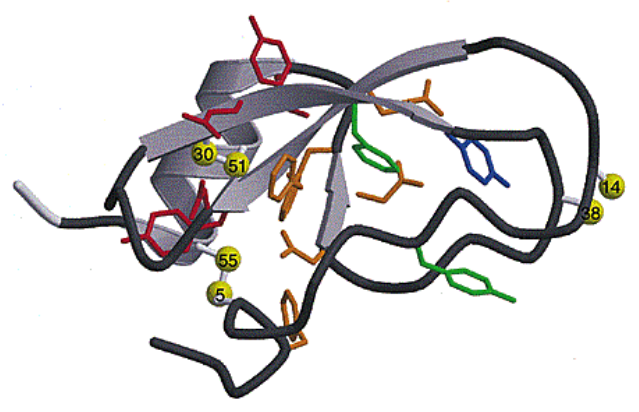

c) $[30-51 ; 5-55 ; 14-38]$

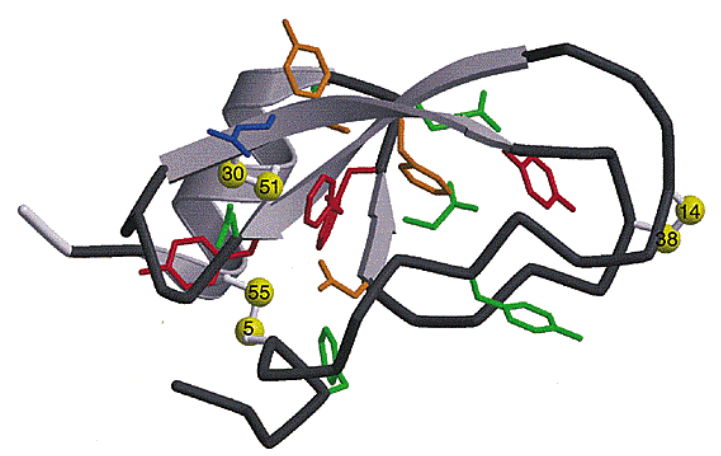

Fig. 1.12 Three stages of BPTI folding with native disulfide bond indicated: a) one-disulfide intermediate, b) two-disulfide intermediate and c) native protein 
Two folding models based on the distribution of disulfide intermediates during the oxidative folding of reduced BPTI were reported by Creighton and Kim. Analysis of folding intermediates reported by Kim revealed the almost exclusive accumulation of intermediates with native disulfide bonds. ${ }^{38}$ The folding intermediates were trapped and isolated reversely by acid quenching to deactivate the thiolate anion in the thiol-disulfide exchange reaction. Native disulfide bonds not only stabilize the final protein structure but also direct the formation of folded structure during the folding process.

Kim's results demonstrated that folding proceeds with rapid accumulation of two one-disulfide intermediates [30-51] and [5-55] followed by formation of another disulfide bond [14-38] between Cys14 and Cys38. The two two-disulfide intermediates $[30-51 ; 14-38]$ and $[5-55 ; 14-38]$ were entitled as $\mathrm{N}^{\prime}$ and $\mathrm{N}^{*}$. However, the two remaining thiols in both $\mathrm{N}^{\prime}$ and $\mathrm{N}^{*}$ were buried in a hydrophobic core, which inhibit the formation of native protein and thus $\mathrm{N}^{\prime}$ and $\mathrm{N}^{*}$ remain as kinetic traps. To achieve the native structure, rearrangement of $\mathrm{N}^{\prime}$ and $\mathrm{N}^{*}$ to another two disulfide intermediate $\mathrm{N}^{\mathrm{SH}}$ [30-51; 5-55], which can be rapidly oxidized to native protein because of the solvent accessible thiol in $\mathrm{N}^{\mathrm{SH}}$ (Cys 14), becomes the only folding pathway. ${ }^{66,69,70}$ The intramolecular disulfide bonds rearrangements in $\mathrm{N}^{\prime}$ and $\mathrm{N}^{*}$ become the rate limiting steps during the folding of BPTI. Therefore, the oxidative folding of BPTI was concluded to proceed via a rearrangement type pathway (Fig. 1.13). 


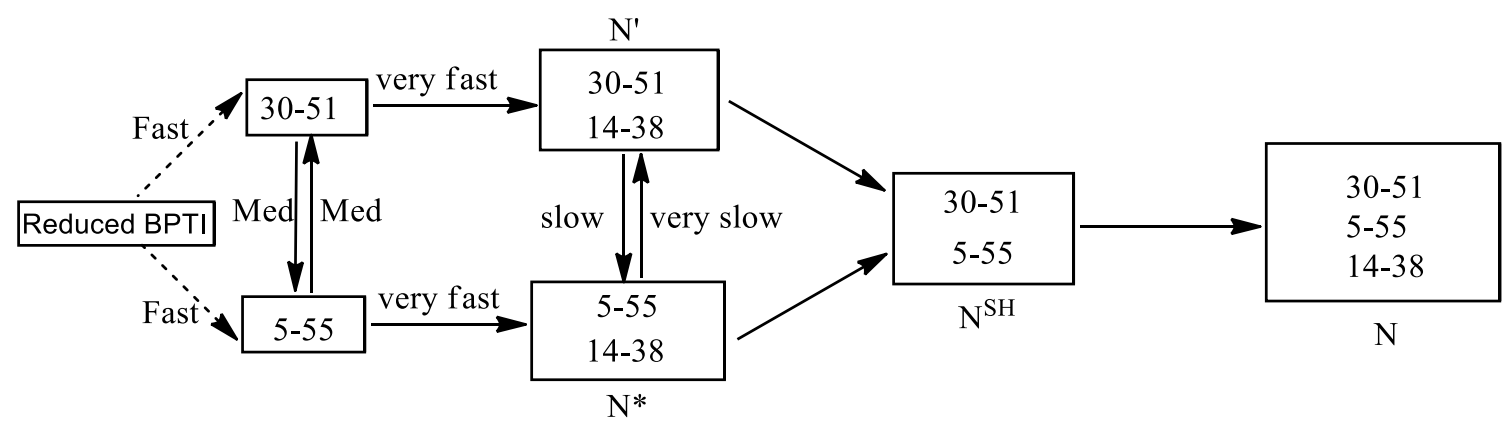

Fig. 1.13 Oxidative folding of BPTI via a rearrangement type pathway

Subsequently, Kim investigated the oxidative folding of BPTI via a growth type pathway (Fig. 1.14). ${ }^{59}$ The failure of oxidative folding of BPTI via a growth type pathway was attributed to the formation of the doubly mixed disulfide $\mathrm{N}^{\prime}(\mathrm{SG})_{2}$ and no direct oxidation of $\mathrm{N}^{*}$ to $\mathrm{N}$ in the presence of GSSG. An efficient production of $\mathrm{N}$ from $\mathrm{N}^{\prime}$ depends upon the competition between two reaction: the conversion of singly mixed disulfide $\mathrm{N}^{\prime}(\mathrm{SG})$ to $\mathrm{N}$ or to $\mathrm{N}^{\prime}(\mathrm{SG})_{2}$ and $\mathrm{N}^{\prime}(\mathrm{SG})$ to $\mathrm{N}^{\prime}(\mathrm{SG})_{2}$. Singly mixed disulfide $\mathrm{N}^{\prime}(\mathrm{SG})$ is formed by oxidizing one of two thiols in $\mathrm{N}^{\prime}$ with GSSG. At low GSSG concentrations, the oxidation rate of $\mathrm{N}^{\prime}$ is slower than intramolecular rearrangements of $\mathrm{N}^{\prime}$ to $\mathrm{N}^{\mathrm{SH}}$ because of the inaccessibility of the two thiols in $\mathrm{N}^{\prime}$. Folding favors the rearrangement of $\mathrm{N}^{\prime}$ to $\mathrm{N}^{\mathrm{SH}}$ which can be rapidly oxidized to native protein. At high GSSG concentrations, oxidation of N' to $N^{\prime}(S G)$, the first step in the growth type pathway becomes faster than rearrangement to $\mathrm{N}^{\mathrm{SH}}$. However, the remaining thiol in $\mathrm{N}^{\prime}(\mathrm{SG})$ is oxidized to $\mathrm{N}^{\prime}(\mathrm{SG})_{2}$ at a rate 30 times faster than the oxidation of $\mathrm{N}^{\prime}$ to $\mathrm{N}^{\prime}(\mathrm{SG})$ and much faster than rearrangement of $N^{\prime}(S G)$ to $N$. Doubly mixed disulfide $N^{\prime}(S G)_{2}$ remains as a kinetic trap since $\mathrm{N}^{\prime}(\mathrm{SG})_{2}$ lacks a free thiol. Therefore, folding via the growth type pathway becomes inefficient because of the formation of a 
nonproductive kinetic trap $\mathrm{N}^{\prime}(\mathrm{SG})_{2}$ at high GSSG concentrations. Conversion of two intermediates $\mathrm{N}^{\prime}$ and $\mathrm{N}^{*}$ to $\mathrm{N}$ requires the unfolding of previously obtained native structure. ${ }^{59}$

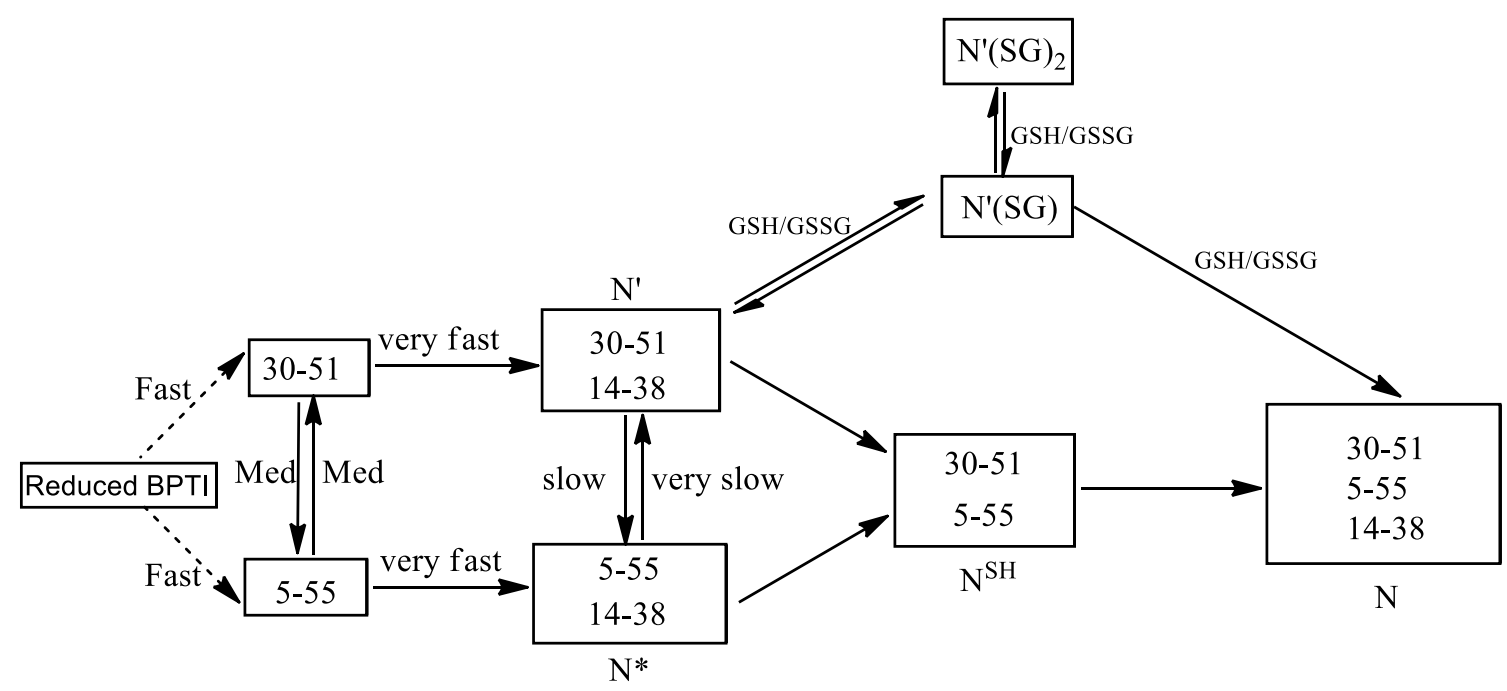

Fig. 1.14 Oxidative folding of BPTI via both rearrangement and growth type pathways

The oxidative folding pathway of reduced BPTI to native protein reported by Creighton involved the accumulation of both nonnative and native disulfide intermediates. ${ }^{71}$ Folding intermediates were characterized by the disulfide bonds they contain. Refolding of reduced BPTI was conducted at $\mathrm{pH} 8.7$ in the presence of $\mathrm{DTT}^{\mathrm{ox}}$ and quenched irreversibly with iodoacetic acid or iodoacetamide, which alkylates the free thiols contained in each intermediate. ${ }^{72}$ In Creighton's model, folding starts with the random formation of one-disulfide intermediates, after the distance between the thiol is accounted for. The one disulfide intermediates then rapidly rearrange to the form the distribution illustrated in Fig. $1.15{ }^{58}$ The $30-51$ disulfide bond, which prevails in the one- 
disulfide intermediates, was found in all two-disulfide intermediates except $\mathrm{N}^{*}$ ([5$55 ; 14-38])$. The one-disulfide intermediate [5-55] was considered to be the precursor of $\mathrm{N}^{*}$. All one-disulfide intermediates, which rearrange intramolecularly and exist in rapid equilibrium, were grouped as species $\mathrm{I}$.

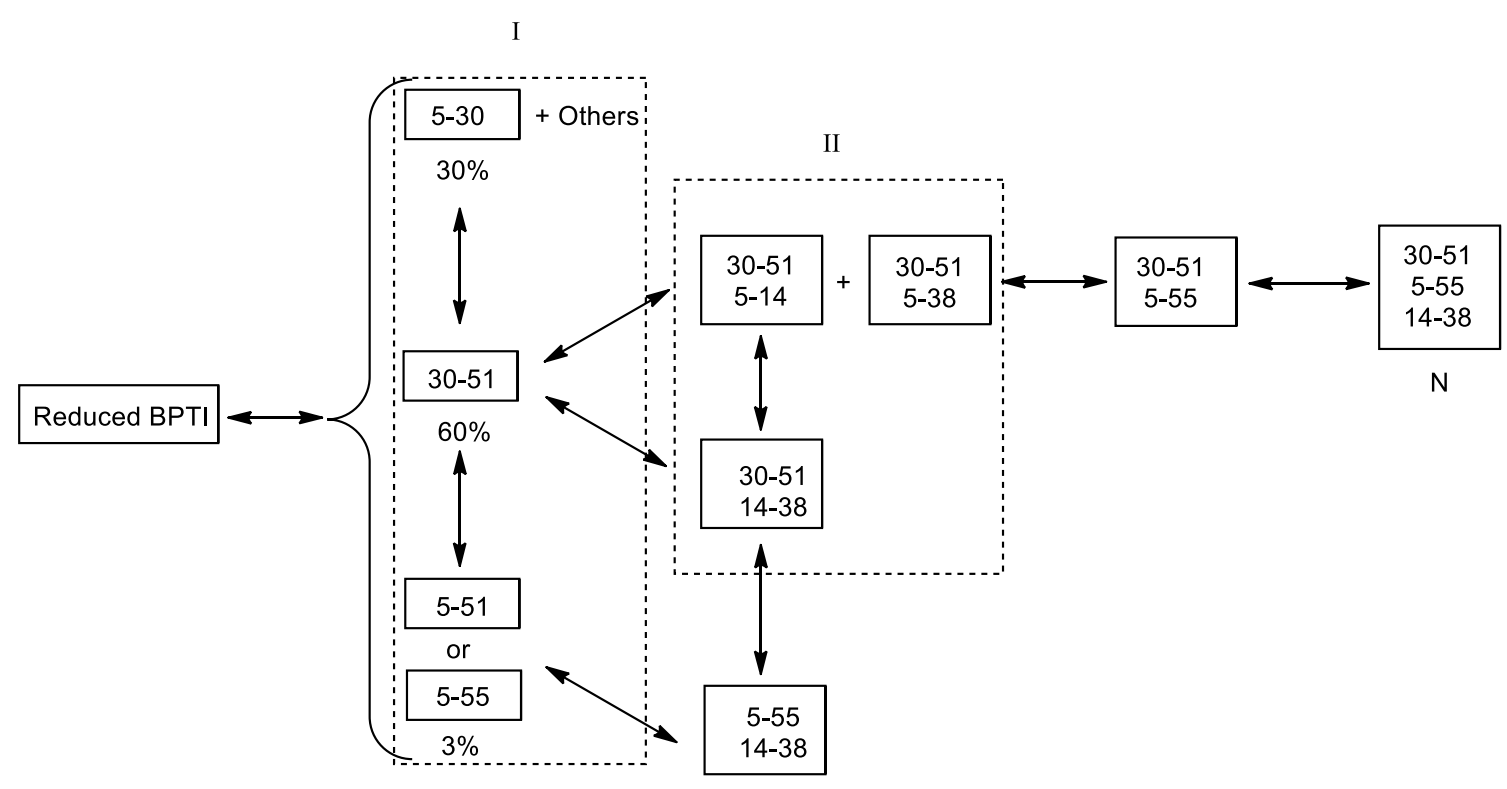

Fig. 1.15 The pathway of unfolding and refolding of BPTI reported by Creighton

Formation of the second disulfide bond from I resulted in two-disulfide intermediates including two nonnative disulfide intermediates [30-51; 5-14] and [30-51; 5-38], and two native disulfide intermediate $\mathrm{N}^{\prime}$ and $\mathrm{N}^{*}$. The two nonnative disulfide intermediates and native disulfide intermediate $\mathrm{N}^{\prime}$ were grouped as species II because of similar kinetic behavior. Group II species did not accumulate substantially during the oxidative folding of reduced BPTI in the presence of DTT ${ }^{\text {ox }}$. Native-like intermediate $\mathrm{N}^{*}$ has very low reactivity and only rearranges slowly to $\mathrm{N}^{\mathrm{SH}}$. Surprisingly, the productive two-disulfide intermediate 
$\mathrm{N}^{\mathrm{SH}}$ was formed mostly via intramolecular rearrangement of species II but not directly by oxidation of free thiols in group I intermediates.

Creighton concluded that one-disulfide intermediates were formed rapidly and reached equilibrium by intramolecular rearrangement. The formation of the second disulfide from one-disulfide intermediates generated two kinds of twodisulfide species, group II and $\mathrm{N}^{*}$. The free thiols in group II were slightly constrained and rearranged to the productive two disulfide intermediate $\mathrm{N}^{\mathrm{SH}}$. The native-like two disulfide intermediate $\mathrm{N}^{*}$ was kinetic stable and only rearranged slowly to $\mathrm{N}^{\prime}$. The conversion of reduced BPTI to native protein relied on the intramolecular rearrangement of group II species to $\mathrm{N}^{\mathrm{SH}}$.

The two folding pathways proposed by Creighton and Kim, which explained the importance of nonnative and native disulfide intermediates formed during folding, represent the historical oxidative folding models for BPTI. The debate between the two folding pathways was critical in understanding protein folding. ${ }^{73,74}$ In Creighton's view, Kim equated the amount of the folding intermediate with its kinetic importance. However, the amount of intermediate that accumulates reversely reflects its productivity. The conversion of the most abundant intermediate to native protein is the rate limiting step during folding and may be the least productive. Moreover, the folding condition $\mathrm{pH} 7.3$ used by Kim, favors the accumulation of native-like disulfide intermediates because protein thiols in the native-like conformation are not ionized and thus in general remain unreactive. As a result, native-like disulfide intermediates tend to accumulate at higher levels than nonnative disulfide intermediates at Kim's model. Besides, the 
two two-disulfide intermediates, $\mathrm{N}^{\prime}$ and $\mathrm{N}^{*}$, were considered as obligatory intermediates in Kim's folding pathway. In Creighton's opinion, folding of modified BPTI which lacks Cys14 or Cys38 should stop at the one-disulfide intermediates following Kim's model. However, modified BPTI with irreversibly blocked Cys14 or Cys38 did refold to native like $\mathrm{N}^{\mathrm{SH}} \cdot{ }^{72}$ As a result, Creighton claimed that his own folding pathway for BPTI was valid and consistent with all experimental results.

In response to Creighton's criticisms, Kim demonstrated that folding intermediates with native disulfide bonds prevail at both neutral and $\mathrm{pH} 8.7$ under the same folding conditions as Creighton's. Formation of $\mathrm{N}^{\prime}$ and $\mathrm{N}^{*}$ is not mandatory but a kinetically preferred route during refolding of BPTI. Modified BPTI molecules which lack Cys 14 or Cys 38 fold to $\mathrm{N}^{\mathrm{SH}}$ via an alternate route instead of stopping at the one-disulfide stage. The folding of reduced BPTI to $\mathrm{N}^{\mathrm{SH}}$ is illustrated by the simplified pathway as shown in Fig $1.16 .{ }^{74}$ Reduced BPTI is oxidized to diverse one-disulfide intermediates, which rearrange rapidly and equilibrium at a distribution I. Intermediates of I are oxidized rapidly to wild-type two-disulfide intermediates II except $\mathrm{N}^{\mathrm{SH}} \cdot{ }^{72,75}$ Normally, intramolecular rearrangements of wild-type II form $\mathrm{N}^{\mathrm{SH}}$, the precursor of native BPTI. In case of double mutant BPTI, which has both Cys14 and Cys38 mutated or blocked, formation of $\mathrm{N}^{\mathrm{SH}}$ is achieved by direct oxidation of the one-disulfide intermediates in I. The rate of folding double mutant BPTI from I to $\mathrm{N}^{\mathrm{SH}}$ is almost the same as the rate of intramolecular rearrangement of II to $\mathrm{N}^{\mathrm{SH}} \cdot{ }^{75,76}$ Thus, Kim claimed that formation of nonnative disulfide intermediates mentioned in Creighton's original 
folding pathway barely facilitate the folding of BPTI. Native disulfide intermediates dominate the folding pathway of BPTI.

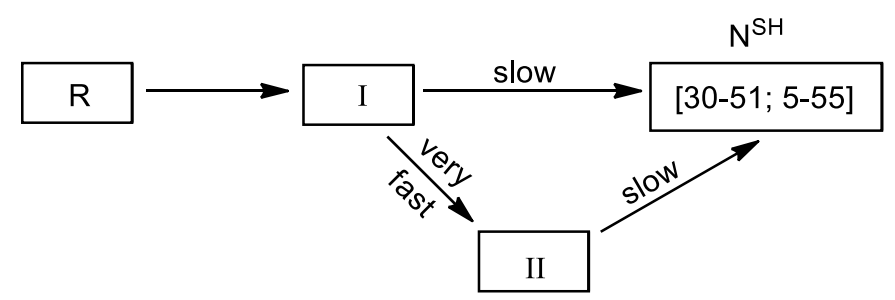

Fig. 1.16 Simplified scheme of folding of reduced BPTI to $\mathrm{N}^{\mathrm{SH}}$

\subsection{Recent developments on oxidative folding of BPTI}

\subsubsection{Folding of BPTI by in vivo like conditions}

Early folding studies of BPTI demonstrated that rearrangements of the kinetic traps $\mathrm{N}^{\prime}$ and $\mathrm{N}^{*}$ to $\mathrm{N}^{\mathrm{SH}}$, became the rate-determining steps during the oxidative folding. Scheraga et al. indicated that rate-determining steps during protein folding were affected by GSH/GGSG composition on the basis of studies with ribonuclease A (RNase A) ${ }^{49-51,77}$ Historically, folding of BPTI was examined in limited GSH/GSSG buffer combinations..$^{38,78,79}$ Folding of BPTI via a rearrangement type pathway was found to be slow and inefficient.

Recently, Lees et al. reported the oxidative folding of BPTI in the 24 different combinations of GSH/GSSG buffers at $\mathrm{pH} 7.3 .^{64}$ The GSH/GSSG concentrations were selected following in vivo conditions. As a result, the folding rate of reduced BPTI to native protein was dramatically improved compared with traditional GSH/GSSG compositions. In general, the production of native protein from reduced BPTI is regulated by the competition between productive and nonproductive pathways. Two intermediates, $\mathrm{N}^{*}$ and $\mathrm{N}^{\prime}(\mathrm{SG})_{2}$ were reported to be 
kinetic traps and nonproductive during oxidative folding. ${ }^{80}$ The destabilizations of either $\mathrm{N}^{*}$ or $\mathrm{N}^{\prime}(\mathrm{SG})_{2}$ would improve folding of BPTI.

The kinetic stability of $\mathrm{N}^{*}$ was reported to be decreased by increasing both GSH and GSSG concentrations. An increase in GSH concentration facilitates the reduction of $\mathrm{N}^{*}$ by breaking its disulfide bonds but the reduction rate is slow because of its native like conformation. As the concentration of GSSG increases, the kinetic stability of $\mathrm{N}^{*}$ was found to be decreased. Another kinetic trap $\mathrm{N}^{\prime}(\mathrm{SG})_{2}$ in which there is no free thiols, requires reduction of a mixed disulfide bond before further reaction. The accumulation of $\mathrm{N}^{\prime}(\mathrm{SG})_{2}$ depends upon the equilibrium between $\mathrm{N}^{\prime}(\mathrm{SG})_{2}$ and $\mathrm{N}^{\prime}(\mathrm{SG})$. At low $\mathrm{GSH}$ and high $\mathrm{GSSG}$ concentrations, formation of $\mathrm{N}^{\prime}(\mathrm{SG})_{2}$ is favored. To minimize accumulation of both $\mathrm{N}^{*}$ and $\mathrm{N}^{\prime}(\mathrm{SG})_{2}$, optimal conditions were found to be $5 \mathrm{mM} \mathrm{GSH}$ or $2 \mathrm{mM} \mathrm{GSH}$ and $5 \mathrm{mM}$ GSSG or $2 \mathrm{mM}$ GSSG respectively. The ratio of GSH/GSSG (1:1) is similar to that found in the endoplasmic reticulum (ER) of homo sapiens. ${ }^{43,81}$

On the basis of the modeling of BPTI folding, the conversion of $\mathrm{N}^{*}$ to $\mathrm{N}$ was fast as the GSSG concentration increases. Consequently, folding of $\mathrm{N}^{*}$ to $\mathrm{N}$ via a mixed disulfide, a growth type pathway, was firstly proposed by Lees et al. ${ }^{64}$ The native like conformation of $\mathrm{N}^{*}$ makes $\mathrm{N}^{*}$ kinetically stable under traditional folding conditions. However, at high GSSG concentration, $\mathrm{N}^{*}$ becomes reactive and is readily oxidized to native protein. The singly mixed disulfide $N^{*}(S G)$ during folding was not observed indicate its transient feature or because it's less stable than $\mathrm{N}^{*}$. The new folding pathway for $\mathrm{N}^{*}$ implied that the oxidative folding of $\mathrm{N}^{*}$ via a growth type pathway was feasible. Moreover, $\mathrm{N}^{\prime}(\mathrm{SG})_{2}$ was considered to be 
a kinetic trap because historical folding conditions involved GSSG only or GSSG with a low concentration of GSH during the oxidative folding of reduced BPTI. At high GSH and GSSG concentrations, however, $\mathrm{N}^{\prime}(\mathrm{SG})_{2}$ is in a rapid equilibrium with $\mathrm{N}^{\prime}(\mathrm{SG})$ and thus the kinetic stability of $\mathrm{N}^{\prime}(\mathrm{SG})_{2}$ is decreased.

At $5 \mathrm{mM} \mathrm{GSH}$ and $5 \mathrm{mM} \mathrm{GSSG}$, both $\mathrm{N}^{*}$ and $\mathrm{N}^{\prime}(\mathrm{SG})_{2}$ did not accumulate substantially during the folding. The folding rates at optimal conditions were reported to be 3-10 times higher than those determined with traditional conditions. The recovery of native protein after one day under optimal conditions was higher than the recovery after $7 \mathrm{~d}$ under traditional conditions. The modeling at optimal condition indicated that protein folding pathway was affected by the composition of GSH/GSSG (Fig 1.17).

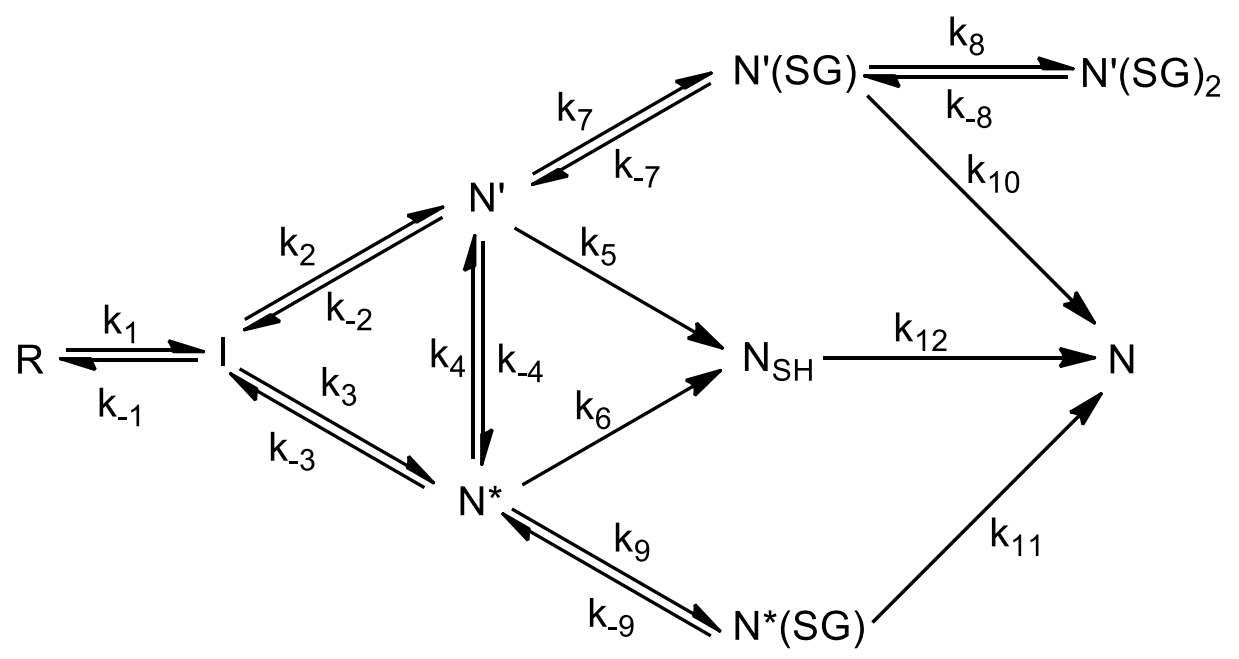

Fig. 1.17 Modeling of folding of reduced BPTI to native protein

\subsubsection{Folding of BPTI with selenoglutathione}

Folding of disulfide containing proteins, such as RNase A and BPTI, with an alternative redox buffer containing selenoglutathione (GSeSeG) was reported by Hilvert et al. recently. ${ }^{82-84}$ The GSeSeG is an analogue of GSSG (Fig 1.18). 
The disulfide bond in glutathione disulfide was replaced by diselenide bond. Diselenide is more reactive than disulfide bonds because the high polarizability of selenium makes the diselenide bond more electrophilicity than disulfide bonds during thiol-disulfide exchange reactions. ${ }^{85,86}$

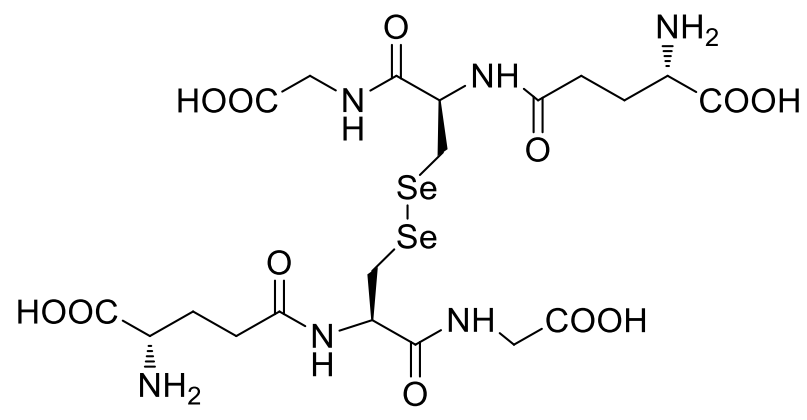

Fig. 1.18 Structure of selenoglutathione (GSeSeG)

Oxidative folding of reduced BPTI was conducted in the presence of GSSG and GSeSeG ${ }^{87}$ The two folding pathways were similar in terms of formation of major folding intermediates. However, oxidation rates of reduced BPTI to one-disulfide intermediates in the presence of GSeSeG were faster than those obtained with GSSG. Generally, the appearance and distribution of folding intermediates were different in terms of folding time. Folding of reduced BPTI to $\mathrm{N}$ was complete after $24 \mathrm{~h}$ in the presence of $\mathrm{GSeSeG}$ while folding conducted with the same GSSG concentration only achieved $50 \%$ recovery.

The two kinetic traps $\mathrm{N}^{\prime}$ and $\mathrm{N}^{*}$ were also investigated in the presence of GSeSeG. Pure N' was refolded in the presence of GSeSeG and compared with folding results from GSSG reactions. The general conversion rate of $N^{\prime}$ to native BPTI obtained by GSeSeG was only slightly faster. The two folding intermediates $\mathrm{N}^{\prime}(\mathrm{SeG})$ and $\mathrm{N}^{\prime}(\mathrm{SeG})_{2}$ were also observed, which indicated the direct oxidation of 
$\mathrm{N}^{\prime}$. However, $\mathrm{N}^{\prime}(\mathrm{SeG})$ was considered to react with the reduced selenoglutathione instead of rearranging to $\mathrm{N}$. The formation of many minor intermediates from $\mathrm{N}^{\prime}(\mathrm{SeG})$ impaired the efficient oxidative folding.

Pure $\mathrm{N}^{*}$ refolded in the presence of $\mathrm{GSeSeG}$ demonstrated distinctive disulfide intermediates. The folding rate of $\mathrm{N}^{*}$ was depended upon the GSeSeG concentration. A direct oxidation of $\mathrm{N}^{*}$ was further confirmed by observing two intermediates $\mathrm{N}^{*}(\mathrm{SeG})$ and $\mathrm{N}^{*}(\mathrm{SeG})_{2}$. Singly mixed disulfide $\mathrm{N}^{*}(\mathrm{SeG})$ rearranged intramolecularly to native protein. The conversion rate of $\mathrm{N}^{*}$ to $\mathrm{N}$ was improved by a factor of $10^{2}$ compared with GSSG reaction. At high GSeSeG concentration, doubly mixed disulfide $\mathrm{N}^{*}(\mathrm{SeG})_{2}$ accumulated significantly. Because $\mathrm{N}^{*}(\mathrm{SeG})_{2}$ lacks free thiols, a reduction of one mixed disulfide bond is essential to prevent its accumulation as an nonproductive intermediate.

Redox buffers containing GSeSeG emerge as new candidates to investigate the oxidative folding of BPTI. Although direct oxidation of $\mathrm{N}^{*}$ to $\mathrm{N}$ is promising, the formation of $\mathrm{N}^{*}(\mathrm{SeG})_{2}$ and the reduction of $\mathrm{N}^{\prime}(\mathrm{SeG})$ retard the application of GSeSeG on oxidative folding of BPTI. The conversion of $\mathrm{N}^{*}$ to $\mathrm{N}$ is slow at low GSeSeG concentration. At high GSeSeG concentration, the formations of two doubly mixed disulfides $\mathrm{N}^{*}(\mathrm{SeG})_{2}$ and $\mathrm{N}^{\prime}(\mathrm{SeG})_{2}$ are favored and $\mathrm{N}^{*}(\mathrm{SeG})_{2}$ and $\mathrm{N}^{\prime}(\mathrm{SeG})_{2}$ accumulate as kinetic traps. A reduced form $\mathrm{GSeH}$ may be utilized to destabilize the two kinetic traps but the reduction of $\mathrm{N}^{\prime}(\mathrm{SeG})$ result in formation of other kinetic or oxidative traps. However, an optimal combination of $\mathrm{GSeSeG}$ and $\mathrm{GSeH}$ has a potential to balance the productive and nonproductive pathways. 


\subsection{Folding of protein with protein disulfide isomerase (PDI)}

\subsubsection{Protein folding with PDI}

Protein disulfide isomerase (PDI) is found at high concentrations in the ER, where it catalyzes the folding of disulfide containing proteins. ${ }^{88-91}$ The enzyme PDI is a multiple thioredoxin domains protein and accelerates the formation and rearrangement of disulfide bonds. ${ }^{92,93}$ The catalytic function of PDI is maintained by its two active sites, which consist of a Cys-Gly-His-Cys (CGHC) sequence. ${ }^{94}$ Each active site has one of the cysteine thiols buried and the other exposed to solvent. The solvent-exposed thiol has a $\mathrm{pK}_{\mathrm{a}}$ of 6.7 making it reactive at physiological $\mathrm{pH}^{95,96}$ The buried thiol only reacts intramolecularly to form a 14membered ring by reducing the mixed disulfide bond formed between PDI and the protein molecule. This characteristic property of PDI enhances protein folding by minimizing the accumulation of mixed disulfides. The reduced form of PDI facilitates the rearrangement of nonnative disulfide bonds to native disulfide bonds while PDI oxidized form catalyzes the oxidation of protein thiols to disulfides (Fig. 1.19).

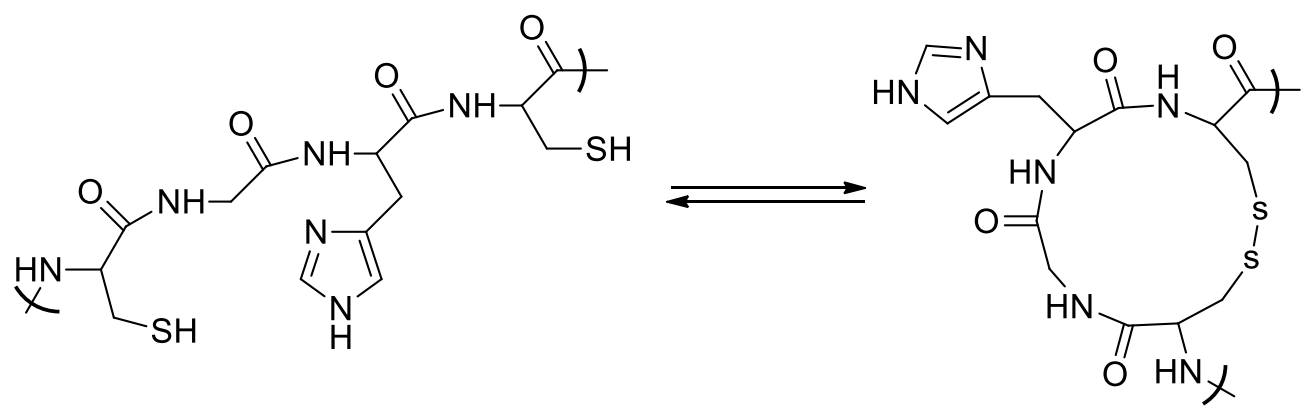

Fig. 1.19 Oxidation of the active site of PDI to form a 14-membered disulfide ring 


\subsubsection{Folding of BPTI in the presence of PDI}

Oxidative folding of BPTI is hampered by the formation of two kinetic traps, $\mathrm{N}^{\prime}$ and $\mathrm{N}^{*}$. Under traditional conditions, the in vitro folding of $\mathrm{N}^{\prime}$ and $\mathrm{N}^{*}$ to $\mathrm{N}$ take days to weeks because of their slow rearrangements. ${ }^{38,58,63,72,79}$ Both $\mathrm{N}^{\prime}$ and $\mathrm{N}^{*}$ have native like conformations resulting in the buried thiols in the hydrophobic core. The rearrangements of $\mathrm{N}^{\prime}$ and $\mathrm{N}^{*}$ require the unfolding of native conformations to expose these thiols. Historically, folding of BPTI was improved by addition of PDI in the presence of DTT, but PDI only increased slightly the folding of BPTI with $\mathrm{GSH}^{97,98}$ In the absence of a reducing reagent, PDIcatalyzed folding of BPTI was improved slightly. For one reason, at that time $\mathrm{N}^{*}$ and native protein were indistinguishable. For the other, redox buffer only contained the oxidizing reagents.

Later, folding of reduced BPTI to native protein with a redox buffer containing PDI, GSSG and GSH was found to be increased dramatically in terms of yield and rate. ${ }^{43}$ Studies by Kim et al. demonstrated that the PDI-catalysed folding of $\mathrm{N}^{\prime}$ and $\mathrm{N}^{*}$ was 3500 - and 6000 -fold faster than folding with GSSG alone, respectively.$^{60}$ In contrast, the folding of reduced BPTI to the two kinetic traps $\mathrm{N}^{\prime}$ and $\mathrm{N}^{*}$ was increased by only 3 -fold in the presence of PDI compared with traditional redox buffer. The effects of PDI on oxidative folding of onedisulfide intermediates [30-51] and [5-55], and the productive two-disulfide intermediate $\mathrm{N}^{\mathrm{SH}}$ were moderate. Therefore, PDI only accelerates the folding of kinetically trapped intermediates, $\mathrm{N}^{\prime}$ and $\mathrm{N}^{*} \cdot{ }^{60}$ The same phenomena were also found during folding of pro-BPTI. ${ }^{79}$ A significant amount of $\mathrm{N}^{*}, \mathrm{~N}^{\mathrm{SH}}$ and $\mathrm{N}$ was 
found during the folding of $\mathrm{N}^{\prime}$ in the presence of PDI without redox reagents. Consequently, PDI may facilitates the intramolecular rearrangement and/or direct oxidation of $\mathrm{N}^{\prime}$ and $\mathrm{N}^{*}$ towards native protein.

The effects of PDI on folding of BPTI and other disulfide containing proteins, such as RNase A, suggest that PDI dramatically improve the folding of kinetically trapped intermediates or structured intermediates. The similarity of these intermediates is that the remaining thiols and formed disulfide bonds are buried in the hydrophobic core, which is known as "locked in". The enzyme PDI slightly improves the folding of disulfide intermediates which can be readily oxidized by traditional redox buffers. The enzyme PDI was found to unfold structured disulfide intermediates of BPTI and retinol-binding protein. ${ }^{97,99}$ It was proposed that PDI could promote locally unfolding and disulfide bond rearrangements in kinetically stable intermediates. ${ }^{60}$

\subsection{Protein folding with small aromatic molecules}

\subsubsection{Design of small aromatic molecules}

Disulfide bonds are formed via the thiol-disulfide exchange reaction, which involves a nucleophile and a disulfide bond. A nucleophile including thiolate anion attacks the disulfide bond resulting in the formation of a new disulfide bond and a new thiolate anion simultaneously. One of the two sulfurs within the disulfide bond acts as an electrophilic center and the other sulfur was released as a leaving group. Thus, the thiol-disulfide exchange rate is affected by the nucleophilicity of the nucleophile and the stability of leaving group. 
Small aromatic molecules were designed by mimic the active sites of PDI. The thiol groups of the aromatic molecules have a relatively low $\mathrm{pK}_{\mathrm{a}}$ values. Aromatic thiols and disulfides react with protein disulfides and thiolate anions via a thiol-disulfide exchange mechanism, respectively. Aromatic thiols facilitate the rearrangement of disulfide bonds within the protein molecule (Fig. 1.20). The difference between the $\mathrm{pH}$ of ambient condition and the $\mathrm{pK}_{\mathrm{a}}$ of thiol determines the corresponding ionization of thiol. Thiolation anion helps to accelerate the disulfide isomerization of protein molecule. The nucleophilicity of the thiolate anion is robust when the $\mathrm{pK}_{\mathrm{a}}$ of the thiol is close to solution $\mathrm{pH}$. The thiols without ionization renders unreactive. The aromatic dithiols have two free thiols which can facilitate the escape mechanism to minimize the formation of mixed disulfides.

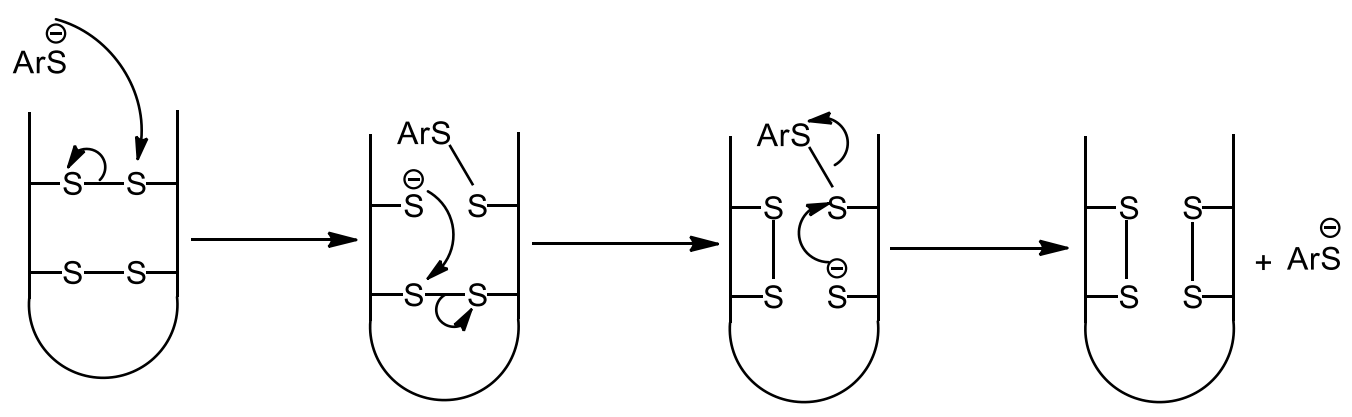

Fig. 1.20 Disulfide isomerization catalyzed by aromatic thiol

The aromatic disulfides, which are oxidation forms of aromatic thiols, were also used to improve the oxidative folding of disulfide containing proteins. The protein thiolate anion is oxidized by aromatic disulfides via a growth type pathway (Fig. 1.21). The thiolate anions of aromatic disulfides are more stable than traditional thiols because of their low $\mathrm{pK}_{\mathrm{a}}$ values. Thus, the protein thiols and 
aromatic disulfides exchange fast due to the enhanced stability of the aromatic thiols as leaving groups.

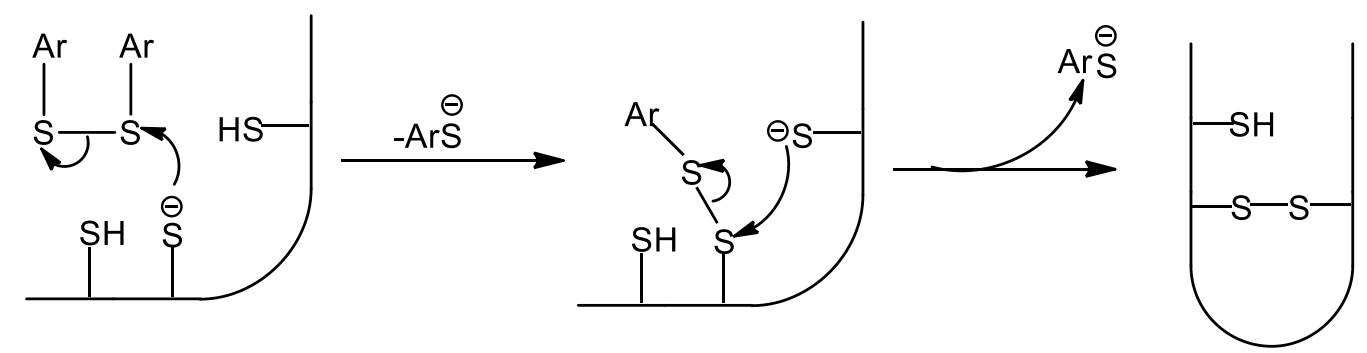

Fig. 1.21 Aromatic disulfide catalyzed oxidative folding of a protein via a growth type pathway

\subsubsection{Aromatic monothiols and disulfides containing different functional groups}

Previously, aromatic monothiols $\left(\mathrm{pK}_{\mathrm{a}}\right.$ 5.5-6.6) were found to be more efficient than traditional aliphatic thiols $\left(\mathrm{pK}_{\mathrm{a}}\right.$ 8.5-10) during folding of some disulfide containing proteins. ${ }^{100}$ The folding rates of RNase A with aromatic monothiols were 10-23 times faster than the rates with $\mathrm{GSH}$ at $\mathrm{pH} 6.0,7-12$ times faster at $\mathrm{pH} 7.0$, and $5-8$ times faster at $\mathrm{pH} 7.7 .^{101,102}$ The folding rate and yield of lysozyme were also increased by 7 times and $20 \%$, respectively, compared with GSH. ${ }^{103-105}$ Three aromatic disulfides $\mathbf{1}, \mathbf{2}$ and $\mathbf{3}$ have been demonstrated to increase the oxidative folding rate of $\mathrm{N}^{*}$, which is the slowest step during the folding of BPTI (Fig. 1.22). Herein, both aromatic monothiols and disulfides had the ability to increase the folding of disulfides containing proteins. 


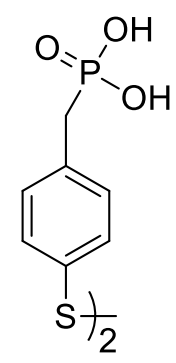

4,4'-disulfanediylbis(4,1-phenylene)bis(methylene)diphosphonic acid (1)

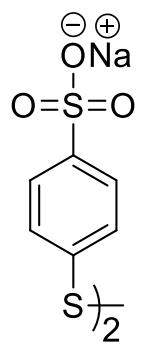

Sodium salt of sulfonic acid disulfide (2)

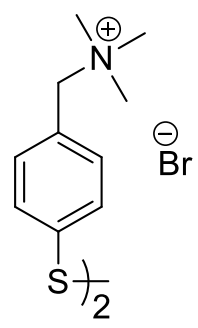

1,1'-(4,4'-disulfanediylbis(4,1-phenylene)bis $(N, N, N$ trimethylmethanaminium) bromide (3)

Fig. 1.22 Aromatic disulfides 1, 2 and $\mathbf{3}$ 


\section{Chapter 2}

\section{Objectives}

The overall aim of my research is to improve oxidative folding of reduced BPTI to native protein by GSSG and GSH, and aromatic disulfides and their corresponding thiols.

2.1 Production of pure reduced BPTI and folding intermediates $\mathbf{N}^{*}, \mathbf{N}^{\prime}$, $\mathbf{N}^{\prime}(\mathrm{SG})_{2}, \mathbf{N}^{\prime}(\mathrm{SG})$

Reduced BPTI has been refolded with GSSG and GSH to elucidate the protein folding pathway. However, folding was inefficient because conversion of reduced BPTI to native protein took days under the reported conditions. To better understand the folding mechanism and pathway, pure reduced BPTI and folding intermediates are produced for further studying.

2.2 Kinetic study of the oxidative folding of intermediates $\mathbf{N}^{*}, \mathbf{N}^{\prime}, \mathbf{N}^{\prime}(\mathrm{SG})_{2}$, $\mathbf{N}^{\prime}(\mathrm{SG})$ and reduced BPTI with GSSG and GSH

The kinetic traps formed during oxidative folding of BPTI are reacted with GSSG and GSH to determine the rate constants. The resulting rate constants are incorporated into folding model to explore the best folding conditions. Reduced $\mathrm{BPTI}$ is refolded under the best folding condition to improve folding efficiency.

2.3 Oxidative folding of BPTI with small molecule aromatic disulfides and thiols

Folding of disulfide containing proteins, such as Ribonuclease A (RNase A) and lysozyme, with small molecule aromatic disulfides and their corresponding 
thiols improved the folding efficiency compared with traditional redox reagents. Herein, folding of BPTI with aromatic disulfides and thiols is investigated. 


\section{Chapter 3}

\section{Production of kinetic traps accumulated during the oxidative folding of \\ BPTI}

\subsection{Abstract}

The protein BPTI has been extensively studied as a paradigm to elucidate the folding mechanism of disulfide containing protein. Historically, the in vitro oxidative folding of reduced BPTI to native protein took weeks to month because the BPTI folding pathway was proposed to be a rearrangement type pathway. The folding pathway was illustrated by studying reactions of reduced BPTI with GSSG and GSH. Folding of pure kinetic traps was barely reported because folding focused on characterizing the folding pathway but not on efficient folding. To better understand the protein folding mechanism, study of pure kinetic traps was considered to be significant. Herein, reduced BPTI and its kinetic traps, which were observed commonly during reaction, were produced and purified.

\subsection{Introduction}

The oxidative folding pathway of BPTI is followed by characterizing the folding intermediates that accumulate during folding. The folding intermediates are characterized by the disulfide bonds they contain. During oxidative folding of reduced BPTI with the traditional redox reagents, GSSG and GSH, a couple of two-disulfide bonds containing intermediates, including $\mathrm{N}^{*}$ and $\mathrm{N}^{\prime}$ accumulate substantially during folding. The native-like structure of $\mathrm{N}^{*}$ and $\mathrm{N}^{\prime}$ prevent the two remaining thiols from oxidizing and forming the final disulfide bond. The only productive folding pathway was reported to be rearrangement of $\mathrm{N}^{*}$ and $\mathrm{N}^{\prime}$ to 
another two-disulfide intermediate $\mathrm{N}^{\mathrm{SH}}$, which can be oxidized to native protein rapidly. Oxidative folding of $\mathrm{N}^{\prime}$ was reported to be inefficient and no direct oxidation of $\mathrm{N}^{*}$ was reported.

A recent report in our group elucidated our best folding condition for oxidative folding of reduced BPTI by investigating 24 different combinations of GSSG and GSH at pH 7.3. With $5 \mathrm{mM} \mathrm{GSSG}$ and $5 \mathrm{mM} \mathrm{GSH}$, more than $80 \%$ native protein could be produced in a day (Fig. 3.1). ${ }^{64}$ The folding of BPTI was limited by the production of kinetic traps, $\mathrm{N}^{*}$ and $\mathrm{N}^{\prime}(\mathrm{SG})_{2}$. Using our best folding condition, the relative concentrations of sum of $\mathrm{N}^{*}$ and $\mathrm{N}^{\prime}(\mathrm{SG})_{2}$ were found to be decreased.

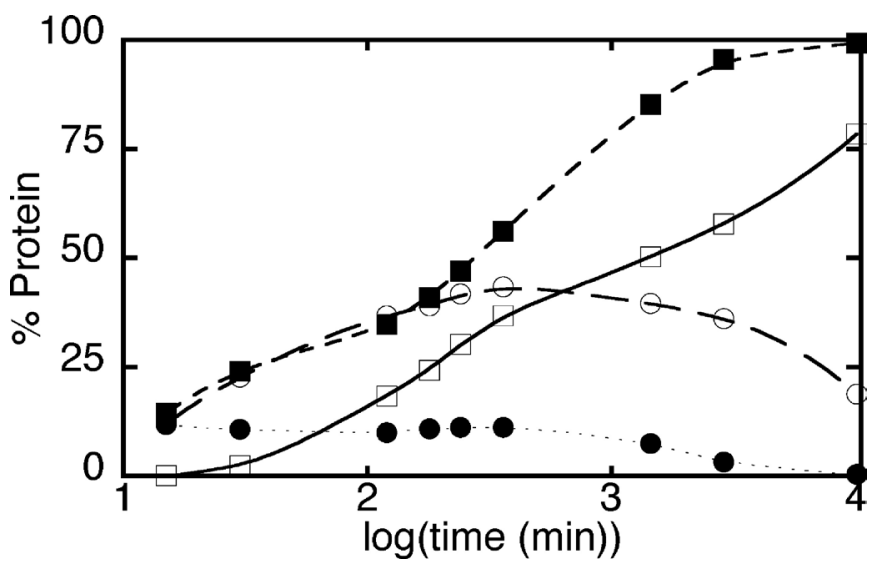

Fig. 3.1 Folding of reduced BPTI with $5 \mathrm{mM}$ GSSG and $5 \mathrm{mM} \mathrm{GSH}$ (black symbols), and $0.125 \mathrm{mM}$ GSSG and no GSH (white symbols). Percentage of native protein (squares), and $\mathrm{N}^{*}$ (circles)

The decrease in $\mathrm{N}^{\prime}(\mathrm{SG})_{2}$ was attributed to the reduction of its two mixed disulfide bonds at high concentration of GSH. The kinetic trap $\mathrm{N}^{\prime}(\mathrm{SG})_{2}$ increases with GSSG concentration and the GSSG/GSH ratio. A high GSH concentration could decrease the kinetic stability of $\mathrm{N}^{\prime}(\mathrm{SG})_{2}$. However, the amount of another 
kinetic trap $\mathrm{N}^{*}$ increases with GSH concentration and the GSH/GSSG ratio. It was found that increasing both GSH and GSSG concentration destabilized the kinetic trap $\mathrm{N}^{*}$, although the kinetic stability of $\mathrm{N}^{*}$ was affected only slightly with GSH concentration. The $\mathrm{N}^{*}$ produced was decreased significantly as the GSSG concentration increase under a given GSH concentration. Thus, balance of the two kinetic traps, $\mathrm{N}^{*}$ and $\mathrm{N}^{\prime}(\mathrm{SG})_{2}$ was achieved using $5 \mathrm{mM}$ GSSG and $5 \mathrm{mM}$ GSH. As a result, the growth type pathways for both $\mathrm{N}^{\prime}$ and $\mathrm{N}^{*}$ towards $\mathrm{N}$ were proposed (Fig 3.2). An initial study with pure $\mathrm{N}^{*}$ by Ms. Shweta M. Mandumula indicated that folding of $\mathrm{N}^{*}$ was dependent upon GSSG concentration. ${ }^{106}$ Herein, to examine the basis of folding with $5 \mathrm{mM} \mathrm{GSSG}$ and $5 \mathrm{mM} \mathrm{GSH}$, pure reduced BPTI and the intermediates $\mathrm{N}^{*}, \mathrm{~N}^{\prime}, \mathrm{N}^{\prime}(\mathrm{SG})_{2}$ and $\mathrm{N}^{\prime}(\mathrm{SG})$ were produced.

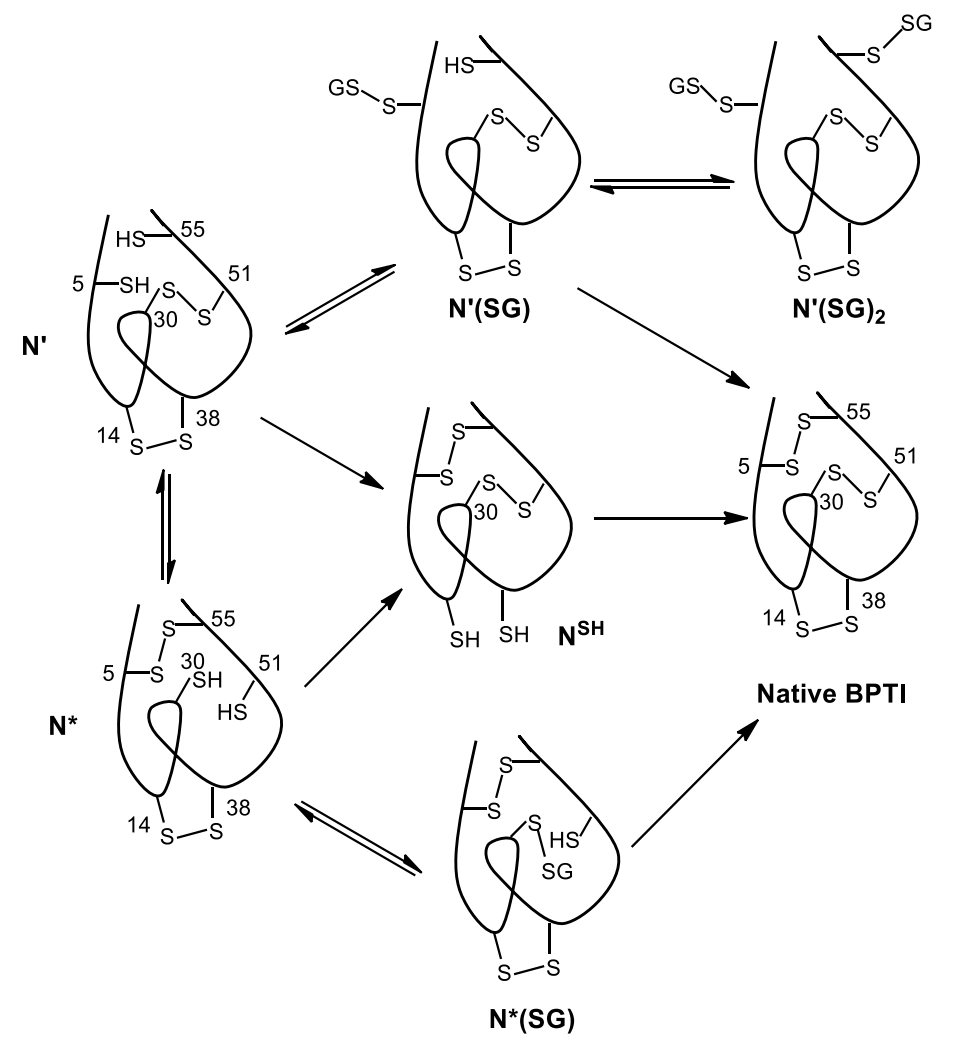

Fig. 3.2 Folding pathway of $\mathrm{N}^{\prime}$ and $\mathrm{N}^{*}$ towards $\mathrm{N}$ 


\subsection{Experimental section}

\subsubsection{Materials and general methods}

Aprotinin, which is also known as BPTI, was purchased in an electrophoretically homogeneous grade from Roche Applied Science and utilized without further purification. Folding buffer agents including guanidine hydrochloride $(\mathrm{GdnHCl}), \quad$ Trizma base, bis-tris propane, ethylenediaminetetraacetic acid disodium salt dihydrate (EDTA), potassium chloride $(\mathrm{KCl})$, dithiothreitol (DTT), reduced glutathione $(\mathrm{GSH})$, glutathione disulfide (GSSG) were purchased from Sigma and used out of the bottles. Sephadex ${ }^{\mathrm{TM}}$ G-25 Fine was purchased from GE Healthcare and presoaked with $0.01 \mathrm{~N} \mathrm{HCl}$ for $24 \mathrm{~h}$ before use. Acetonitrile (ACN) and trifloroacetic acid (TFA) at HPLC grade and concentrated $\mathrm{HCl}(12.1 \mathrm{~N})$ was purchased from Fisher Scientific. Nanopure deionized water was prepared using a Barnstead D3750 and deoxygenated by bubbling argon through it for 30 min before each protein folding assay. The UV-Vis spectra were measured with a Cary 300 spectrophotometer. High performance liquid chromatography analysis (HPLC) was performed on a Hitachi D-7000 system equipped with a L-7400 UV-Vis detector and column oven. The $\mathrm{pH}$ was measured by a VWR symphony SB20 pH meter which was calibrated routinely before use. The protein solution was lyophilized by a Labconco FreeZone 2.5 L Benchtop freeze dryer.

Reverse phase HPLC (RP-HPLC) was carried out using three different scale C18 column: Altech Macrosphere C18 preparative column $(250 \times 22 \mathrm{~mm})$; Vydac C18 semi-preparative column $(250 \times 10 \mathrm{~mm})$ and Vydac C18 analytical 
column $(250 \times 4.6 \mathrm{~mm})$. The mobile phase was a mixture of $0.1 \%$ TFA in water (solvent A) and $90 \%$ vol $/ \mathrm{vol}$ ACN in water with $0.1 \%$ TFA (solvent B). The solvent for washing auto sampler's injector was composed of $10 \% \mathrm{vol} / \mathrm{vol} \mathrm{ACN}$ in water with $0.5 \%$ TFA.

\subsubsection{Preparation and purification of reduced BPTI}

A Trizma buffer was prepared by dissolving Trizma $(1.213 \mathrm{~g}), \mathrm{KCl}(1.491 \mathrm{~g})$ and EDTA $(0.0373 \mathrm{~g})$ in $80 \mathrm{~mL}$ deionized water. The mixture was stirred until all the solids had dissolved. The $\mathrm{pH}$ of the resulting solution was adjusted to 8.7 with concentrated $\mathrm{HCl}(12.1 \mathrm{~N})$. The obtained solution was transferred to a $100 \mathrm{~mL}$ volumetric flask followed by addition of deionized water to the final volume. The ultimate concentration of each agent is $0.10 \mathrm{M}$ Trizma, $0.20 \mathrm{M} \mathrm{KCl}$ and $1.0 \mathrm{mM}$ EDTA. To unfold the protein, a reduction mixture was prepared by dissolving $\mathrm{GdnHCl}(60 \mathrm{mmol}, 5.731 \mathrm{~g})$ and DTT $(0.5 \mathrm{mmol}, 0.0771 \mathrm{~g})$ in Trizma buffer in a $15 \mathrm{~mL}$ centrifuge tube. The final volume of reduction mixture was made up to 10 $\mathrm{mL}$ followed by equilibrating in a $25{ }^{\circ} \mathrm{C}$ water bath. The final concentration of denaturants was $6 \mathrm{M} \mathrm{GdnHCl}$ and $0.05 \mathrm{M} \mathrm{DTT} .^{107}$

Native BPTI was added to the reduction mixture at a concentration of 6.5 $\mathrm{mg} / \mathrm{mL}$ and kept in the $25^{\circ} \mathrm{C}$ water bath for $1 \mathrm{~h}$. The $\mathrm{pH}$ of the resulting protein solution was lowered to between 2 and 3 with $0.2 \mathrm{~N} \mathrm{HCl}$ followed by purification via gel filtration on a Sephadex G-25 column using $0.01 \mathrm{~N} \mathrm{HCl}$ as the mobile phase. The eluate was collected by a fraction collector and examined by a UVVis spectrophotometer at $280 \mathrm{~nm}$ as the protein has an extinction coefficient of $5377 \mathrm{~cm}^{-1} \mathrm{M}^{-1}$ at $280 \mathrm{~nm}$. All the fractions containing reduced protein were 
combined and the protein concentration was calculated using the absorbance. The reduced protein was then lyophilized. The lyophilized protein was dissolved in $0.01 \mathrm{~N} \mathrm{HCl}$ at a final concentration of $4 \mathrm{mg} / \mathrm{mL}$ and stored at $-20{ }^{\circ} \mathrm{C}$ prior to HPLC separation. The reduced BPTI was purified by RP-HPLC on an Alltech C18 preparative column. A flow rate of $5 \mathrm{~mL} / \mathrm{min}$ was used with the following linear elution gradient: 0 min, $90 \%$ solvent $A ; 20$ min, $65 \%$ solvent $A ; 100$ min, $61 \%$ solvent $\mathrm{A}$. The injection volume was $2 \mathrm{~mL}$ and the column was heated at $50{ }^{\circ} \mathrm{C}$. The UV-Vis absorbance was monitored at $280 \mathrm{~nm}$. In each $15 \mathrm{~mL}$ centrifuge tube, $8 \mathrm{~mL}$ eluate containing reduced BPTI was collected and the purity of each fraction was determined on a Vydac C18 analytical column at a flow rate of 1 $\mathrm{mL} / \mathrm{min}$. The absorbance was monitored at $229 \mathrm{~nm}$ and the linear gradient used was 0 min, $90 \%$ solvent $A ; 15$ min, $73 \%$ solvent $A ; 35$ min, $71 \%$ solvent $A, 50$ min, $69 \%$ solvent $A ; 70$ min, $65 \%$ solvent $A$. The pure reduced BPTI was lyophilized. The resulting protein was dissolved in $0.01 \mathrm{~N} \mathrm{HCl}$ at a concentration of $1 \mathrm{mg} / \mathrm{mL}$ and stored at $-20^{\circ} \mathrm{C}$ for further use.

\subsubsection{Production and purification of $\mathbf{N}^{*}$}

A concentrated bis-tris propane buffer (1.5X) was prepared as followed for protein refolding experiments. In $80 \mathrm{~mL}$ deionized water, bis-tris propane (4.234 g), $\mathrm{KCl}(2.236)$ and EDTA (0.0559 g) was added and dissolved completely. The $\mathrm{pH}$ of the bis-tris propane buffer was adjusted to 7.3 with concentrated $\mathrm{HCl}(12.1$ $\mathrm{N}$ ) and the solution was made up to $100 \mathrm{~mL}$ in a volumetric flask by addition of deionized water. The obtained buffer was deoxygenated by flowing argon through it for $30 \mathrm{~min}$. The redox buffer containing GSSG and GSH were prepared 
separately with deoxygenated deionized water and deoxygenated bis-tris propane buffer (1.5X), respectively. The $\mathrm{pH}$ of both GSSG and GSH stock solutions was adjusted to 7.3 with $1 \mathrm{M} \mathrm{KOH}$. The stock solutions were further deoxygenated by bubbling argon through them $30 \mathrm{~min}$.

Pure reduced BPTI dissolved in $0.01 \mathrm{~N} \mathrm{HCl}(1 \mathrm{mg} / \mathrm{mL})$ was diluted to 30 $\mu \mathrm{M}$ by addition of redox buffer and refolded in the presence of $0.125 \mathrm{mM}$ GSSG and $20 \mathrm{mM} \mathrm{GSH}$. The final folding buffer contained $0.10 \mathrm{M}$ bis-tris propane, 0.20 $\mathrm{M} \mathrm{KCl}$ and $1.0 \mathrm{mM}$ EDTA. The folding reaction was conducted under argon at $25{ }^{\circ} \mathrm{C}$. After $48 \mathrm{~h}$, the folding process was quenched by addition of $1 / 20^{\text {th }}$ by volume of formic acid to the folding mixture. The buffer salts in the quenched folding solution were removed by gel filtration on a Sephadex G-25 column using $0.01 \mathrm{~N} \mathrm{HCl}$ as the mobile phase. The fractions were examined by UV-Vis spectrophotometry at $280 \mathrm{~nm}$. All the fractions containing protein were combined and the corresponding concentration was determined from the UV absorbance at $280 \mathrm{~nm}$. The obtained protein solution was frozen and lyophilized. The lyophilized protein containing $\mathrm{N}^{*}$ was dissolved in $0.01 \mathrm{~N} \mathrm{HCl}$ at a concentration of $2.5 \mathrm{mg} / \mathrm{mL}$ and stored at $-20{ }^{\circ} \mathrm{C}$ prior to HPLC purification.

The purification of $\mathrm{N}^{*}$ was carried out by manually injecting of $2 \mathrm{~mL}$ of $\mathrm{N}^{*}$ (2 mg/mL) solution onto a Vydac C18 semi-preparative column heated to $50{ }^{\circ} \mathrm{C}$. The gradient used was 0 min, $90 \%$ solvent $A ; 15$ min, $75 \%$ solvent $A ; 35$ min, $73 \%$ solvent $A ; 50$ min, $72 \%$ solvent $A ; 100$ min, $65 \%$ solvent $A$. Purification of $\mathrm{N}^{*}$ proceeded at a flow rate of $3 \mathrm{~mL} / \mathrm{min}$ and the protein was monitored at $280 \mathrm{~nm}$. The $\mathrm{N}^{*}$ peak was determined on the basis of the retention time and the 
corresponding $\mathrm{N}^{*}$ solution was collected in $3 \mathrm{~mL}$ fractions. The purity of $\mathrm{N}^{*}$ was investigated by RP-HPLC on a Vydac C18 analytical column at a flow rate of 1 $\mathrm{mL} / \mathrm{min}$. The protein was detected at $229 \mathrm{~nm}$ and the linear gradient used was 0 min, $90 \%$ solvent $A ; 15$ min, $75 \%$ solvent $A ; 35$ min, $73 \%$ solvent $A ; 50$ min, $72 \%$ solvent $A ; 70$ min, $69 \%$ solvent $A$. The eluates containing pure $N^{*}$ were combined and lyophilized. The resulting $\mathrm{N}^{*}$ solid was dissolved in $0.01 \mathrm{~N} \mathrm{HCl}$ at a concentration of $1 \mathrm{mg} / \mathrm{mL}$. Pure $\mathrm{N}^{*}$ was stored in a glass vial at $-20{ }^{\circ} \mathrm{C}$ prior to folding studies. The fractions containing impurities were combined and lyophilized. The resulting impure $\mathrm{N}^{*}$ solid was dissolved in $0.01 \mathrm{~N} \mathrm{HCl}$ and repurified via a Vydac C18 semi-preparative column.

\subsubsection{Preparation and purification of $\mathrm{N}^{\prime}$}

Pure reduced BPTI was refolded with $0.5 \mathrm{mM} \mathrm{GSSG}$ and $5 \mathrm{mM} \mathrm{GSH}$ in the presence of bis-tris propane buffer to produce $\mathrm{N}^{\prime}$. The folding reaction was conducted under argon at $25^{\circ} \mathrm{C}$. Folding was quenched after 15 min by addition of $1 / 20^{\text {th }}$ by volume of formic acid to the folding mixture. The acid quenched mixture was desalted on a Sephadex G-25 column using $0.01 \mathrm{~N} \mathrm{HCl}$ as the mobile phase and lyophilized. The resulting protein solid was dissolved in $0.01 \mathrm{~N}$ $\mathrm{HCl}$. Purification of $\mathrm{N}^{\prime}$ was performed on a Vydac C18 semi-preparative column using the following linear gradient: 0 min, $90 \%$ solvent $A ; 15$ min, $75 \%$ solvent $A$; $35 \mathrm{~min}, 73 \%$ solvent $A ; 50 \mathrm{~min}, 72 \%$ solvent $A ; 100 \mathrm{~min}, 65 \%$ solvent $A$. The purity of each fraction was analyzed by RP-HPLC and the gradient used was 0 min, $90 \%$ solvent $A ; 15$ min, $75 \%$ solvent $A ; 35$ min, $73 \%$ solvent $A ; 50$ min, $72 \%$ solvent $\mathrm{A} ; 70 \mathrm{~min}, 69 \%$ solvent $\mathrm{A}$. Pure $\mathrm{N}$ ' was lyophilized and stored at $-20{ }^{\circ} \mathrm{C}$ 
prior to folding studies. The fractions containing impurities were combined and repurified as above.

\subsubsection{Production and purification of $\mathrm{N}^{\prime}(\mathrm{SG})_{2}$}

The kinetic trap $\mathrm{N}^{\prime}(\mathrm{SG})_{2}$ was prepared directly from reduced BPTI. Pure reduced BPTI was refolded in the presence of bis-tris propane buffer containing $20 \mathrm{mM}$ GSSG only. The conversion of reduced BPTI to $\mathrm{N}^{\prime}(\mathrm{SG})_{2}$ reaction was conducted under argon at $25^{\circ} \mathrm{C}$. Folding was quenched after $6 \mathrm{~h}$ by addition of $1 / 20^{\text {th }}$ by volume of formic acid to the folding mixture. The acid quenched mixture was desalted on a Sephadex G-25 column using $0.01 \mathrm{~N} \mathrm{HCl}$ as the mobile phase. The protein fractions were lyophilized. The resulting protein solid was dissolved in $0.01 \mathrm{~N} \mathrm{HCl}$. Purification of $\mathrm{N}^{\prime}(\mathrm{SG})_{2}$ was performed on a Vydac $\mathrm{C} 18$ semipreparative column with the following linear gradient: 0 min, $90 \%$ solvent $A ; 15$ min, $75 \%$ solvent $A ; 35$ min, $73 \%$ solvent $A ; 50$ min, $72 \%$ solvent $A ; 100$ min, $65 \%$ solvent $A$. The purity of each fraction containing $\mathrm{N}^{\prime}(\mathrm{SG})_{2}$ was analyzed by HPLC and the gradient used was 0 min, $90 \%$ solvent $A ; 15$ min, $75 \%$ solvent $A ; 35$ min, $73 \%$ solvent $A ; 50$ min, $72 \%$ solvent $A ; 70$ min, $69 \%$ solvent $A$. Pure $\mathrm{N}^{\prime}(\mathrm{SG})_{2}$ was lyophilized and stored at $-20{ }^{\circ} \mathrm{C}$ prior to folding studies. Fractions containing impurities were combined and repurified as above.

\subsubsection{Production and purification of N'(SG)}

The intermediate $\mathrm{N}^{\prime}(\mathrm{SG})$ was produced by reduction of pure $\mathrm{N}^{\prime}(\mathrm{SG})_{2}$ in the presence of bis-tris propane buffer containing $10 \mathrm{mM} \mathrm{GSH}$. The reaction of $\mathrm{N}^{\prime}(\mathrm{SG})_{2}$ with $\mathrm{GSH}$ was conducted under argon at $25{ }^{\circ} \mathrm{C}$ to avoid air oxidation. The folding reaction was quenched after 6 min by addition of $1 / 20^{\text {th }}$ by volume of 
formic acid to the folding mixture. The acid quenched mixture was desalted on a Sephadex G-25 column using $0.01 \mathrm{~N} \mathrm{HCl}$ as the mobile phase. Purification of $\mathrm{N}^{\prime}(\mathrm{SG})$ was performed on a Vydac C18 semi-preparative column using the following linear gradient: 0 min, $90 \%$ solvent $A ; 15$ min, $75 \%$ solvent $A ; 35$ min, $73 \%$ solvent $A ; 50$ min, $72 \%$ solvent $A ; 100$ min, $65 \%$ solvent $A$. The purity of each fraction containing $\mathrm{N}^{\prime}(\mathrm{SG})$ was analyzed by RP-HPLC using the following gradient: 0 min, $90 \%$ solvent $A ; 15$ min, $75 \%$ solvent $A ; 35$ min, $73 \%$ solvent $A$; 50 min, $72 \%$ solvent $A ; 70$ min, $69 \%$ solvent $A$. Fractions containing pure $\mathrm{N}^{\prime}(\mathrm{SG})$ were lyophilized and stored at $-20{ }^{\circ} \mathrm{C}$ prior to folding studies. The fractions containing impurities were combined and repurified as above.

\subsection{Results and discussion}

\subsubsection{Production of reduced BPTI}

Native BPTI (1 mM) was reduced with cleavage of its three native disulfide bonds in the presence of $6 \mathrm{M} \mathrm{GdnHCl}$ and $50 \mathrm{mM}$ DTT. The resulting mixture was desalted by gel filtration and analyzed by RP-HPLC to determine the purity of the reduced BPTI (Fig. 3.3). A minor peak was observed in addition to the peak for reduced BPTI. It was reported previously that the minor peak was because of the oxidation of methionine. ${ }^{82}$ Thus, the mixture was purified on an Alltech C18 preparative column. The protein collected was examined using a Vydac C18 analytical column to ensure the purity (Fig. 3.4). The purity of the reduced BPTI was improved after HPLC separation. Pure reduced BPTI could minimize contamination during the folding studies. 


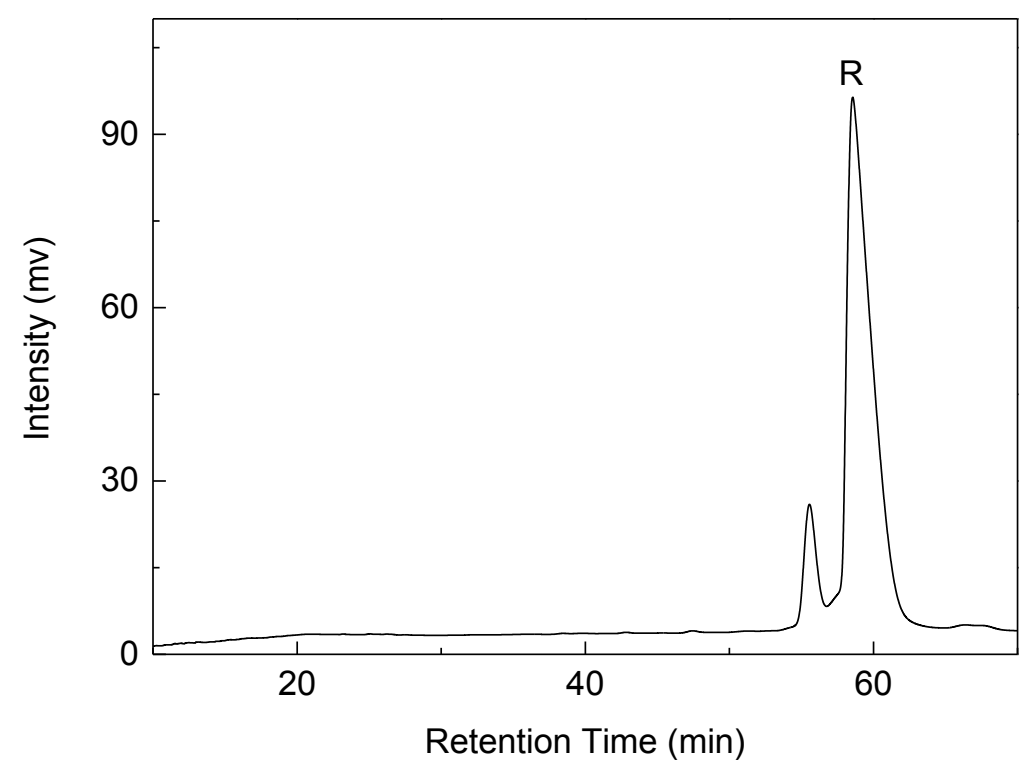

Fig. 3.3 BPTI reduction mixture after gel filtration, $\mathrm{R}$ is reduced BPTI

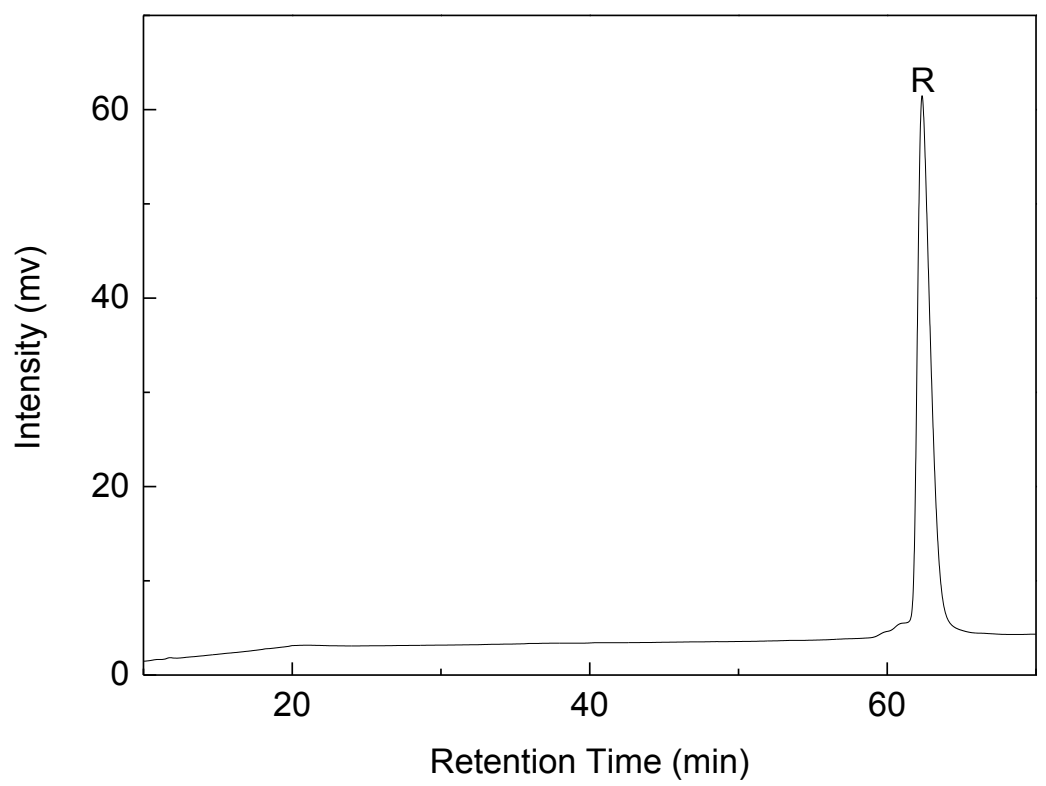

Fig. 3.4 Reduced BPTI after purification by RP-HPLC, $R$ is reduced BPTI

\subsubsection{Production of kinetic trap $\mathrm{N}^{*}$ from reduced BPTI}

Folding pathway of BPTI was proposed to be a rearrangement type pathway because the slowest step was rearrangement of kinetic trap $\mathrm{N}^{*}$ to other two-disulfide intermediate $\mathrm{N}^{\mathrm{SH}}$ and $\mathrm{N}^{\prime}$, which can be more readily oxidized. To 
better understand the folding of reduced BPTI to native protein, the kinetic trap $\mathrm{N}^{*}$ was prepared. Pure reduced BPTI was refolded in the presenc of $0.125 \mathrm{mM}$ GSSG and $20 \mathrm{mM} \mathrm{GSH}$ for $48 \mathrm{~h}$ to maximize the amount of $\mathrm{N}^{*}$ based on the previous folding model. A high concentration of GSH was added to destabilize the kinetic trap $\mathrm{N}^{\prime}$ and facilitate the production of the thermodynamically more favorable intermediate $\mathrm{N}^{*}$. The small amount of GSSG contributed the oxidizing equivalents. The folding mixture was desalted by gel filtration and analyzed on a Vydac C18 analytical column (Fig. 3.5). Folding mixture was then purified on a Vydac C18 semi-preparative column and the fractions containing $\mathrm{N}^{*}$ were collected based on chromatogram (Fig. 3.6). Each fraction was examined on a Vydac C18 analytical column to determine purity (Fig. 3.7).

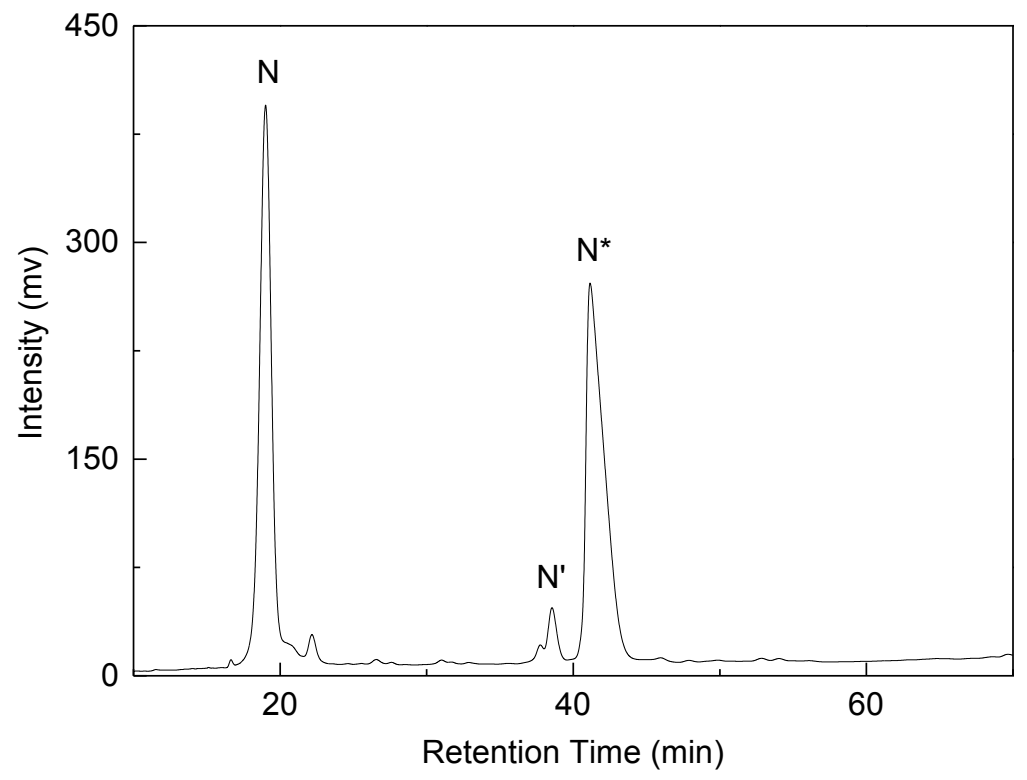

Fig. 3.5 Preparation of $\mathrm{N}^{*}$ from reduced $\mathrm{BPTI}, 55 \% \mathrm{~N}^{*}$ was produced

The intermediate $\mathrm{N}^{*}$ was proposed to be the major kinetic trap during the oxidative folding of reduce BPTI. Because $\mathrm{N}^{*}$ has a native-like conformation, the 
reduction of two native disulfide bonds and the oxidation of two remaining thiols are very slow as they are inaccessible. In order to kinetically study the oxidation and reduction of $\mathrm{N}^{*}$, production of pure $\mathrm{N}^{*}$ is necessary.

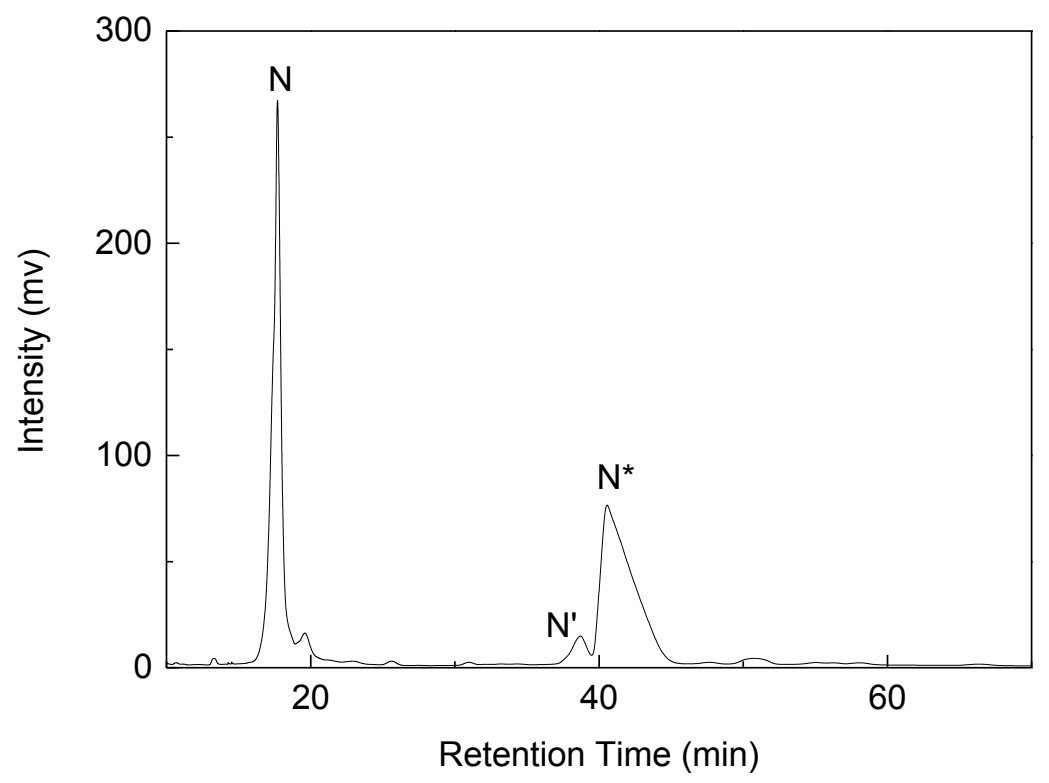

Fig. 3.6 Separation of $\mathrm{N}^{*}$ on a Vydac $\mathrm{C} 18$ semi-preparative column

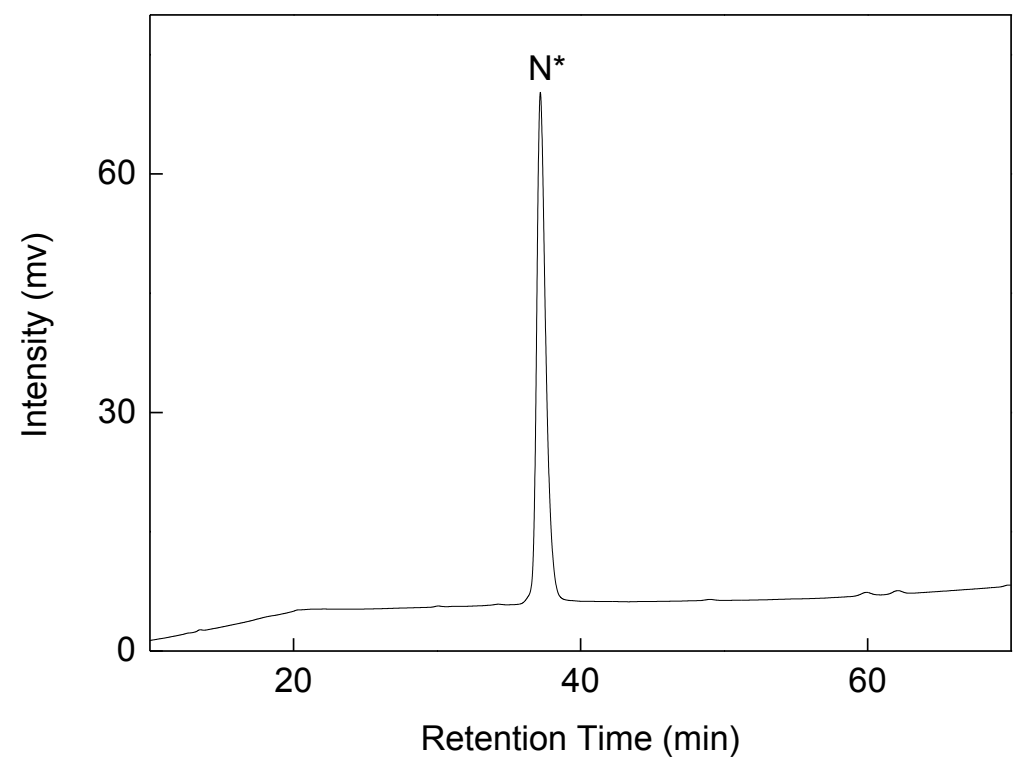

Fig. 3.7 HPLC chromatogram of pure $\mathrm{N}^{*}$ 


\subsubsection{Production of kinetic trap N' from reduced BPTI}

Pure reduced BPTI was refolded in the presence of $0.5 \mathrm{mM} \mathrm{GSSG}$ and 5 $\mathrm{mM} \mathrm{GSH}$ for 15 min to maximize the amount of $\mathrm{N}^{\prime}$ determined by previous folding studies. The acid quenched folding mixture was desalted by gel filtration and analyzed on a Vydac C18 analytical column (Fig. 3.8). After 15 min, reduced BPTI was oxidized almost completely (more than 99\%). The yields of $\mathrm{N}^{\prime}$ and $\mathrm{N}^{*}$ were around $50 \%$ and $28 \%$, respectively. Two minor peaks, $\mathrm{N}$ and $\mathrm{N}^{\prime}(\mathrm{SG})_{2}$ were found during analysis. To purify N', the protein mixture was injected manually onto a semi-preparative column (Fig. 3.9).

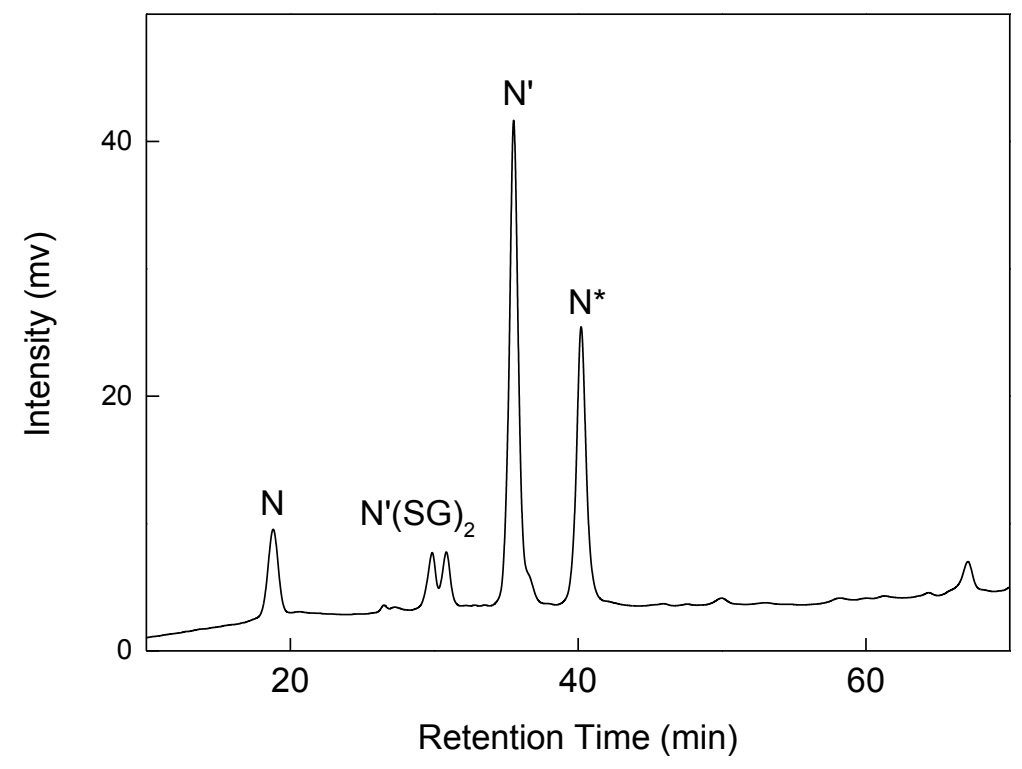

Fig. 3.8 Reaction of reduced BPTI with $0.5 \mathrm{mM}$ GSSG and $5 \mathrm{mM} \mathrm{GSH}$ after 15 $\min$ 


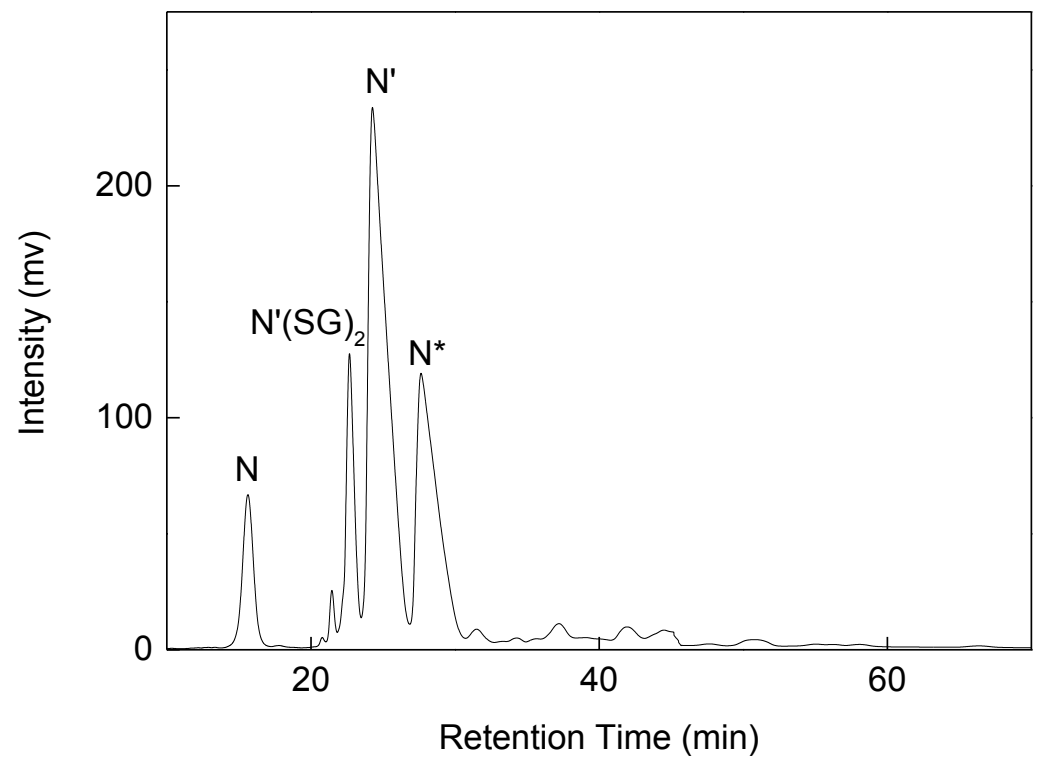

Fig. 3.9 Separation of N' on C18 semi-preparative column

The purity of collected $\mathrm{N}^{\prime}$ fraction was examined on a Vydac C18 analytical column (Fig. 3.10). Fractions containing impurities were combined and repurified using Vydac C18 semi-preparative column. Intermediate N' was classified as a kinetic trap because the conversion of $\mathrm{N}^{\prime}$ to $\mathrm{N}$ was proposed to occur via a rearrangement pathway. The intromolecular rearrangement was independent of oxidant concentration. Direct oxidation of $\mathrm{N}^{\prime}$ was considered to be inefficient because oxidation of the two thiols, Cys 5 and Cys 55 in $\mathrm{N}^{\prime}$, resulted in rapid formation of the doubly mixed disulfides $\mathrm{N}^{\prime}(\mathrm{SG})_{2}$. 


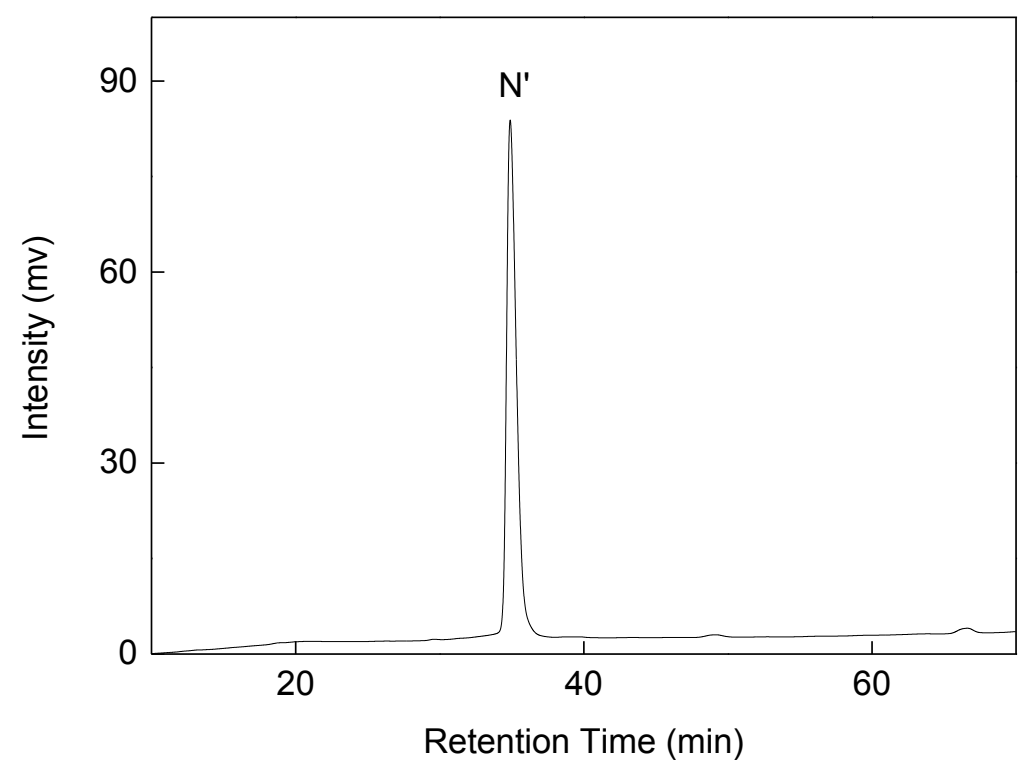

Fig. 3.10 HPLC chromatogram of pure $\mathrm{N}^{\prime}$

\subsubsection{Production of kinetic trap N'(SG) $)_{2}$ from reduced BPTI}

Pure reduced BPTI was refolded in the presence of $20 \mathrm{mM}$ GSSG, and the folding mixture was quenched after $6 \mathrm{~h}$ and desalted by gel filtration. A high concentration of GSSG without GSH was used to produce a substantial amount of $\mathrm{N}^{\prime}(\mathrm{SG})_{2}$. The protein folding mixture was analyzed on a Vydac $\mathrm{C} 18$ analytical column (Fig. 3.11). The yield of $\mathrm{N}^{\prime}(\mathrm{SG})_{2}$ was found to be $53 \%$. The folding mixture was then separated on a Vydac C18 semi-preparative column (Fig. 3.12). The purity of $\mathrm{N}^{\prime}(\mathrm{SG})_{2}$ was examined prior to use (Fig. 3.13). Intermediate $\mathrm{N}^{\prime}(\mathrm{SG})_{2}$ has two mixed disulfide bonds by oxidizing Cys 5 and Cys 55 with GSSG. Because of not having free thiol, $\mathrm{N}^{\prime}(\mathrm{SG})_{2}$ was considered to be a kinetic trap. 


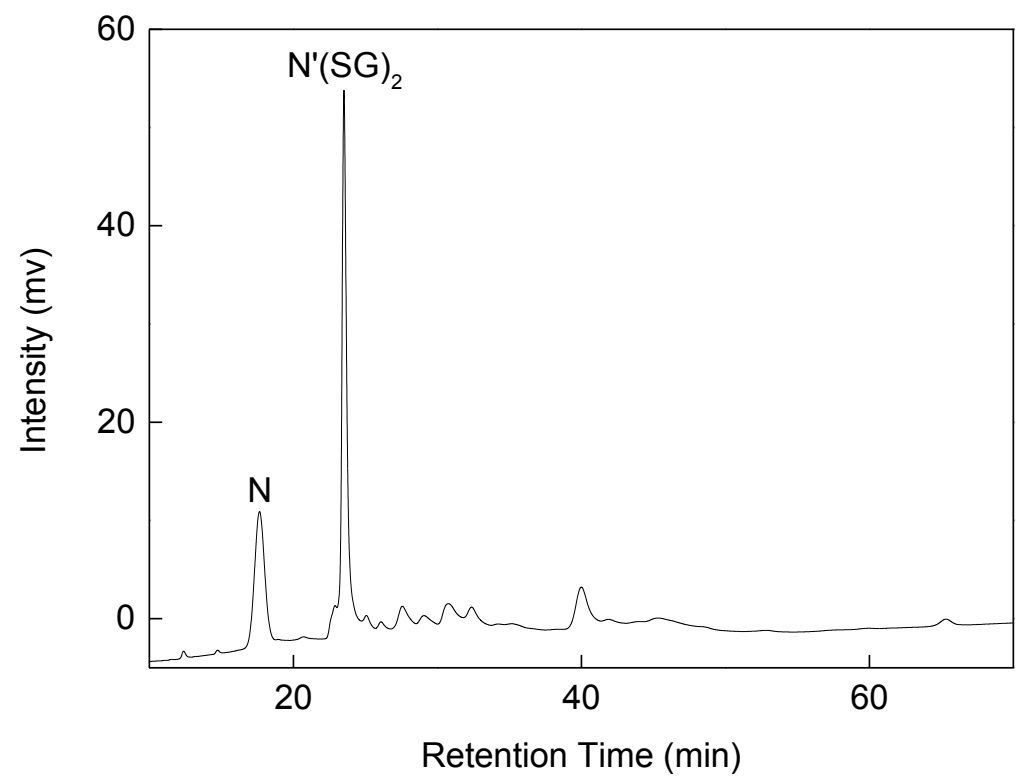

Fig. 3.11 Reaction of reduced BPTI with $20 \mathrm{mM} \mathrm{GSSG}$ after $6 \mathrm{~h}$

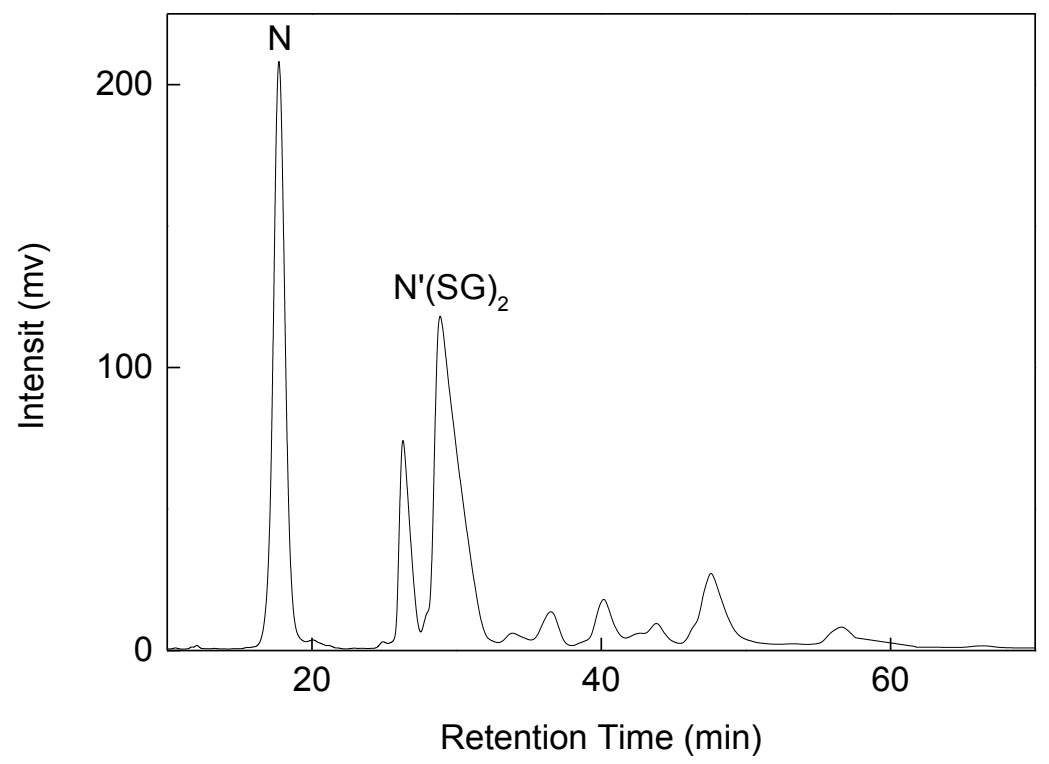

Fig. 3.12 Separation of $\mathrm{N}^{\prime}(\mathrm{SG})_{2}$ on a $\mathrm{C} 18$ semi-preparative column 


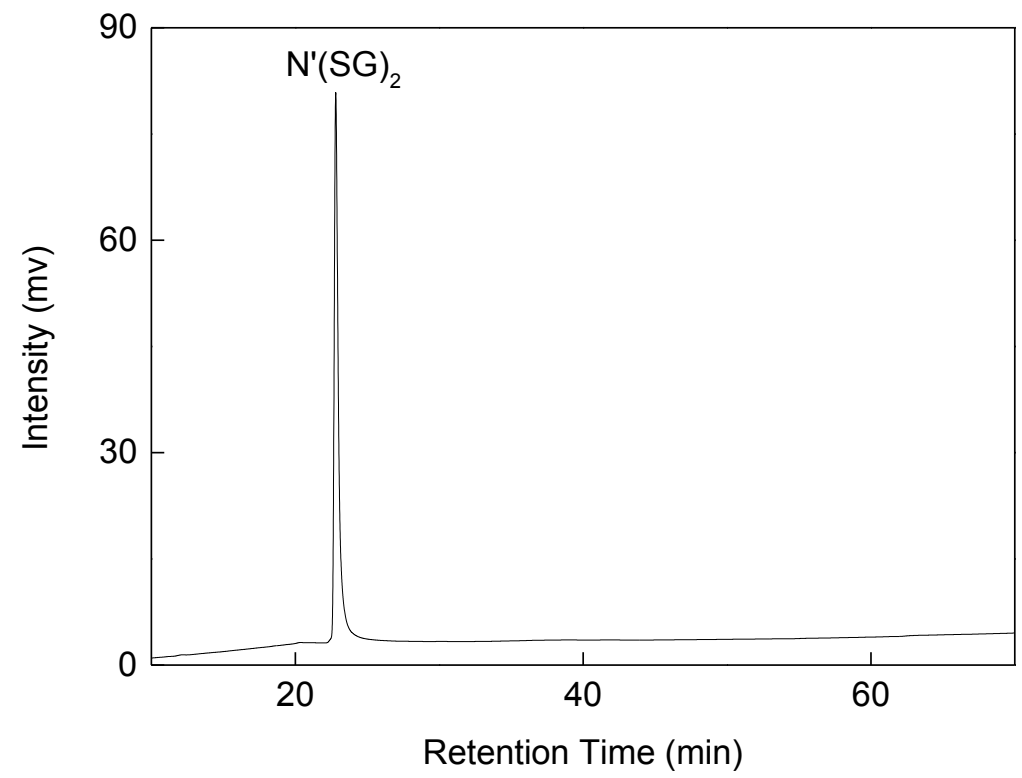

Fig. 3.13 HPLC chromatogram of pure $\mathrm{N}^{\prime}(\mathrm{SG})_{2}$

\subsubsection{Preparation of $\mathrm{N}^{\prime}(\mathrm{SG})$ by reduction of $\mathrm{N}^{\prime}(\mathrm{SG})_{2}$}

The singly mixed disulfide $\mathrm{N}^{\prime}(\mathrm{SG})$ was prepared by reduction of $\mathrm{N}^{\prime}(\mathrm{SG})_{2}$ in the presence of $10 \mathrm{mM} \mathrm{GSH}$. The reaction was quenched after $6 \mathrm{~min}$. The folding mixture was purified and analyzed by HPLC (Fig. 3.14). Only one kind of singly mixed disulfide $\mathrm{N}^{\prime}(\mathrm{SG})$ was observed with a yield of $77 \%$. The singly mixed disulfide bond in $\mathrm{N}^{\prime}$ can be formed between Cys 5 and GSH, which was referred as $\mathrm{N}^{\prime}(5-\mathrm{SSG})$, and Cys 55 and $\mathrm{GSH}$, which was referred as $\mathrm{N}^{\prime}(55-\mathrm{SSG})$. Because $N^{\prime}(55-S S G)$ was reported to rearrange rapidly to $N^{\prime}(5-S S G)$, the obtained singly mixed disulfide was $\mathrm{N}^{\prime}(5-S S G)$. Acid quenched N'(5-SSG) was found to be stable and isolated on a C18 semi-preparative column (Fig. 3.15). The collected protein fractions containing $N^{\prime}(S G)$ were further analyzed to ensure the purity (Fig. 3.16). 


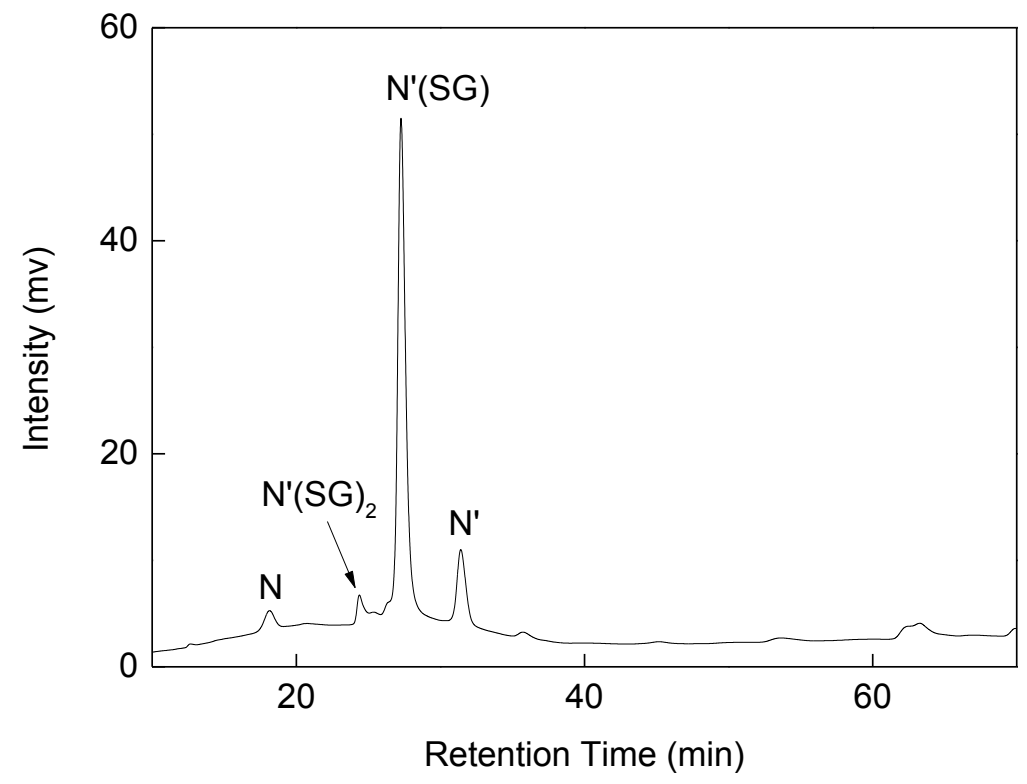

Fig. 3.14 Reduction of $\mathrm{N}^{\prime}(\mathrm{SG})_{2}$ with $10 \mathrm{mM} \mathrm{GSH}$ after $6 \mathrm{~min}$

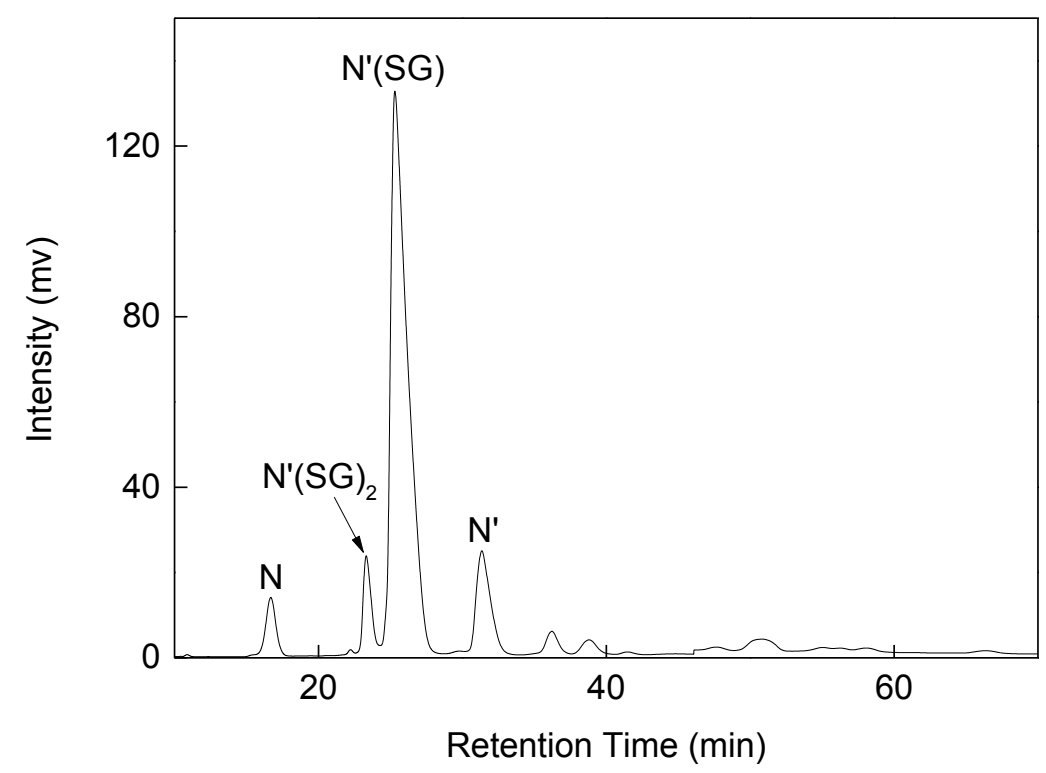

Fig. 3.15 Separation of $\mathrm{N}^{\prime}(\mathrm{SG})$ on a C18 semi-preparative column 


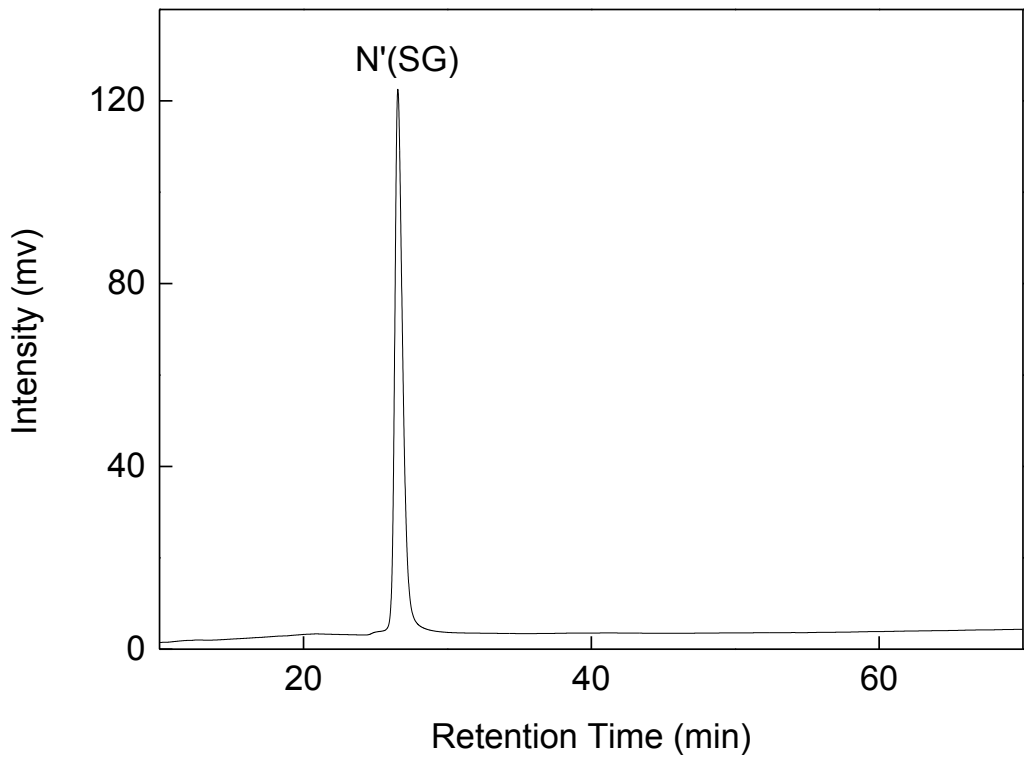

Fig. 3.16 HPLC chromatogram of pure $\mathrm{N}^{\prime}(\mathrm{SG})$

\subsection{Conclusion}

In summary, pure reduced BPTI and the intermediates $\mathrm{N}^{*}, \mathrm{~N}^{\prime}, \mathrm{N}^{\prime}(\mathrm{SG})_{2}$ and $\mathrm{N}^{\prime}(\mathrm{SG})$ were prepared and purified. Folding using bis-tris propane buffer minimize protein precipitation compared with phosphate buffer. Singly mixed disulfide, $\mathrm{N}^{\prime}(\mathrm{SG})$, was for the first time produced directly by reduction of $\mathrm{N}^{\prime}(\mathrm{SG})_{2}$ with $\mathrm{GSH}$. Previously, N'(SG) was produced by reduction of N'(5-TNB, 55-TNB), which was

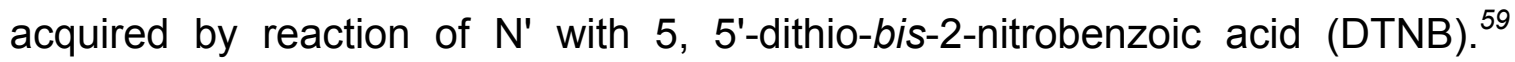
Kinetic study of the folding intermediates, especially the kinetic traps, helps to better understanding the folding pathway of BPTI and improve the folding efficiency. 


\section{Chapter 4}

\section{Kinetic study of the oxidative folding of intermediates $\mathbf{N}^{*}, \mathbf{N}^{\prime}, \mathbf{N}^{\prime}(\mathbf{S G})_{2}, \mathbf{N}^{\prime}(\mathrm{SG})$ and reduced BPTI with GSSG and GSH}

\subsection{Abstract}

Formation of kinetic traps, $\mathrm{N}^{*}, \mathrm{~N}^{\prime}, \mathrm{N}^{\prime}(\mathrm{SG})_{2}$ slowed the oxidative folding of reduced BPTI with GSSG and GSH. Folding of $\mathrm{N}^{*}$ and $\mathrm{N}^{\prime}$ focused on oxidation with GSSG and rearrangement. The best folding conditions for reduced BPTI indicated that an efficient folding of disulfide containing protein involved an oxidant and reductant in approximately a 1:1 ratio. However, the best folding conditions were determined empirically, not by modeling using rate constants. Study of kinetic traps was only performed on reaction with GSSG. The reverse direction, reduction rates of kinetic traps with GSH, was not reported. Herein, a kinetic study of the oxidative folding of intermediates $\mathrm{N}^{*}, \mathrm{~N}^{\prime}$, and $\mathrm{N}^{\prime}(\mathrm{SG})$ with GSSG was conducted. All intermediates, $\mathrm{N}^{*}, \mathrm{~N}^{\prime}, \mathrm{N}^{\prime}(\mathrm{SG})_{2}$ and $\mathrm{N}^{\prime}(\mathrm{SG})$ were reduced with GSH to determine the reduction rate constants. The results were incorporated into folding model of reduced BPTI. The best folding condition to convert kinetic traps to native protein was folding under a changing concentration of GSSG and GSH. The novel folding strategy improved the production of native protein from reduced BPTI within $12 \mathrm{~h}$.

\subsection{Introduction}

The folding pathway of BPTI has been illustrated previously in detail. However, the folding was inefficient in terms of rate and overall yield. Oxidative folding of BPTI with traditional redox reagents, GSSG and GSH, was limited by 
formation of kinetic traps, $\mathrm{N}^{*}, \mathrm{~N}^{\prime}$ and $\mathrm{N}^{\prime}(\mathrm{SG})_{2}$. To escape from kinetic traps formed during oxidative folding of disulfide containing proteins, three general pathways can be used: reduction or rearrangement of disulfide bonds or oxidation of remaining protein thiols. Both $\mathrm{N}^{*}$ and $\mathrm{N}^{\prime}$ have native-like conformations and bury the two remaining thiols in their hydrophobic core preventing further oxidation. Studies with a limited concentration of GSSG and GSH indicated that the only productive folding pathway of $\mathrm{N}^{*}$ and $\mathrm{N}^{\prime}$ was intramolecular rearrangement to another two-disulfide intermediate $\mathrm{N}^{\mathrm{SH}}$. The intramolecular rearrangement of $\mathrm{N}^{*}$ and $\mathrm{N}^{\prime}$ require substantially unfolding of their native-like structure. Thus, unfolding of acquisitive structure of kinetic traps becomes a general folding phenomenon for most disulfide containing proteins.

The oxidative folding of $N^{\prime}$ with GSSG was reported to be inefficient for two reasons: The formation of $\mathrm{N}^{\prime}(\mathrm{SG})$, the first step in $\mathrm{N}^{\prime}$ oxidation, was slow at low GSSG concentrations; Singly mixed disulfide $\mathrm{N}^{\prime}(\mathrm{SG})$ could be oxidized rapidly to $\mathrm{N}^{\prime}(\mathrm{SG})_{2}$, which was considered to be a kinetic trap in the absence of a reducing reagent because $\mathrm{N}^{\prime}(\mathrm{SG})_{2}$ has no free thiols. The formation of a mixed disulfide bond between Cys 5 and GSSG, or Cys 55 and GSSG appears to promote the local unfolding of $\mathrm{N}^{\prime}$. As a result, the other thiol, Cys5 or Cys55 in the singly mixed disulfide $\mathrm{N}^{\prime}(\mathrm{SG})$ is exposed and can be easily oxidized to form $\mathrm{N}^{\prime}(\mathrm{SG})_{2}$. The oxidative folding efficiency of $\mathrm{N}^{\prime}$ to $\mathrm{N}$ depends on the competition between the intramolecular rearrangement of $\mathrm{N}^{\prime}(\mathrm{SG})$ to $\mathrm{N}$ and oxidation of $\mathrm{N}^{\prime}(\mathrm{SG})$ to $\mathrm{N}^{\prime}(\mathrm{SG})_{2}$. At low GSSG concentration $(<0.5 \mathrm{mM})$, the direct oxidation rate of $\mathrm{N}^{\prime}$ to $N^{\prime}(S G)$ is slower than the intramolecular rearrangement rate of $N^{\prime}$ to $N^{S H}$. At 
high GSSG concentration, formation of the doubly mixed disulfide $\mathrm{N}^{\prime}(\mathrm{SG})_{2}$ limits the yield of native protein.

Previous research by Lees et al. demonstrated the best folding conditions for oxidative folding of reduced BPTI with GSSG and GSH. By modeling the folding pathway with 17 different rate constants, the model indicated the potential importance of additional folding pathways not reported previously. However, not all of rate constants determined from the model agreed with the previously reported rate constants. In order to improve the folding efficiency of reduced BPTI, the accuracy of rate constants is vital because the production of native protein can be predicted by the model as long as the rate constants are accurate. Herein, reaction of the intermediates $\mathrm{N}^{*}, \mathrm{~N}^{\prime}, \mathrm{N}^{\prime}(\mathrm{SG})_{2}$ and $\mathrm{N}^{\prime}(\mathrm{SG})$ with GSSG and GSH were investigated.

\subsection{Experimental section}

\subsubsection{Determination of rate constants for the reaction of $N^{*}, N^{\prime}$ and $N^{\prime}(S G)$ with GSSG}

Pure $\mathrm{N}^{*}, \mathrm{~N}^{\prime}$ and $\mathrm{N}^{\prime}(\mathrm{SG})$ were reacted with various concentrations of GSSG to determine the oxidation rate constants. Bis-tris propane buffer was prepared as described in Chapter 3 and deoxygenated for $30 \mathrm{~min}$. The oxidant GSSG was dissolved in bis-tris buffer and the $\mathrm{pH}$ was adjusted to 7.3 with $1 \mathrm{M} \mathrm{KOH}$. The final folding buffer contained protein $30 \mu \mathrm{M}, 0.1 \mathrm{M}$ bis-tris propane, $0.2 \mathrm{M} \mathrm{KCl}, 1$ mM EDTA and the desired concentration of GSSG. Folding reactions was conducted under argon at $25^{\circ} \mathrm{C} .{ }^{107}$ At each specific time, a $300 \mu \mathrm{L}$ aliquot was removed and quenched by the addition of $15 \mu \mathrm{L}$ of formic acid. All aliquots were 
kept in a refrigerator set at $4{ }^{\circ} \mathrm{C}$ prior to HPLC analysis. Each aliquot was analyzed by RP-HPLC on a Vydac C18 analytical column using the following gradient: 0 min, $90 \%$ solvent $A ; 15$ min, $75 \%$ solvent $A ; 35$ min, $73 \%$ solvent $A$; 50 min, $72 \%$ solvent $A ; 70$ min, $69 \%$ solvent $A$. The absorbance was monitored at $229 \mathrm{~nm}$ and the column temperature was maintained at $50{ }^{\circ} \mathrm{C}$. Each protein peak was assigned on the basis of literature results. All peak areas were summed and the total was assigned a value of $100 \%$. The concentration of each peak was derived from its relative peak area. The rate constants were calculated by inputting the concentration of all species as a function of time.

\subsubsection{Determination of rate constants for the reduction of $\mathrm{N}^{*}, \mathrm{~N}^{\prime}, \mathrm{N}^{\prime}(\mathrm{SG})$ and $\mathbf{N}^{\prime}(\mathbf{S G})_{2}$ with $\mathbf{G S H}$}

Pure $\mathrm{N}^{*}, \mathrm{~N}^{\prime}, \mathrm{N}^{\prime}(\mathrm{SG})$ and $\mathrm{N}^{\prime}(\mathrm{SG})_{2}$ were reduced with various concentrations of GSH to determine the reduction rate of each kinetic traps. The reaction was carried out under argon at $25{ }^{\circ} \mathrm{C}$ to prevent air oxidation. At each specific time, a $300 \mu \mathrm{L}$ aliquot was removed and quenched by the addition of $15 \mu \mathrm{L}$ of formic acid. All aliquots were kept at $4{ }^{\circ} \mathrm{C}$ prior to HPLC analysis. Each aliquot was analyzed by RP-HPLC on a Vydac C18 analytical column using the following linear gradient: 0 min, $90 \%$ solvent $A ; 15$ min, $75 \%$ solvent $A ; 35$ min, $73 \%$ solvent $A ; 50 \mathrm{~min}, 72 \%$ solvent $A ; 100 \mathrm{~min}, 50 \%$ solvent $A$. The column temperature was maintained at $50{ }^{\circ} \mathrm{C}$ and the absorbance was monitored at 229 $\mathrm{nm}$. The rate constants were determined as inputting the concentrations of all species as a function of time into the model. 


\subsubsection{Folding of reduced BPTI by optimizing concentration of GSSG and GSH as a function of time}

Pure reduced BPTI was refolded directly in the presence of bis-tris propane buffer containing GSSG and GSH to from significant amount of disulfide intermediates. The folding conditions were conducted at $25{ }^{\circ} \mathrm{C}$ under argon. At specific time, a small portion of concentrated GSH was added to convert $\mathrm{N}^{\prime}$ to $\mathrm{N}^{*}$. When most of the intermediates was converted to $\mathrm{N}^{*}$, another small portion of concentrated GSSG was added to fold $\mathrm{N}^{*}$ to $\mathrm{N}$ directly. At specific time points, a $300 \mu \mathrm{L}$ aliquot was removed and quenched by addition of $15 \mu \mathrm{L}$ of formic acid. All aliquot was stored in at $4{ }^{\circ} \mathrm{C}$ prior to HPLC examination. Each aliquot was analyzed by RP-HPLC on a Vydac C18 analytical column. The absorbance was monitored at $229 \mathrm{~nm}$ and the column temperature was maintained at $50{ }^{\circ} \mathrm{C}$. A flow rate of $1 \mathrm{~mL} / \mathrm{min}$ linear gradient was used: $0 \mathrm{~min}, 90 \%$ solvent $\mathrm{A} ; 15 \mathrm{~min}, 75 \%$ solvent $A ; 35$ min, $73 \%$ solvent $A ; 50$ min, $72 \%$ solvent $A ; 110$ min, $70 \%$ solvent A. All protein peaks were assigned based on literature results. Finally, the folding efficiency was compared with the previously reported BPTI folding studies.

\subsection{Results and discussion}

\subsubsection{Determination of rate constants for the reaction of $N^{*}, N^{\prime}$ and $N^{\prime}(S G)$ with GSSG}

\subsubsection{Folding of $\mathrm{N}^{*}$ with GSSG}

Pure $\mathrm{N}^{*}$ was refolded in the presence of 2 and $50 \mathrm{mM}$ GSSG. The concentrations were selected on the basis of previous research in our group. At $50 \mathrm{mM}$ GSSG, $90 \% \mathrm{~N}^{*}$ was folded to $\mathrm{N}$ exclusively within $6 \mathrm{~h}$ (Fig. 4.1). The only 
intermediate observed was always less than $4 \%$. The intramolecular rearrangement of $\mathrm{N}^{*}$ to $\mathrm{N}^{\prime}$ could take place during reaction resulting the formation of $\mathrm{N}^{\prime}(\mathrm{SG})_{2}$, which has a similar retention time as the peak in Fig. 4.1. In the absence of $\mathrm{GSH}, \mathrm{N}^{\prime}(\mathrm{SG})_{2}$ is very stable and should increase with time because the intramolecular rearrangement of $\mathrm{N}^{*}$ to $\mathrm{N}^{\prime}$ depends on the reaction time. However, the observed intermediate increased at the early folding time and decreased after $1 \mathrm{~h}$. At $6 \mathrm{~h}$, the intermediate was less than $0.4 \%$ of the total protein. Moreover, the intermediate was observed at $30 \mathrm{~min}$, which rules out the possibility of the intermediate $\mathrm{N}^{\prime}(\mathrm{SG})_{2}$ because the rearrangement of $\mathrm{N}^{*}$ to $\mathrm{N}^{\prime}$ is very slow.

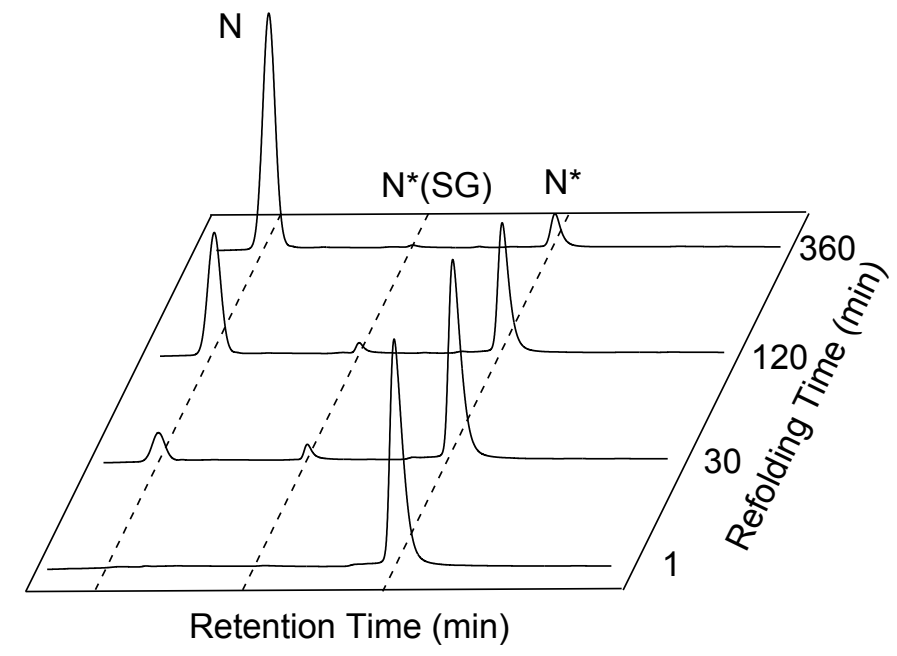

Fig. 4.1 Folding of $\mathrm{N}^{*}$ with $50 \mathrm{mM}$ GSSG

To isolate the intermediate, $\mathrm{N}^{*}$ was refolded with $160 \mathrm{mM}$ GSSG and the folding reaction was quenched after $9 \mathrm{~min}$ by addition of formic acid. Acid quenched folding mixture was manually injected onto a Vydac C18 semipreparative column (Fig. 4.2). The intermediate was collected on the basis of the 
chromatogram. The collected protein fraction was analyzed by ESI-TOF to determine the $\mathrm{m} / \mathrm{z}$ value (Fig. 4.3). Additional peaks were caused by background.

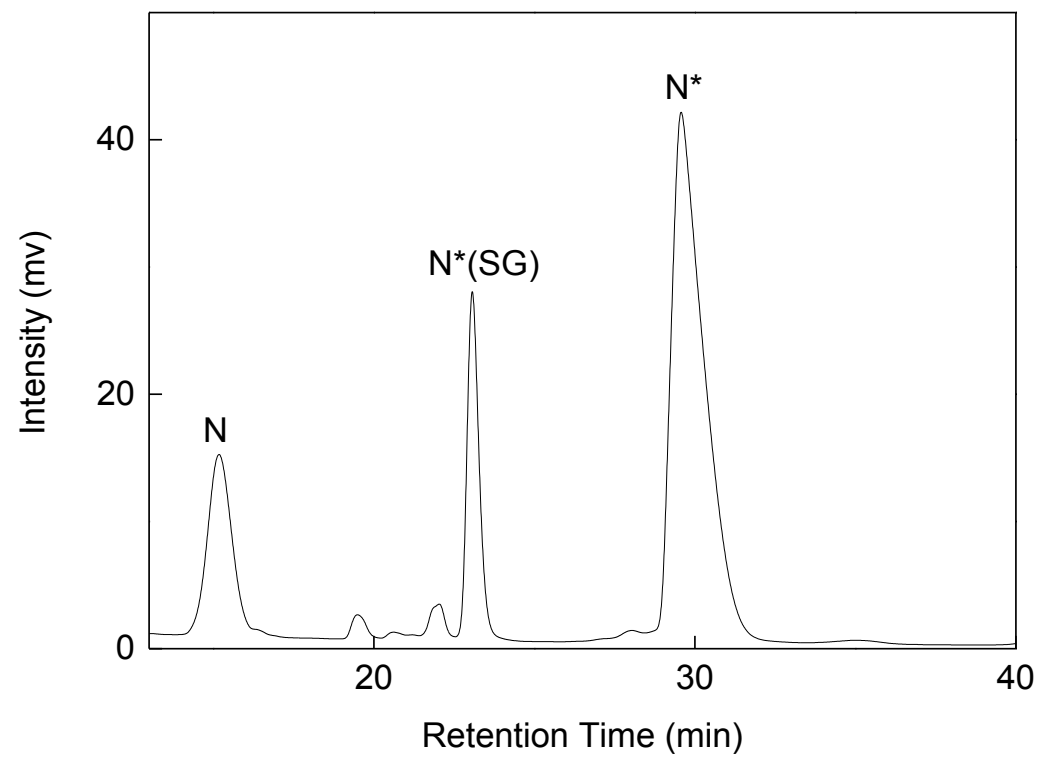

Fig. 4.2 Folding of $\mathrm{N}^{*}$ with $160 \mathrm{mM}$ GSSG after $9 \mathrm{~min} ; \mathrm{N}$ and $\mathrm{N}^{*}(\mathrm{SG})$ were produced $16 \%$ and $15 \%$, respectively

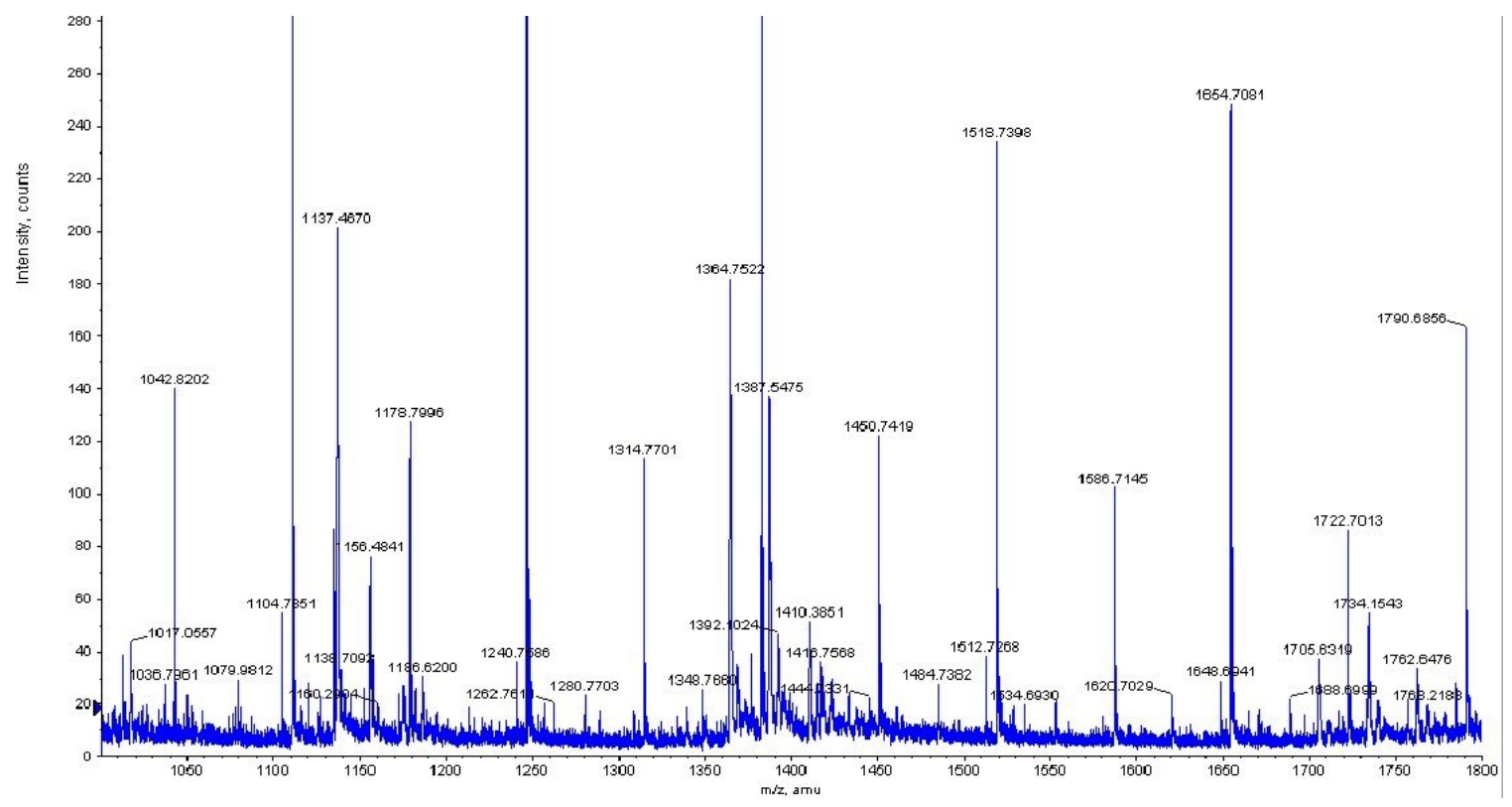

Fig. 4.3 Mass spectrum of singly mixed disulfide $\mathrm{N}^{*}(\mathrm{SG})$ 
The mass spectra results were summarized in Table 1. The experimental results matched with theoretical values, which confirmed the intermediate to be $\mathrm{N}^{*}(\mathrm{SG})$. Intermediate $\mathrm{N}^{*}$ was folded to $\mathrm{N}$ via singly mixed disulfide $\mathrm{N}^{*}(\mathrm{SG})$, a growth type pathway, which was reported not to occur previously. Therefore, $\mathrm{N}^{*}$ is not a kinetic trap and can be oxidized directly to $\mathrm{N}^{*}(\mathrm{SG})$, which can rearrangement to $\mathrm{N}$ protein.

Table 1 . Mass results of singly mixed disulfide $N^{*}(S G)$

\begin{tabular}{cccc}
\hline Charges on $\mathrm{N}^{*}(\mathrm{SG})$ & Theoretical m/z & Experimental m/z & $\begin{array}{c}\text { Mass error } \\
(\mathrm{ppm})\end{array}$ \\
\hline $\mathrm{N}^{*}(\mathrm{SG})+4 \mathrm{H}^{+}$ & 1705.7025 & 1705.6319 & 40 \\
$\mathrm{~N}^{*}(\mathrm{SG})+5 \mathrm{H}^{+}$ & 1364.7620 & 1364.7522 & 7 \\
$\mathrm{~N}^{*}(\mathrm{SG})+6 \mathrm{H}^{+}$ & 1137.4683 & 1137.4670 & 1 \\
\hline
\end{tabular}

Folding of $\mathrm{N}^{*}$ was also carried out in the presence of $2 \mathrm{mM}$ GSSG (Fig. 4.4). Although the reaction of $\mathrm{N}^{*}$ with $2 \mathrm{mM}$ GSSG was slow, the predominant folding product was found to be N. Native protein was the only observed product for the first $24 \mathrm{~h}$. At later times, a minor peak was observed. The peak was very stable and increased with the folding time until reaching a steady state. The accumulated intermediate was $3 \%$ of the total protein. Intermediate $N^{*}(S G)$ observed in $50 \mathrm{mM}$ GSSG reaction only accumulated at early folding time because the formation of $\mathrm{N}^{*}(\mathrm{SG})$ was fast at the beginning. Reaction of $\mathrm{N}^{*}$ with 2 $m M$ GSSG formed $N^{*}(S G)$ slowly but the rearrangement of $N^{*}(S G)$ was very fast. Therefore, it was impossible to observe $\mathrm{N}^{*}(\mathrm{SG})$ at $2 \mathrm{mM} \mathrm{GSSG}$. On the basis of chromatogram, the peak was proposed to be $\mathrm{N}^{\prime}(\mathrm{SG})_{2}$. The intramolecular 
rearrangement of $\mathrm{N}^{*}$ to $\mathrm{N}^{\prime}$ followed by relatively rapid oxidation of the thiols in $\mathrm{N}^{\prime}$ formed the doubly mixed disulfide $\mathrm{N}^{\prime}(\mathrm{SG})_{2}$.

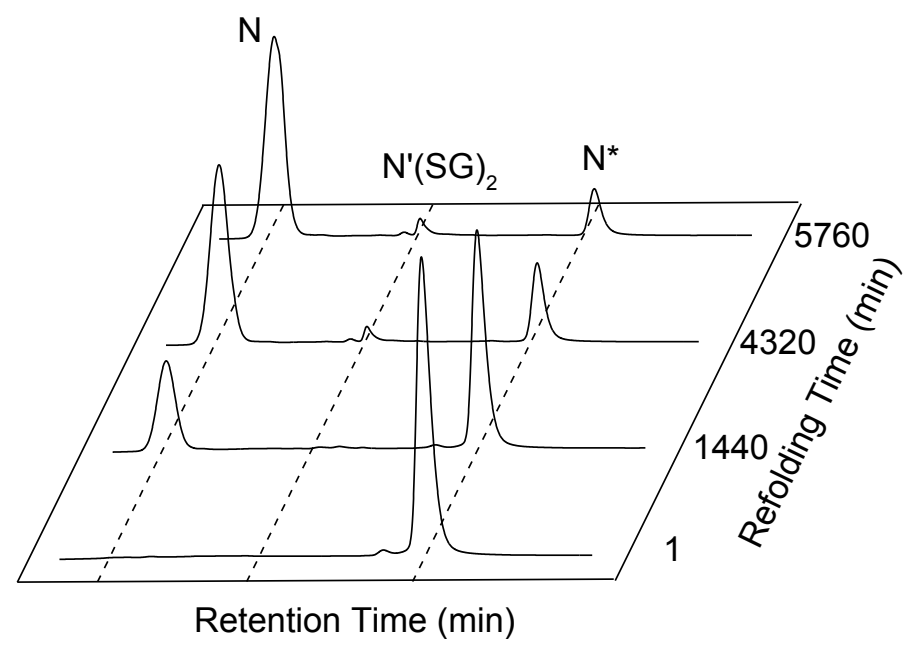

Fig. 4.4 Folding of $\mathrm{N}^{*}$ with $2 \mathrm{mM}$ GSSG

The oxidative folding of pure $\mathrm{N}^{*}$ with GSSG indicated that $\mathrm{N}^{*}$ can fold to $\mathrm{N}$ via a growth type pathway because the folding rate of $\mathrm{N}^{*}$ is dependent upon GSSG concentration and the rate constants was calculated to be $0.15 \mathrm{M}^{-1} \mathrm{~min}^{-1}$. Observation of $\mathrm{N}^{*}(\mathrm{SG})$ at high concentration of GSSG confirmed folding via a growth type pathway. A striking feature of $\mathrm{N}^{*}$ is that oxidative folding of $\mathrm{N}^{*}$ with GSSG produce exclusively native protein. Thus, folding of $\mathrm{N}^{*}$ via mixed disulfide $\mathrm{N}^{*}(\mathrm{SG})$ was important in terms of protein production. Because $\mathrm{N}^{*}$ is a thermodynamically stable intermediate during folding, $\mathrm{N}^{*}$ can be produced in large amount. The remaining thiol in $\mathrm{N}^{*}(\mathrm{SG})$ rapidly attack the mixed disulfide resulting in the formation of the last native disulfide bond. No doubly mixed disulfide was observed during folding of $\mathrm{N}^{*}$ with $50 \mathrm{mM}$ GSSG, which indicated that the oxidation of the remaining thiol in $N^{*}(S G)$ should be very slow. Consequently, folding of reduced BPTI via $\mathrm{N}^{*}$ maybe feasible. 
Pure $\mathrm{N}^{*}$ was also refolded in the presence of $50 \mathrm{mM}$ GSSG and $35 \mathrm{mM}$ $\mathrm{GSH}$. Addition of GSH slowed the conversion of $\mathrm{N}^{*}$ towards $\mathrm{N}$ because of the reduction of $\mathrm{N}^{*}(\mathrm{SG})$ to $\mathrm{N}^{*}$. The reaction rate of $\mathrm{N}^{*}$ to $\mathrm{N}$ was only half when folding was performed in $35 \mathrm{mM} \mathrm{GSH}$ and $50 \mathrm{mM}$ GSSG compared with $50 \mathrm{mM}$ GSSG. Thus, a high concentration of GSH could slow the folding of $\mathrm{N}^{*}$ towards $\mathrm{N}$.

\subsubsection{Folding of $N^{\prime}$ in the buffer alone and GSSG}

Pure N' was also examined in deoxygenated bis-tris buffer alone at $\mathrm{pH} 7.3$ to investigate the intramolecular rearrangement rate (Fig. 4.5). The rearrangement of $\mathrm{N}^{\prime}$ to $\mathrm{N}^{*}$ indicated that $\mathrm{N}^{*}$ was more thermodynamically stable than $\mathrm{N}^{\prime}$. In the absence of redox reagents, $\mathrm{N}^{*}$ barely rearranges and stays as a kinetic trap. The rearrangement of $\mathrm{N}^{\prime}$ to another two-disulfide bond intermediate $\mathrm{N}^{\mathrm{SH}}$ was also observed. Previously, the rearrangement of $\mathrm{N}^{\prime}$ to $\mathrm{N}^{\mathrm{SH}}$ followed by oxidation to $\mathrm{N}$ was reported to be the only productive pathway. The formation of native protein indicated that $\mathrm{N}^{\mathrm{SH}}$ was much more reactive than $\mathrm{N}^{*}$ and $\mathrm{N}^{\prime}$, and converted to $\mathrm{N}$ by air oxidation. A striking feature of $\mathrm{N}$ ' rearrangement was that the rearrangement rates of $\mathrm{N}^{\prime}$ to $\mathrm{N}^{\mathrm{SH}}$ and $\mathrm{N}^{\prime}$ to $\mathrm{N}^{*}$ were almost the same, $1.9 \mathrm{x}$ $10^{-3} \mathrm{~min}^{-1}$ and $1.7 \times 10^{-3} \mathrm{~min}^{-1}$, respectively. The rearrangement of $\mathrm{N}^{\prime}$ appears to result in the formation of two thermodynamically stable two-disulfide intermediates $\mathrm{N}^{*}$ and $\mathrm{N}^{\mathrm{SH}}$. If the folding of $\mathrm{N}^{\prime}$ proceeds via a rearrangement type pathway, the conversion of $\mathrm{N}^{\prime}$ to $\mathrm{N}$ will be half of the disappearance rate of $\mathrm{N}^{\prime}$ because the two rearrangement rates $\mathrm{N}^{\prime}$ to $\mathrm{N}^{\mathrm{SH}}$ and $\mathrm{N}^{\prime}$ to $\mathrm{N}^{*}$ are the same. Consequently, the folding of $\mathrm{N}^{\prime}$ to $\mathrm{N}$ via a rearrangement type pathway becomes inefficient. 


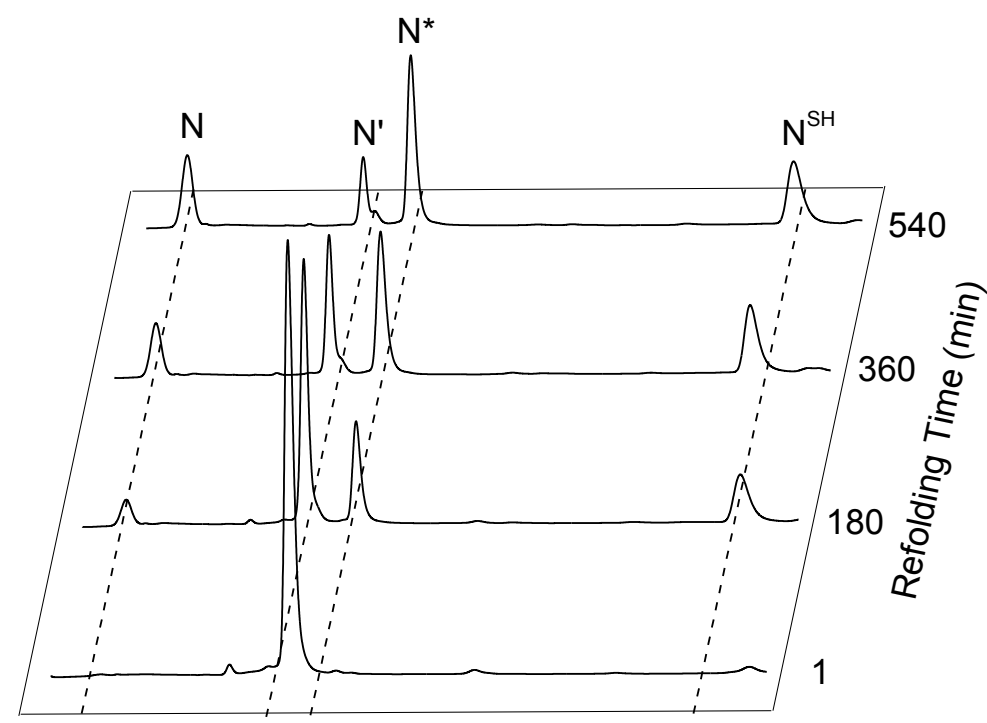

Retention Time (min)

Fig. 4.5 Rearrangement of $\mathrm{N}^{\prime}$ in bis-tris buffer alone

The folding rate of $\mathrm{N}^{\prime}$ was reexamined because folding of $\mathrm{N}^{\prime}$ via a growth type pathway was also proposed to be important. Pure N' was refolded in the presence of 2, 5 and $20 \mathrm{mM}$ GSSG to determine the oxidation rate constant. At 5 and $20 \mathrm{mM}$ GSSG, $\mathrm{N}^{\prime}$ was converted almost exclusively to $\mathrm{N}^{\prime}(\mathrm{SG})_{2}$ because of the relatively rapid reaction of $\mathrm{N}^{\prime}(\mathrm{SG})$ with GSSG (Fig. 4.6, 4.7). The singly mixed disulfide $\mathrm{N}^{\prime}(\mathrm{SG})$ was observed to accumulate at very low level during the folding process because the folding of $\mathrm{N}^{\prime}$ to $\mathrm{N}^{\prime}(\mathrm{SG})$ was the rate determining step. The folding rate was determined to be $2.5 \mathrm{M}^{-1} \mathrm{~min}^{-1}$ which matched with the previous rate obtained by Kim et al. The reaction of N' with GSSG was slow because in the native-like structure of $\mathrm{N}^{\prime}$ two remaining thiols are buried. The oxidation of $\mathrm{N}^{\prime}$ to $\mathrm{N}^{\prime}(\mathrm{SG})$ depended on the unfolding of the native-like conformation of $\mathrm{N}^{\prime}$ to expose the remaining thiol in $\mathrm{N}^{\prime}$. As a result, the reactivity of $\mathrm{N}^{\prime}$ was determined by the conformational change of the native-like structure. Normally, the reaction 
of $\mathrm{N}^{\prime}$ with low GSSG concentration was slow while folding at high GSSG concentration favored the formation of kinetic trap $\mathrm{N}^{\prime}(\mathrm{SG})_{2}$.

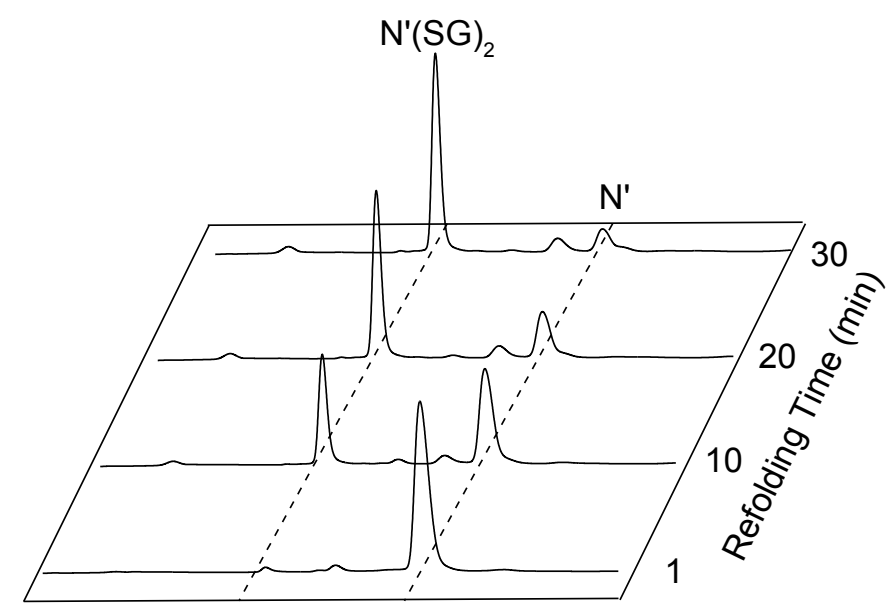

Retention Time (min)

Fig. 4.6 Folding of $\mathrm{N}^{\prime}$ with $20 \mathrm{mM}$ GSSG

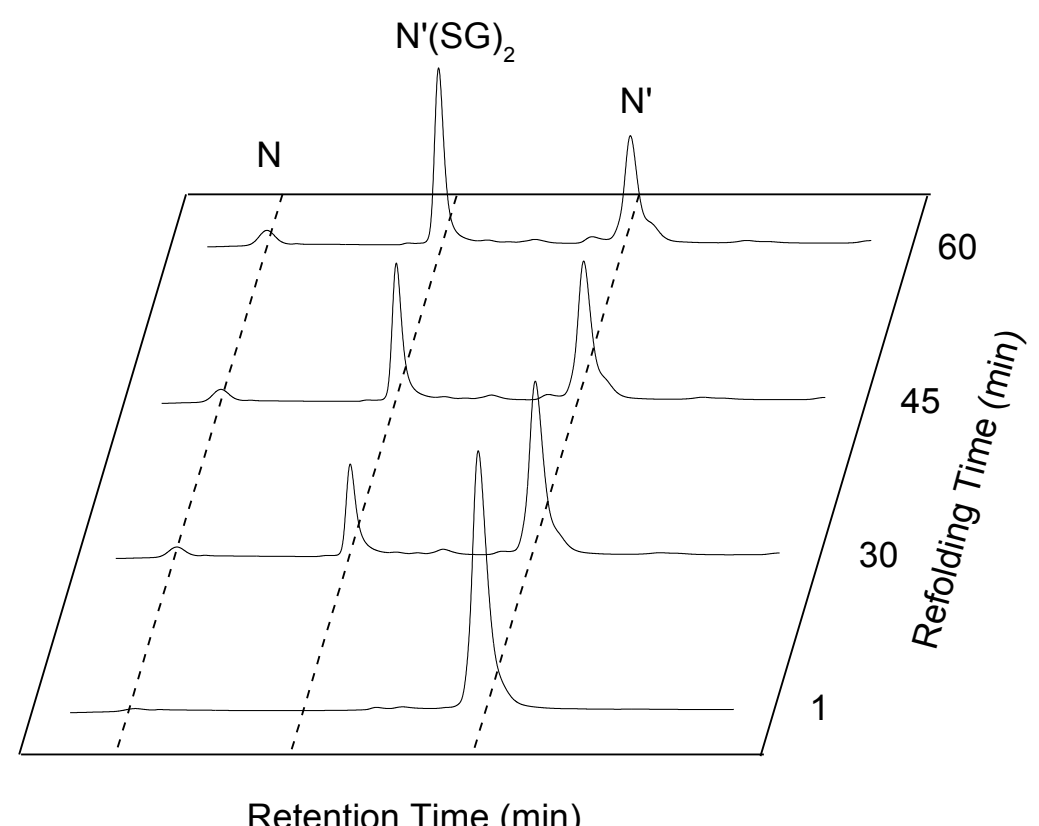

Fig. 4.7 Folding of N' with 5 mM GSSG

Previously, formation of $\mathrm{N}^{\prime}(\mathrm{SG})_{2}$ during the reaction of $\mathrm{N}^{*}$ with $2 \mathrm{mM}$ GSSG indicated that $\mathrm{N}^{*}$ rearranges to $\mathrm{N}^{\prime}$ slowly. The rearrangement rate of $\mathrm{N}^{*}$ to 
$\mathrm{N}^{\prime}$ can be measured on the basis of $\mathrm{N}^{\prime}(\mathrm{SG})_{2}$ formation. Folding of $\mathrm{N}^{\prime}$ with $2 \mathrm{mM}$ GSSG was conducted as a control to examine the productivity of $\mathrm{N}^{\prime}(\mathrm{SG})_{2}$ from $\mathrm{N}^{\prime}$ (Fig. 4.8). Reaction of $\mathrm{N}^{\prime}$ and $\mathrm{N}^{*}$ with $2 \mathrm{mM}$ GSSG produced $40 \%$ and $3 \%$ $\mathrm{N}^{\prime}(\mathrm{SG})_{2}$, respectively. The rate constant for $\mathrm{N}^{*}$ to $\mathrm{N}^{\prime}$ conversion was calculated to be $2 \times 10^{-5} \mathrm{~min}^{-1}$.

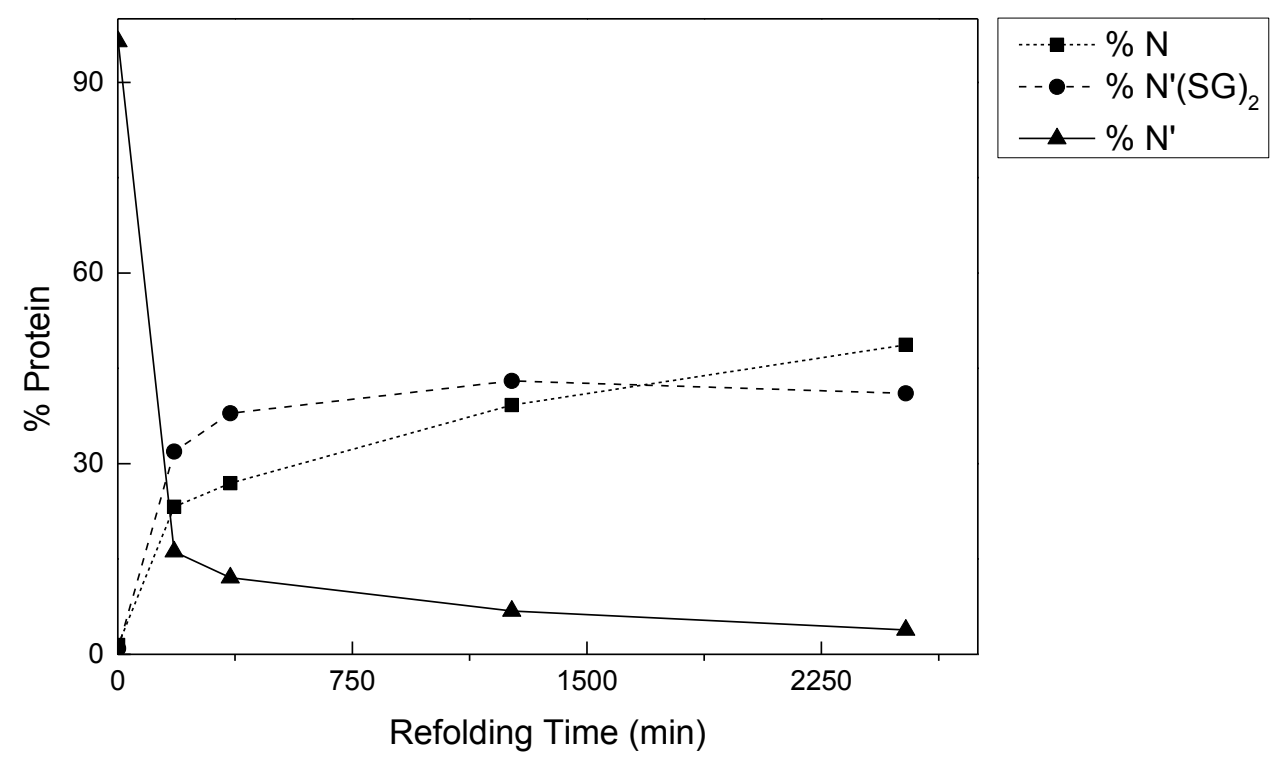

Fig. 4.8 Folding of $\mathrm{N}^{\prime}$ with $2 \mathrm{mM}$ GSSG

\subsubsection{Folding of $N^{\prime}(S G)$ in the buffer alone and GSSG}

Singly mixed disulfide $\mathrm{N}^{\prime}(\mathrm{SG})$ was examined in the buffer alone to determine the rearrangement rate of $N^{\prime}(S G)$ to $N$ (Fig. 4.9). Besides native protein, other intermediates were also observed at later retention times during the rearrangements of $\mathrm{N}^{\prime}(\mathrm{SG})$. The multiple peaks might be formed by two ways: $\mathrm{N}^{\prime}(\mathrm{SG})$ was reduced by GSH, which was formed by the breaking of mixed disulfide bond in $\mathrm{N}^{\prime}(\mathrm{SG})$ during rearrangement; Intramolecular rearrangement 
also took place between the two native disulfide bonds and the remaining thiol in $\mathrm{N}^{\prime}(\mathrm{SG})$. The singly mixed disulfide $\mathrm{N}^{\prime}(\mathrm{SG})$ was also confirmed to be $\mathrm{N}^{\prime}(5-\mathrm{SSG})$ because the other singly mixed disulfide $\mathrm{N}^{\prime}(55-\mathrm{SSG})$ was reported to rearrange to $\mathrm{N}^{\prime}(5-\mathrm{SSG})$ before further reaction. The formation rate of $\mathrm{N}$ was found to be almost half of the disappearance rate of $\mathrm{N}^{\prime}(\mathrm{SG})$. As a result, the formation rate of $\mathrm{N}$ was found to be almost half of the disappearance rate of $\mathrm{N}^{\prime}(\mathrm{SG})$. The rearrangement rate of $\mathrm{N}^{\prime}(\mathrm{SG})$ to $\mathrm{N}$ was calculated to be $2.2 \times 10^{-3} \mathrm{~min}^{-1}$.

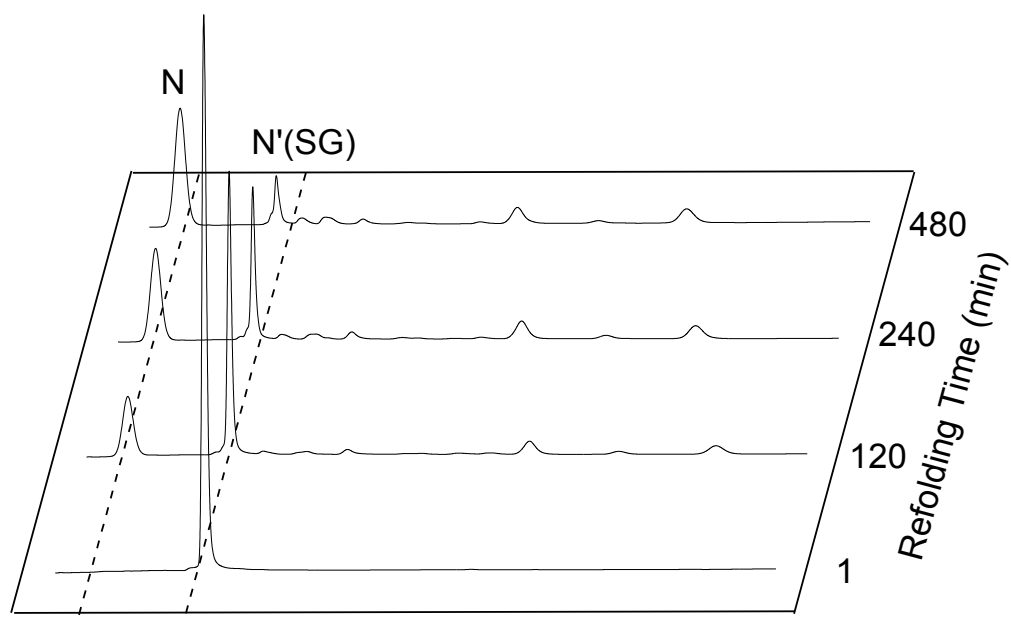

Retention Time (min)

Fig. 4.9 Rearrangement of $\mathrm{N}^{\prime}(\mathrm{SG})$ in bis-tris buffer alone

The oxidation rate of $\mathrm{N}^{\prime}(\mathrm{SG})$ with GSSG was reexamined. In the presence of $2 \mathrm{mM}$ GSSG, $\mathrm{N}^{\prime}(\mathrm{SG})$ was converted exclusively to $\mathrm{N}^{\prime}(\mathrm{SG})_{2}$ because of the rapid oxidation of the remaining thiol in $\mathrm{N}^{\prime}(\mathrm{SG})$ (Fig. 4.10). The reaction rate of $\mathrm{N}^{\prime}(\mathrm{SG})$ to $\mathrm{N}^{\prime}(\mathrm{SG})_{2}$ was determined to be $80 \mathrm{M}^{-1} \mathrm{~min}^{-1}$. No native protein was observed because the intramolecular rearrangement of $\mathrm{N}^{\prime}(\mathrm{SG})$ to $\mathrm{N}$ was slow compared with the oxidation rate of $N^{\prime}(S G)$ with GSSG. In the presence of GSSG only, conversion of $\mathrm{N}^{\prime}$ to $\mathrm{N}$ via singly mixed disulfide $\mathrm{N}^{\prime}(\mathrm{SG})$ became inefficient 
because of the rapid formation of the kinetic trap $\mathrm{N}^{\prime}(\mathrm{SG})_{2}$. The reaction rate of kinetic trap $\mathrm{N}^{\prime}(\mathrm{SG})_{2}$ with $\mathrm{GSH}$ was not reported previously. However, thioldisulfide exchange is an equilibrium reaction. Oxidative folding of $\mathrm{N}^{\prime}$ to $\mathrm{N}$ via the mixed disulfide $N^{\prime}(S G)$, a growth type pathway, could be feasible if the kinetic trap $\mathrm{N}^{\prime}(\mathrm{SG})_{2}$ can be reduced to $\mathrm{N}^{\prime}(\mathrm{SG})$ with $\mathrm{GSH}$.

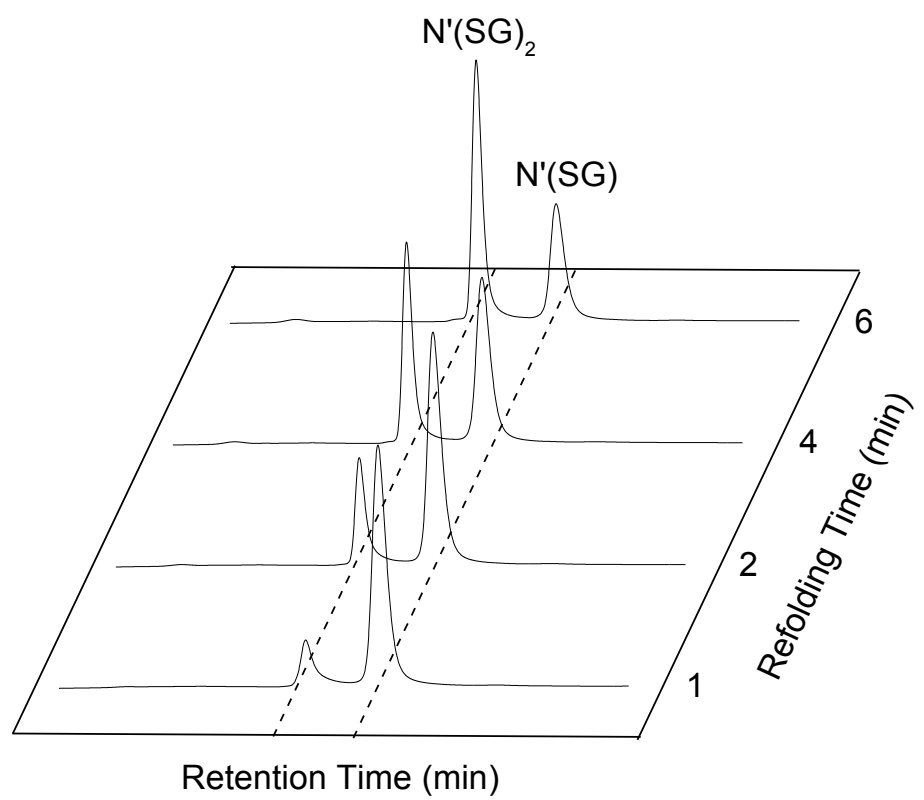

Fig. 4.10 Oxidative folding of $\mathrm{N}^{\prime}(\mathrm{SG})$ with $2 \mathrm{mM}$ GSSG

4.4.2 Determination of rate constants for the reduction of $\mathbf{N}^{*}, \mathbf{N}^{\prime}, \mathbf{N}^{\prime}(\mathrm{SG})$ and $\mathbf{N}^{\prime}(\mathbf{S G})_{2}$ with $\mathbf{G S H}$

\subsubsection{Reduction of $\mathrm{N}^{*}$ with $\mathrm{GSH}$}

Pure $\mathrm{N}^{*}$ was reduced with $50 \mathrm{mM}$ GSH because $\mathrm{N}^{*}$ was the most kinetically stable intermediate during the folding of BPTI (Fig. 4.11). The reduction rate constant of $\mathrm{N}^{*}$ was determined to be $6 \times 10^{-2} \mathrm{M}^{-1} \mathrm{~min}^{-1}$. The kinetic trap $\mathrm{N}^{*}$ was very stable in the presence of GSH because the two native disulfide bonds in $\mathrm{N}^{*}$ are buried as they are in the native structure. The reduction of $\mathrm{N}^{*}$ 
with GSH produced a mixture of intermediates. When one native disulfide bond in $\mathrm{N}^{*}$ is reduced, the resulting intermediate can be reduced further or rearrange and be reduced. The intermediates mixture may contain one-disulfide intermediate, mixed disulfide formed between one-disulfide intermediate and $\mathrm{GSH}$, and reduced BPTI. The back reaction was also observed because $\mathrm{N}^{*}$ is a thermodynamically stable intermediate.

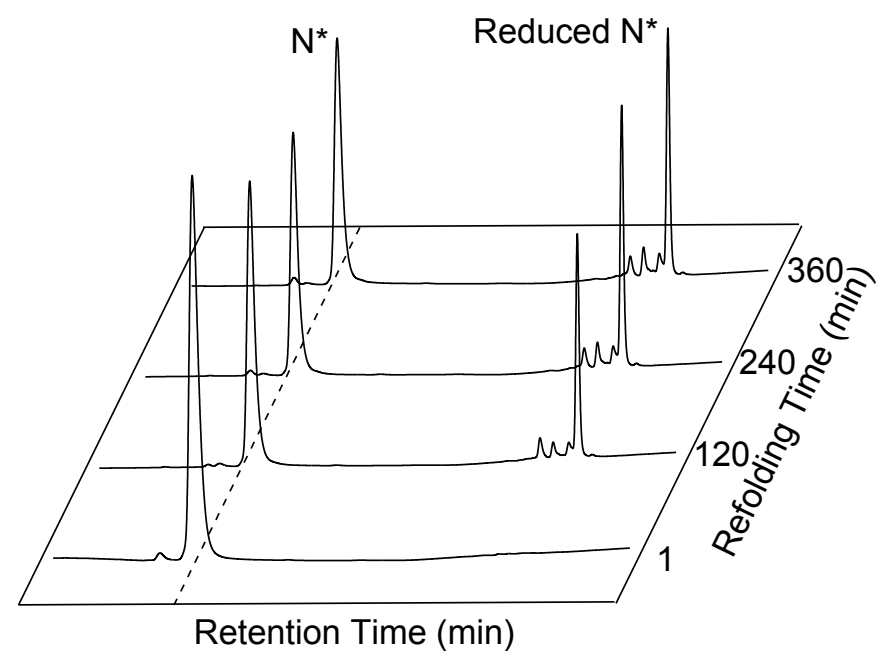

Fig. 4.11 Reduction of $\mathrm{N}^{*}$ with $50 \mathrm{mM} \mathrm{GSH}$

\subsubsection{Reduction of N' with GSH}

Reduction of $\mathrm{N}^{\prime}$ was conducted in the presence of $5,10,20,50$ and 100 mM GSH (Fig. 4.12). In the presence of GSH, N' was reduced by breaking its native disulfide bonds. At 5, 10, $20 \mathrm{mM} \mathrm{GSH}$, the reduction rate constant was found to be $1.7 \mathrm{M}^{-1} \mathrm{~min}^{-1}$ while at 50 and $100 \mathrm{mM} \mathrm{GSH}$, the rate constant was calculated to be $7.1 \mathrm{M}^{-1} \mathrm{~min}^{-1}$. The reduction rate of $\mathrm{N}^{\prime}$ was not linearly dependent on GSH concentration on the basis of the reduction results. The inconsistence in the rate constants indicated that the two native disulfide bonds in $\mathrm{N}^{\prime}$ were not reduced sequentially with all GSH concentrations. It appears that one native 
disulfide bond is reduced first followed by reduction of the other one at low GSH concentrations. At high GSH concentrations, reduction of one native disulfide promotes the rapid reduction of the other one. As a result, the rate constant at high GSH concentrations increased dramatically. Intermediate $\mathrm{N}^{*}$ was also observed during reaction. The reduction of $\mathrm{N}^{\prime}$ can form one-disulfide bond intermediates which are oxidized to $\mathrm{N}^{*}$ by air oxidation. Because $\mathrm{N}^{*}$ is more thermodynamically stable than $\mathrm{N}^{\prime}$, the formation of $\mathrm{N}^{*}$ is favored during the oxidation of one-disulfide intermediates.

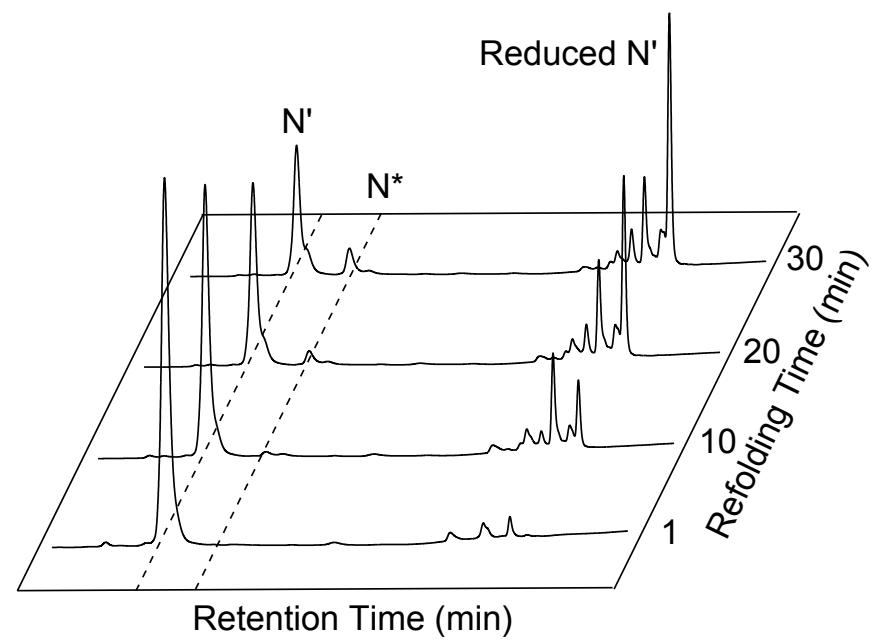

Fig. 4.12 Reduction of N' with $20 \mathrm{mM} \mathrm{GSH}$

\subsubsection{Reduction of $\mathrm{N}^{\prime}(\mathrm{SG})$ with $\mathrm{GSH}$}

Intermediate $\mathrm{N}^{\prime}(\mathrm{SG})$ was reduced in the presence of 5 and $20 \mathrm{mM} \mathrm{GSH}$ to examine its stability towards GSH. At $5 \mathrm{mM} \mathrm{GSH}$, a significant amount of $\mathrm{N}$ was observed because of intramolecular rearrangement of $N^{\prime}(S G)$ to $N$ (Fig. 4.13). However, the reaction at $20 \mathrm{mM} \mathrm{GSH}$, the reduction of $\mathrm{N}^{\prime}(\mathrm{SG})$ was so fast that only a minor rearrangement of $\mathrm{N}^{\prime}(\mathrm{SG})$ to $\mathrm{N}$ was observed (Fig. 4.14). Two intermediates, $\mathrm{N}^{\prime}$ and $\mathrm{N}^{*}$ accumulated more during the reduction of $\mathrm{N}^{\prime}(\mathrm{SG})$ with 5 
$\mathrm{mM} \mathrm{GSH}$ than with $20 \mathrm{mM} \mathrm{GSH}$ because reduction of $\mathrm{N}$ ' was fast at higher GSH concentration while the formation of $\mathrm{N}^{*}$ was less likely. The mixed disulfide bond and native disulfide bonds in $\mathrm{N}^{\prime}(\mathrm{SG})$ were found to have similar reactivity. The disappearance rate constant of $\mathrm{N}^{\prime}(\mathrm{SG})$ was determined to be $3.8 \mathrm{M}^{-1} \mathrm{~min}^{-1}$. The reduction rate of $\mathrm{N}^{\prime}(\mathrm{SG})$ to $\mathrm{N}^{\prime}$ was calculated by modeling the concentration of each intermediate as a function of time. The reduction rate constants of $\mathrm{N}^{\prime}(\mathrm{SG})$ to $\mathrm{N}^{\prime}$ and $\mathrm{N}^{\prime}(\mathrm{SG})$ to one-disulfide intermediates were determined to be $1.9 \mathrm{M}^{-1} \mathrm{~min}^{-1}$ and $1.2 \mathrm{M}^{-1} \mathrm{~min}^{-1}$, respectively.

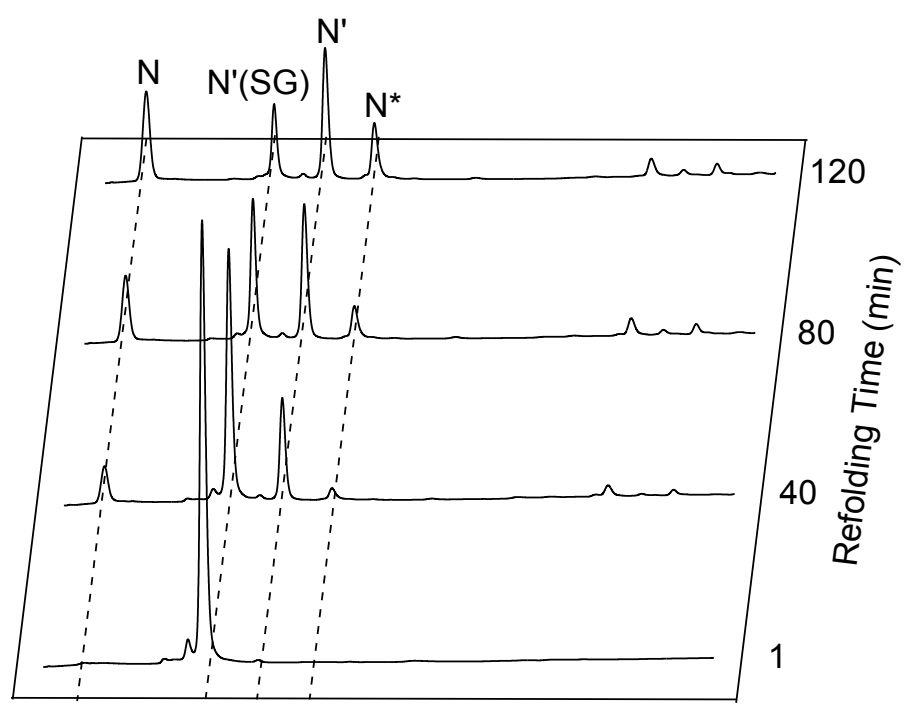

Retention Time (min)

Fig. 4.13 Reduction of $\mathrm{N}^{\prime}(\mathrm{SG})$ with $5 \mathrm{mM}$ GSH 


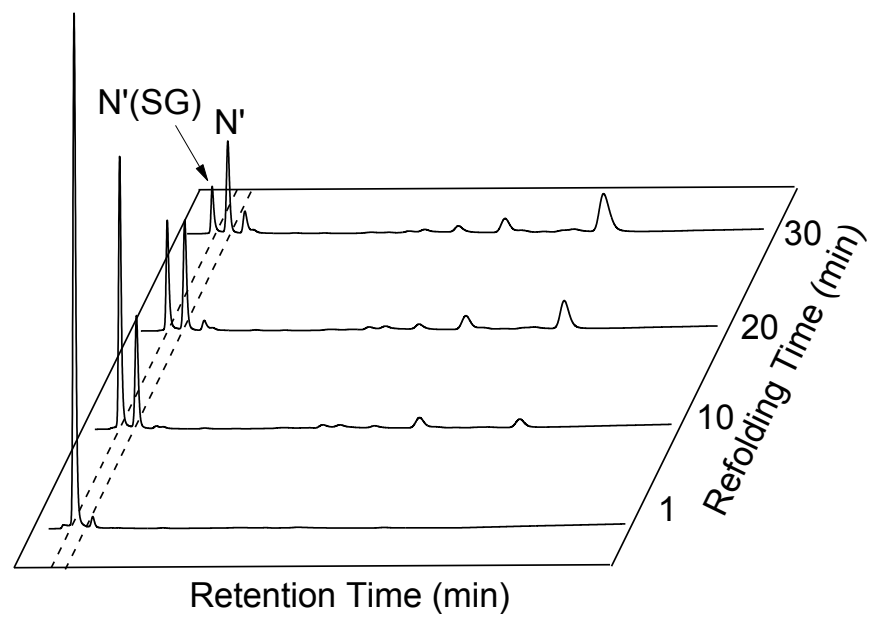

Fig. 4.14 Reduction of N'(SG) with $20 \mathrm{mM} \mathrm{GSH}$

\subsubsection{Reduction of $\mathrm{N}^{\prime}(\mathrm{SG})_{2}$ with $\mathrm{GSH}$}

The reduction rate of $\mathrm{N}^{\prime}(\mathrm{SG})_{2}$ with $\mathrm{GSH}$ has not been reported previously. Intermediate $\mathrm{N}^{\prime}(\mathrm{SG})_{2}$ was considered to be a kinetic trap because $\mathrm{N}^{\prime}(\mathrm{SG})_{2}$ has no free thiol. In order to fold N' via a growth type pathway, the accumulation of the kinetic trap $\mathrm{N}^{\prime}(\mathrm{SG})_{2}$ must be avoid. To escape from the kinetic trap, $\mathrm{N}^{\prime}(\mathrm{SG})_{2}$ can be reduced to $N^{\prime}(S G)$ with $G S H$. Herein, the reduction of $N^{\prime}(S G)_{2}$ with $G S H$ was investigated. In the presence of various GSH concentrations $(0.25,0.5,1,10$ and $20 \mathrm{mM}), \mathrm{N}^{\prime}(\mathrm{SG})_{2}$ was reduced to determine the reduction rate constant. The reaction of $\mathrm{N}^{\prime}(\mathrm{SG})_{2}$ with low $\mathrm{GSH}$ concentrations $(0.25,0.5,1 \mathrm{mM})$ proceeded readily (Fig. 4.15). The kinetic trap $\mathrm{N}^{\prime}(\mathrm{SG})_{2}$ was reduced to $\mathrm{N}^{\prime}(\mathrm{SG})$ predominantly. The rearrangement of $\mathrm{N}^{\prime}(\mathrm{SG})$ to $\mathrm{N}$ was observed but there is no indication of $\mathrm{N}^{\prime}(\mathrm{SG})$ reduction. The accumulation of $\mathrm{N}^{\prime}(\mathrm{SG})$ at low $\mathrm{GSH}$ concentration indicated that the reduction of singly mixed disulfide $N^{\prime}(S G)$ was slower than the reduction of the kinetic trap $\mathrm{N}^{\prime}(\mathrm{SG})_{2}$. 


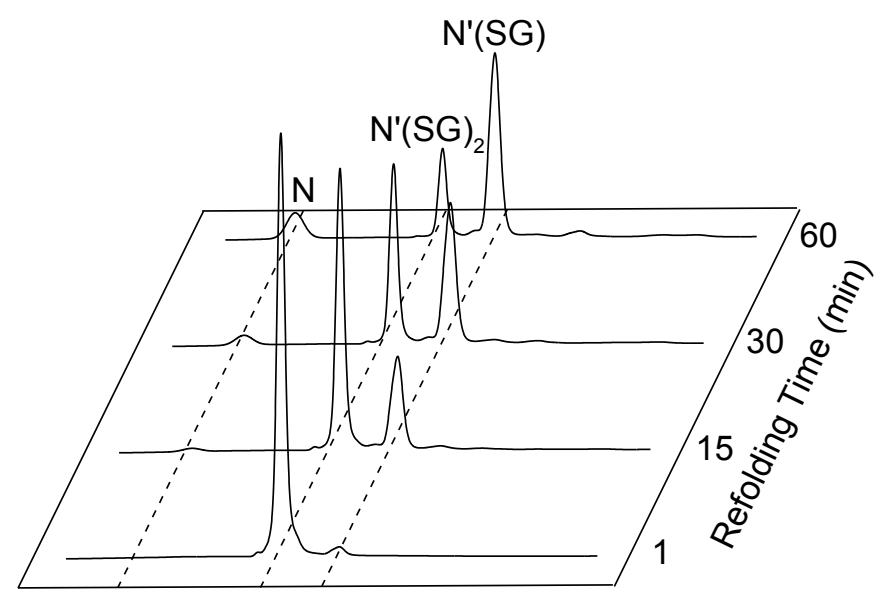

Retention Time (min)

Fig. 4.15 Reduction of $\mathrm{N}^{\prime}(\mathrm{SG})_{2}$ with $0.5 \mathrm{mM}$ GSH

At high GSH concentrations (10 and $20 \mathrm{mM}), \mathrm{N}^{\prime}(\mathrm{SG})_{2}$ was reduced to $\mathrm{N}^{\prime}(\mathrm{SG})$ rapidly (Fig. 4.16). The resulting intermediate $\mathrm{N}^{\prime}(\mathrm{SG})$ was reduced in the same way as pure $\mathrm{N}^{\prime}(\mathrm{SG})$. The singly mixed disulfide $\mathrm{N}^{\prime}(\mathrm{SG})$ was reduced to multiple intermediates including N', one-disulfide intermediates and reduced BPTI. The intramolecular rearrangement of $\mathrm{N}^{\prime}(\mathrm{SG})$ to $\mathrm{N}$ was also observed. On the basis of $\mathrm{N}^{\prime}(\mathrm{SG})_{2}$ reduction studies, the rate constant of $\mathrm{N}^{\prime}(\mathrm{SG})_{2}$ to $\mathrm{N}^{\prime}(\mathrm{SG})$ was determined to be $55 \mathrm{M}^{-1} \mathrm{~min}^{-1}$. The modeling of $\mathrm{N}^{\prime}(\mathrm{SG})_{2}$ with high concentration of 10 and $20 \mathrm{mM} \mathrm{GSH}$ also indicated that the disappearance rate of $\mathrm{N}^{\prime}(\mathrm{SG})$ was 3.8 $\mathrm{M}^{-1} \min ^{-1}$. 


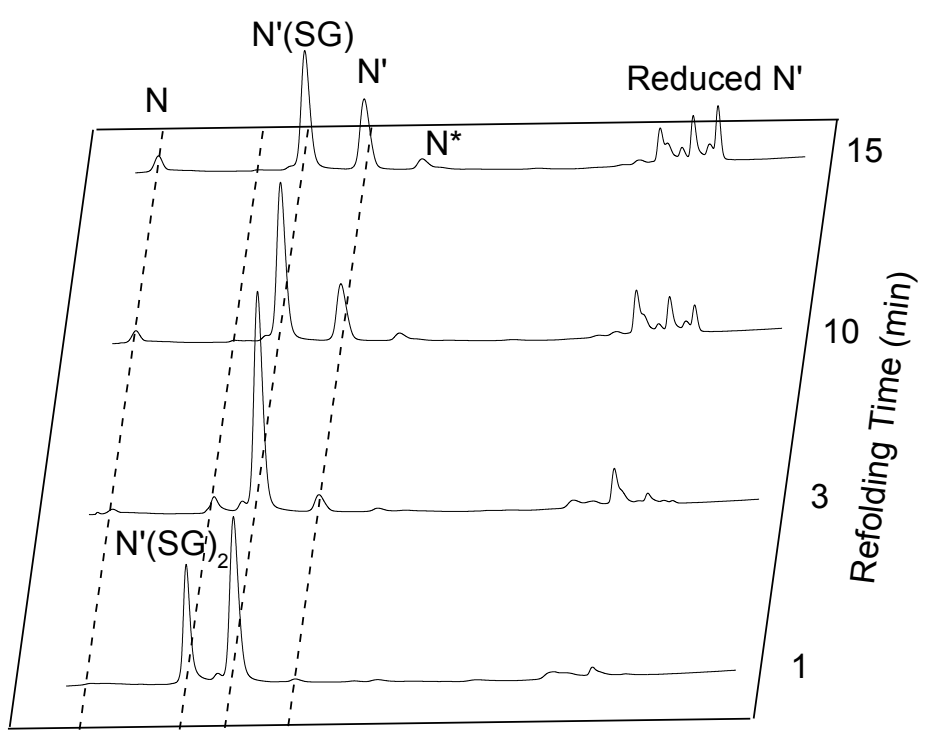

Retention Time ( $\mathrm{min})$

Fig. 4.16 Reduction of $\mathrm{N}^{\prime}(\mathrm{SG})_{2}$ with $20 \mathrm{mM}$ GSH

All the rate constants determined herein are summarized in Fig. 4.17. The equilibrium constant between oxidation of $\mathrm{N}^{\prime}(\mathrm{SG})$ with $\mathrm{GSSG}$ and reduction of $\mathrm{N}^{\prime}(\mathrm{SG})_{2}$ with $\mathrm{GSH}$ is 1.5 . Under conditions where GSSG and GSH concentrations are similar, $\mathrm{N}^{\prime}(\mathrm{SG})_{2}$ can be rapidly converted back to $\mathrm{N}^{\prime}(\mathrm{SG})$ and escape from being a kinetic trap because the reduction rate constant of $N^{\prime}(S G)_{2}$ to $N^{\prime}(S G)$ is $55 \mathrm{M}^{-1} \mathrm{~min}^{-1}$. Folding of $\mathrm{N}^{\prime}$ to native protein via both pathways, rearrangement and growth type pathway, become feasible. Folding of $\mathrm{N}^{*}$ via growth type pathway was observed and the rate constants was confirmed to be second order. The reaction rate of $\mathrm{N}^{*}$ can be increased by raising GSSG concentration. Folding of $N^{*}$ via $N^{*}(S G)$, a growth type pathway indicated that folding of reduced BPTI via $\mathrm{N}^{*}$ might be best because $\mathrm{N}^{*}$ can be oxidized to $\mathrm{N}$ without accumulation of any kinetic traps. 


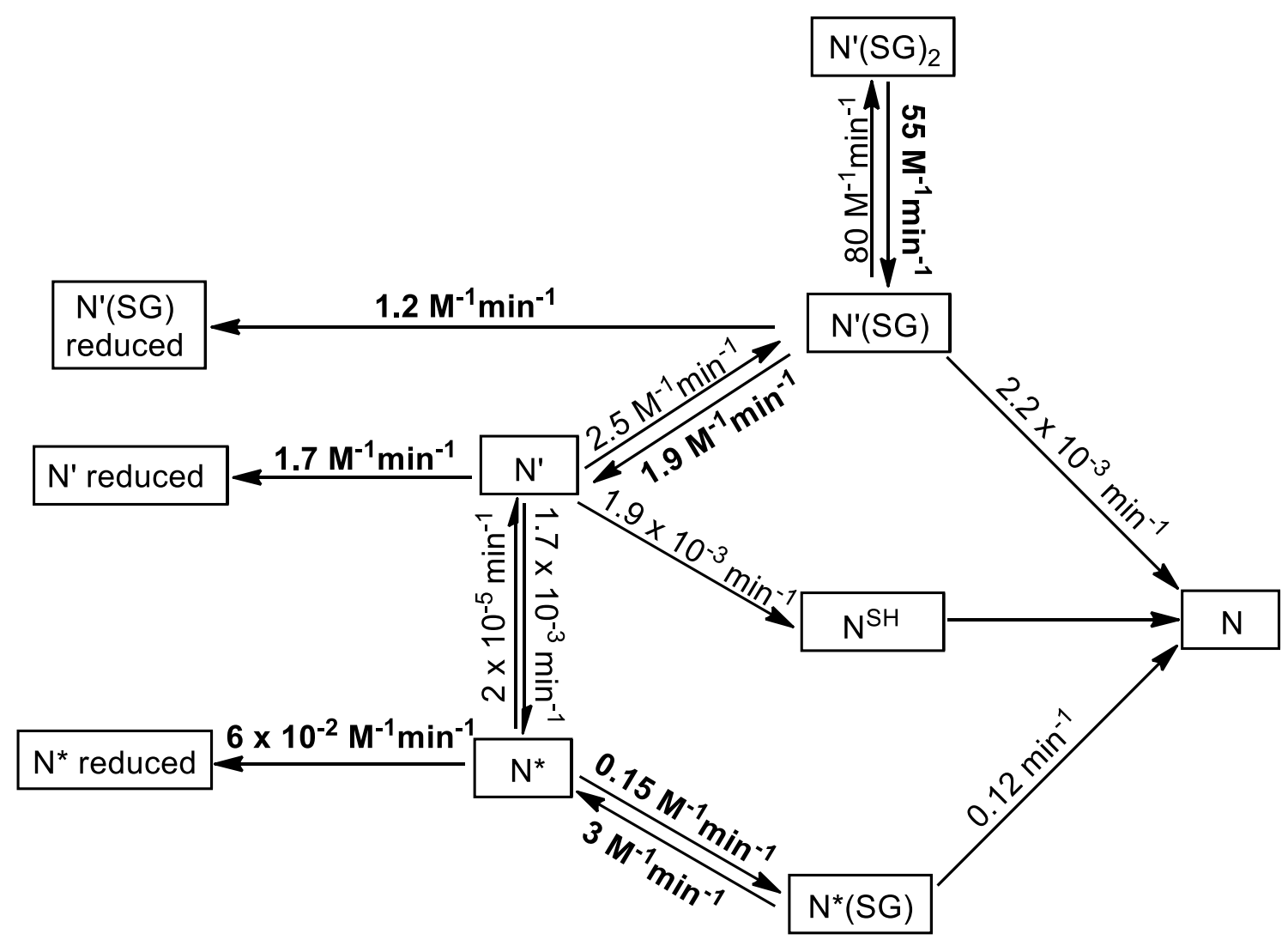

Fig. 4.17 Both oxidation and reduction rate constants involving all the kinetic traps

\subsubsection{Folding of reduced BPTI by optimizing concentration of GSSG and GSH as a function of time}

After obtaining most rate constants for the oxidation, reduction and rearrangement of kinetic traps, I expected to improve the folding efficiency using these rate constants. Historically, one relatively constant set of conditions have been used to fold BPTI. Recent studies in Dr. Lees' group demonstrated that folding of reduced BPTI with $5 \mathrm{mM}$ GSSG and $5 \mathrm{mM} \mathrm{GSH}$ produced $83 \%$ and $93 \%$ native protein in 1 day and 2 days, respectively, at $\mathrm{pH}$ 7.3. The folding pathway of protein intermediates was proposed to be affected by the composition of redox 
reagents. Changing the GSH and GSSG concentrations during folding reaction was expected to alter the main folding pathway of disulfide intermediates and improve the folding efficiency of BPTI. Under traditional conditions, the intramolecular rearrangement of the kinetic traps was very slow. One way to improve the BPTI folding would be to fold kinetic traps via growth type pathway. In my previous study, folding of $\mathrm{N}^{*}$ with $50 \mathrm{mM}$ GSSG produced exclusively native protein. Therefore, I expected that folding of reduced BPTI via $\mathrm{N}^{*}$ might be feasible. The predominant intermediates accumulated during folding were kinetic traps $\mathrm{N}^{*}$ and $\mathrm{N}^{\prime}$. Folding of $\mathrm{N}^{\prime}$ via a growth type pathway was limited by oxidation of $N^{\prime}$ to $N^{\prime}(S G)$ and intramolecular rearrangement of $N^{\prime}(S G)$ to $N$ and $N^{\prime}$ to $N^{S H}$. Thus, if all the intermediates can be converted to $\mathrm{N}^{*}$, folding of $\mathrm{N}^{*}$ with high concentration of GSSG will be the most efficient productive route. It's impossible to produced exclusively $\mathrm{N}^{*}$ intermediate under a relatively constant set of condition within a short folding time. Therefore, folding with a changing condition was expected to maximize the accumulation of $\mathrm{N}^{*}$ at the beginning followed by oxidative folding to $\mathrm{N}$.

The initially experiment was conducted without modeling to examine the possibility of folding reduced BPTI under a changing conditions. Reduced BPTI was refolded in the presence of $2 \mathrm{mM} \mathrm{GSSG}$ and $5 \mathrm{mM} \mathrm{GSH}$ for $15 \mathrm{~min}$. After 15 min, the concentration of $\mathrm{GSH}$ was increased to $15 \mathrm{mM}$. After $4 \mathrm{~h}$, the concentration of GSSG was increased to $30 \mathrm{mM}$ by addition of concentrated GSSG solution. Folding reaction was monitored by analysis of acid quenched aliquots at specific time points. Reduced BPTI was folded to disulfide 
intermediates after 15 min (Fig. 4.18). Several intermediates with two native disulfide bonds including $\mathrm{N}^{*}, \mathrm{~N}^{\prime}, \mathrm{N}^{\prime}(\mathrm{SG})$ and $\mathrm{N}^{\prime}(\mathrm{SG})_{2}$ were observed. The two major intermediates, $\mathrm{N}^{*}$ and $\mathrm{N}^{\prime}$ accounted for $60 \%$ of total protein. Native protein was also observed after 15 min with a concentration of $10 \%$. After 15 min, the concentration of GSH was increased dramatically. A high concentration of GSH was added to reduce kinetic traps, such as $\mathrm{N}^{\prime}$ and $\mathrm{N}^{\prime}(\mathrm{SG})_{2}$. The resulting disulfide intermediates were expected to be oxidized to the thermodynamically stable intermediate $\mathrm{N}^{*}$. After $4 \mathrm{~h}$, a high concentration of GSSG was added to fold $\mathrm{N}^{*}$ to $\mathrm{N}$ directly. A significant amount of $\mathrm{N}^{*}$ was oxidized and $85 \%$ of native protein was produced in $12 \mathrm{~h}$. At $24 \mathrm{~h}, 95 \%$ of native protein was produced under the changing condition. Folding of reduced BPTI under changing conditions was confirmed to be practical on the basis of this preliminary study.

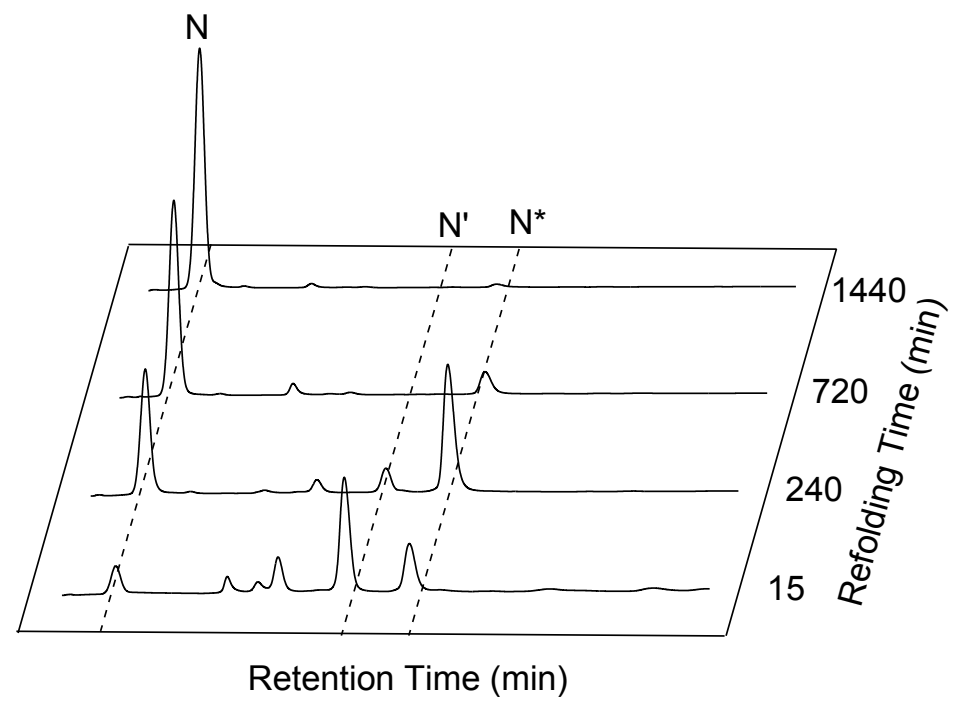

Fig. 4.18 Folding of reduced BPTI with $15 \mathrm{mM} \mathrm{GSH}$ and $30 \mathrm{mM}$ GSSG under changing condition: 0 to $15 \mathrm{~min}, 2 \mathrm{mM} \mathrm{GSSG}$ and $5 \mathrm{mM} \mathrm{GSH} ; 15$ to $240 \mathrm{~min}, 2$ mM GSSG and $15 \mathrm{mM}$ GSH; After $240 \mathrm{~min}, 30 \mathrm{mM}$ GSSG and $15 \mathrm{mM} \mathrm{GSH}$ 
To further improve the folding efficiency of reduced BPTI under changing conditions, all the rate constants determined during my research were used for modeling. As the rate constants were determined for the later stages folding, the experimentally obtained 15 min folding time point was used as a starting point in the model. The folding reaction was modeled to maximize the production of native protein in $12 \mathrm{~h}$ by varying the concentration of GSSG and GSH as a function of time. For practical application, the concentrations of GSSG and GSH were limited to $50 \mathrm{mM}$. Modeling of the data indicated that conversion of folding intermediates to $\mathrm{N}^{*}$ with high concentration of GSH followed by oxidation of $\mathrm{N}^{*}$ to $\mathrm{N}$ with high concentration of GSSG would be best. The folding pathway under changing conditions can be illustrated in the Fig. 4.19. Reduced BPTI is refolded to one-disulfide intermediates (I) rapidly. The reaction of I with GSSG forms twodisulfide intermediates quickly resulting in formation of $\mathrm{N}^{\prime}$ and $\mathrm{N}^{*}$. At a specific time, a high concentration of GSH is added to reduce $\mathrm{N}^{\prime}$ and other intermediates to I. Meanwhile, reaction of I with GSSG facilitates the formation of $\mathrm{N}^{*}$. Finally, oxidative folding of $\mathrm{N}^{*}$ to $\mathrm{N}$ is achieved by addition of concentrated GSSG solution. 


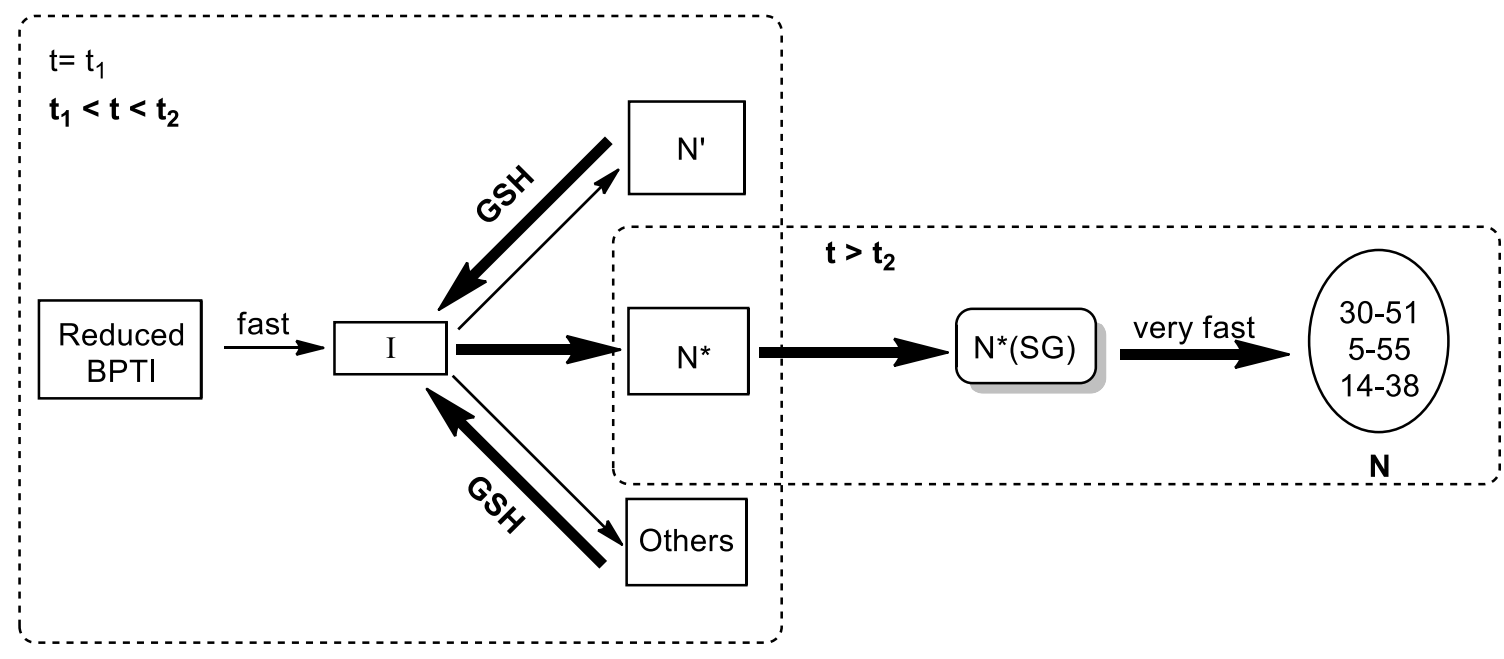

Fig. 4.19 Folding of reduced BPTI with changing condition

On the basis of modeling results, addition of $30 \mathrm{mM} \mathrm{GSH}$ at $15 \mathrm{~min}$ followed by the addition of $50 \mathrm{mM} \mathrm{GSSG}$ at $1 \mathrm{~h}$ would be the most efficient condition. Folding of reduced BPTI with changing condition after modeling was demonstrated in Fig. 4.20. Initially, reduced BPTI was refolded in the presence of $2 \mathrm{mM}$ GSSG and $5 \mathrm{mM} \mathrm{GSH}$. The reason of using $2 \mathrm{mM} \mathrm{GSSG}$ and $5 \mathrm{mM} \mathrm{GSH}$ was to convert all reduced BPTI to disulfide intermediates. At 15 min, all the reduced BPTI was refolded to disulfide intermediates. Two major intermediates, $\mathrm{N}^{*}$ and $\mathrm{N}^{\prime}$ was observed with a concentration of $50 \%$ of the total protein. To increase the amount of $\mathrm{N}^{*}$, after 15 min, the concentrated GSH solution was added to a final concentration of $35 \mathrm{mM}$. Undesired intermediates, such as $\mathrm{N}^{\prime}(\mathrm{SG})_{2}, \mathrm{~N}^{\prime}(\mathrm{SG})$ and $\mathrm{N}^{\prime}$ were reduced. The reaction of resulting intermediates with GSSG favored formation of thermodynamically stable intermediate $\mathrm{N}^{*}$. Because native protein and $\mathrm{N}^{*}$ are more stable than other intermediates, $\mathrm{N}^{*}$ and $\mathrm{N}$ will be reduced very slow and will not be reduced, respectively, under $35 \mathrm{mM}$ GSH. At 60 min, a significant amount of $\mathrm{N}^{*}$ was produced, although reduction of 
$\mathrm{N}^{\prime}$ was slow. After $60 \mathrm{~min}, \mathrm{~N}^{*}$ was refolded to $\mathrm{N}$ by addition of concentrated GSSG solution to the folding mixture. Folding under the above changing condition produced $93 \% \mathrm{~N}$ in $12 \mathrm{~h}$. Oxidative folding of reduced BPTI with $5 \mathrm{mM}$ GSSG and $5 \mathrm{mM} \mathrm{GSH}$, and glutathione diselenide (GSeSeG) was reported to produce $83 \%$ and $95 \%$ native protein, respectively, in 1 day at $\mathrm{pH} 7.3 .^{64,87}$ Apparently, oxidative folding of reduced BPTI with traditional redox reagents, GSSG and GSH, was improved under changing conditions. The traditional kinetic trap $\mathrm{N}^{*}$ became a productive intermediate during folding. The folding efficiency was determined by the formation of $\mathrm{N}^{*}$ at the early time.

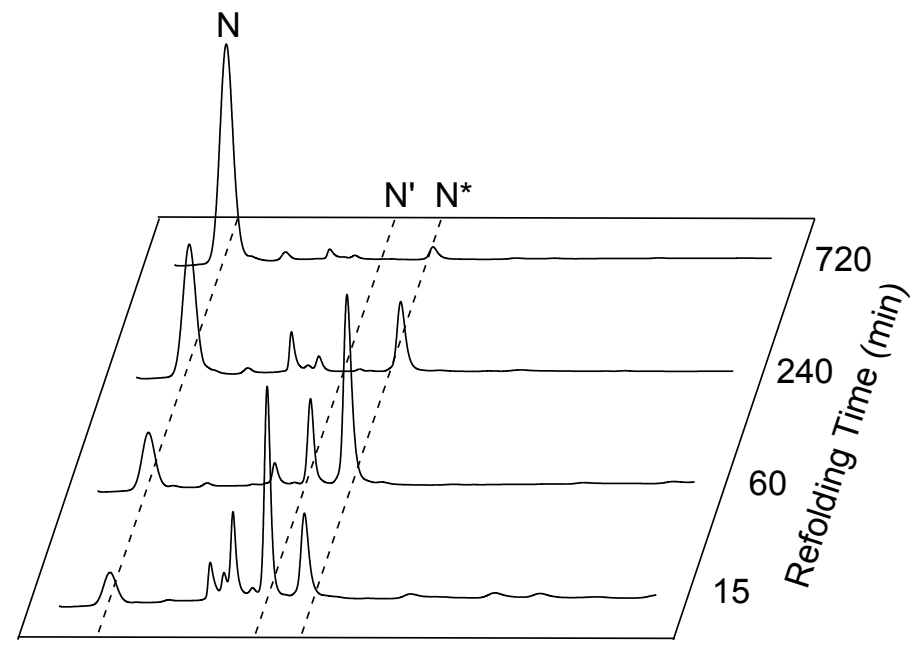

Retention Time (min)

Fig. 4.20 Folding of reduced BPTI with $50 \mathrm{mM}$ GSSG and $35 \mathrm{mM} \mathrm{GSH}$ under changing condition

Folding of BPTI under changing conditions indicated that BPTI could fold efficiently not only via rearrangement type pathways but also via growth type pathways with GSSG and GSH. The in vitro oxidative folding pathway of BPTI 
was updated accordingly (Fig. 4.21). Folding via multiple pathways is significant during protein production.

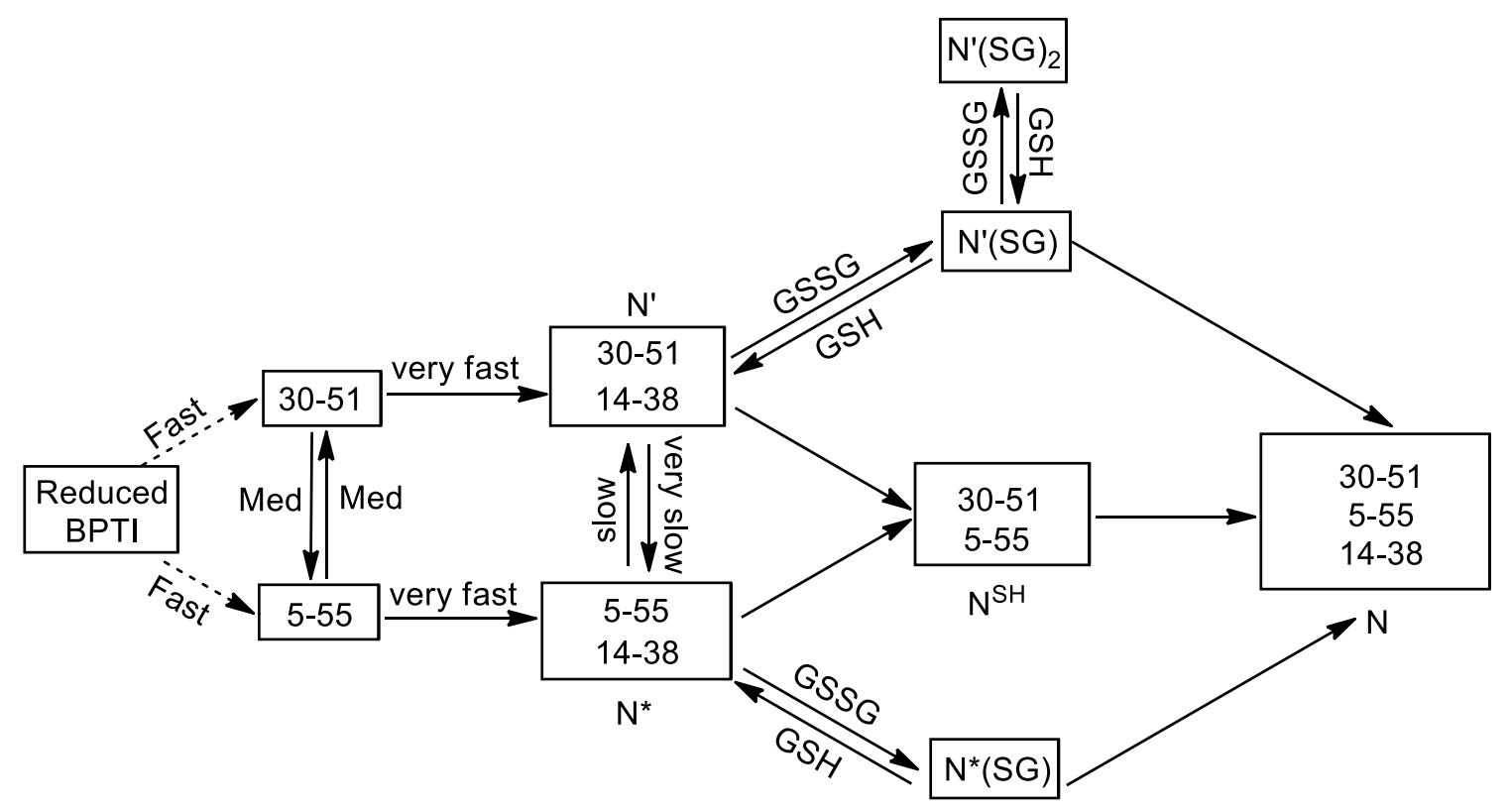

Fig. 4.21 Folding pathway of BPTI

\subsection{Conclusion}

Folding of intermediates $\mathrm{N}^{*}, \mathrm{~N}^{\prime}, \mathrm{N}^{\prime}(\mathrm{SG})_{2}$ and $\mathrm{N}^{\prime}(\mathrm{SG})$ were investigated in the presence of GSSG and GSH and all rate constants in the forward and reverse directions were determined. Intermediate $\mathrm{N}^{*}$, which was reported to be a kinetic trap previously, was refolded to N with GSSG via a growth type pathway. In the presence of $\mathrm{GSH}, \mathrm{N}^{\prime}(\mathrm{SG})_{2}$ was reduced readily instead of being a kinetic trap. Folding of reduced $\mathrm{BPTI}$ under changing conditions indicated that the protein folding pathways and folding efficiency are affected by the concentration of redox reagents. 


\section{Chapter 5}

\section{Oxidative folding of BPTI with small molecule aromatic disulfides and}

\section{thiols}

\subsection{Abstract}

Aromatic disulfides and thiols have been demonstrated to improve the folding efficiency of disulfide containing proteins including ribonuclease A (RNase A) and lysozyme. Herein, $\mathrm{N}^{*}$ and $\mathrm{N}^{\prime}$, two kinetic traps formed during the oxidative during folding of reduced BPTI, were refolded in the presence of aromatic disulfides. Folding of the two kinetic traps with aromatic disulfides indicated that folding rates were linearly dependent upon the concentration of aromatic disulfides. In addition, folding intermediates were observed during the folding of $\mathrm{N}^{*}$ and $\mathrm{N}^{\prime}$ with some aromatic disulfides. The oxidative folding of reduced BPTI with aromatic disulfides and thiols were also investigated. Reduced BPTI was folded to disulfide intermediates rapidily.

\subsection{Introduction}

Folding of protein via a growth type pathway was demonstrated to be practical for GSSG and GSH. Because folding via a growth type pathway involves an exogenous oxidizing agent, such as a small molecule disulfide, changes in the redox reagent can affect the folding efficiency. ${ }^{108}$ Disulfide bonds are formed via thiol-disulfide exchange reaction. The thiol-disulfide exchange rate is affected by the nucleophilicity of the nucleophile and the stability of the leaving group. Thus, folding of BPTI using reactive disulfides is expected to improve the folding efficiency. Previously, aromatic disulfides were synthesized and utilized to 
fold disulfide containing proteins, such as RNase A and lysozyme. ${ }^{105}$ Herein, three aromatic disulfides were used to study the folding of kinetic traps (Fig. 5.1). Generally, the reactivity of aromatic disulfides is inversely correlated with their corresponding thiol $\mathrm{pK}_{\mathrm{a}}$.<smiles>O=P(O)(O)Cc1ccc(SSc2ccc(CP(=O)(O)O)cc2)cc1</smiles>

1

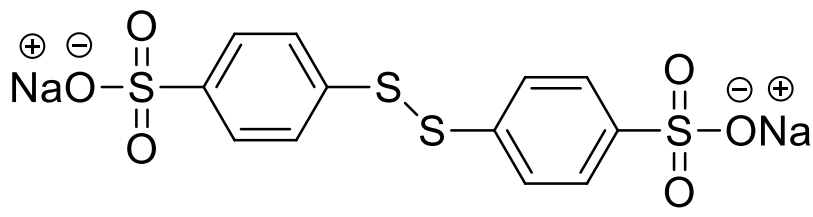

2

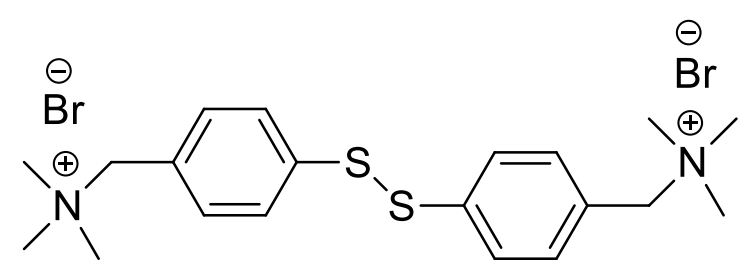

3<smiles>O=P(O)(O)Cc1ccc(S)cc1</smiles>

4<smiles>O=S(=O)(O)c1ccc(S)cc1</smiles>

5

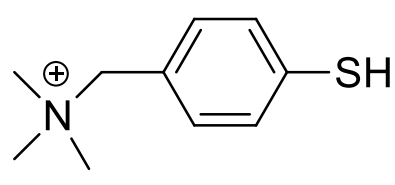

6

Fig. 5.1 Aromatic disulfide 1, 2 and 3, and the corresponding thiols, 4, 5 and 6

\subsection{Experimental section}

\subsubsection{Kinetic study of oxidative folding of kinetic trap $\mathbf{N}^{*}$ with aromatic} disulfides 1,2 and 3

\subsubsection{Folding of $\mathbf{N}^{*}$ with aromatic disulfide 1}

Bis-tris propane buffer was prepared as described in Chapter 3. Aromatic disulfide 1 was dissolved in deoxygenated bis-tris propane buffer. The $\mathrm{pH}$ of resulting solution was adjusted to 7.3 by addition of $1 \mathrm{M} \mathrm{KOH}$. The obtained 
buffer was equilibrated at $25{ }^{\circ} \mathrm{C}$ for $10 \mathrm{~min}$. Pure $\mathrm{N}^{*}$ dissolved in $0.01 \mathrm{~N} \mathrm{HCl}$ was refolded in the presence of aromatic disulfide 1. The folding reaction was conducted under argon at $25{ }^{\circ} \mathrm{C}$. Initially, $\mathrm{N}^{*}$ was refolded with low concentrations of aromatic disulfide $1(\leq 1 \mathrm{mM})$. At specific time points, a $300 \mu \mathrm{L}$ aliquot was removed and quenched by addition of $15 \mu \mathrm{L}$ of formic acid. The resulting acid quenched mixtures were analyzed on a Vydac C18 analytical column. The absorbance was monitored at $229 \mathrm{~nm}$ and the column temperature was maintained at $50{ }^{\circ} \mathrm{C}$. A linear gradient with a flow rate of $1 \mathrm{~mL} / \mathrm{min}$ was used: 0 min, $90 \%$ solvent $A ; 15$ min, $75 \%$ solvent $A ; 35$ min, $73 \%$ solvent $A ; 50$ min, $72 \%$ solvent $A ; 70$ min, $69 \%$ solvent $A$.

If higher concentration of aromatic disulfide 1 was used $(\geq 1 \mathrm{mM})$, then precipitation occurred upon acid quenching. A co-solvent dimethylformamide (DMF) was utilized to keep the aromatic disulfide 1 soluble during quenching. Different amount of DMF was used when folding was carried out under different concentrations of aromatic disulfide 1. Aromatic disulfide 1 was found to appear between native protein and $\mathrm{N}^{*}$ during HPLC analysis. The peak of aromatic disulfide 1 may cause potential overlapping with the folding intermediates. Thus, the acid quenched folding mixture was purified on a pipet column using G-25 as the solid phase and $0.01 \mathrm{HCl}$ as the mobile phase to remove the aromatic disulfide 1 . The fraction containing protein was analyzed in the same way as it was folded at lower concentration of aromatic disulfide 1. 


\subsubsection{Folding of $\mathrm{N}^{*}$ with aromatic disulfide 2}

The reactions of pure $\mathrm{N}^{*}$ with different concentrations of aromatic disulfide

2 were conducted in bis-tris propane buffer at $\mathrm{pH}$ 7.3. Aromatic disulfide 2 was dissolved in deoxygenated bis-tris propane buffer and the $\mathrm{pH}$ of the resulting solution was adjusted to 7.3 by addition of $1 \mathrm{M} \mathrm{KOH}$. The obtained buffer was equilibrated at $25^{\circ} \mathrm{C}$ for 10 min. Pure $\mathrm{N}^{*}$ dissolved in $0.01 \mathrm{~N} \mathrm{HCl}$ was refolded at a concentration of $30 \mu \mathrm{M}$. The folding reaction was conducted under argon at $25{ }^{\circ} \mathrm{C}$. At specific time points, $300 \mu \mathrm{L}$ aliquots of folding mixture were removed and quenched with $15 \mu \mathrm{L}$ of phosphoric acid. The acid quenched folding mixtures were analyzed on a Vydac C18 analytical column. A linear gradient with a flow rate of $1 \mathrm{~mL} / \mathrm{min}$ was used: $0 \mathrm{~min}, 90 \%$ solvent $A ; 15 \mathrm{~min}, 75 \%$ solvent $A ; 35 \mathrm{~min}$, $73 \%$ solvent $A ; 50$ min, $72 \%$ solvent $A ; 70$ min, $69 \%$ solvent $A$. The absorbance was monitored at $229 \mathrm{~nm}$ and the column temperature was maintained at $80{ }^{\circ} \mathrm{C}$. The rate constants were calculated using Euler's method.

During folding of $\mathrm{N}^{*}$ with aromatic disulfides 2, two intermediates were observed. To collect the folding intermediates, $2 \mathrm{~mL}$ of folding mixture containing $30 \mu \mathrm{M} \mathrm{N}{ }^{*}$ was prepared. At a specific time, the folding mixture was quenched with $5 \%$ by volume of phosphoric acid to the folding to maximize the amount of target folding intermediate. The acid quenched folding mixture was injected manually onto a Vydac C18 semi-preparative column. A linear gradient with a flow rate of $3 \mathrm{~mL} / \mathrm{min}$ was used: $0 \mathrm{~min}, 90 \%$ solvent $A ; 15 \mathrm{~min}, 75 \%$ solvent $A ; 35$ min, $73 \%$ solvent $A ; 50$ min, $72 \%$ solvent $A ; 100$ min, $65 \%$ solvent $A$. The absorbance was monitored at $280 \mathrm{~nm}$ and the column temperature was 
maintained at $80^{\circ} \mathrm{C}$. The folding intermediates were collected and analyzed by ESI-TOF.

\subsubsection{Folding of $\mathbf{N}^{*}$ with aromatic disulfide 3}

Pure $\mathrm{N}^{*}$ was refolded with different concentrations of aromatic disulfide 3 in bis-tris buffer at $\mathrm{pH} 7.3$. Folding reaction was carried out under argon at $25^{\circ} \mathrm{C}$. At each specific time point, a $300 \mu \mathrm{L}$ was removed from the folding mixture and quenched with $15 \mu \mathrm{L}$ of formic acid. The acid quenched folding mixtures were analyzed by RP-HPLC on a Vydac C18 analytical column heated to $50{ }^{\circ} \mathrm{C}$. A linear gradient with a flow rate of $1 \mathrm{~mL} / \mathrm{min}$ was used: $0 \mathrm{~min}, 90 \%$ solvent $A ; 15$ min, $75 \%$ solvent $A ; 35$ min, $73 \%$ solvent $A ; 50$ min, $72 \%$ solvent $A ; 70$ min, $69 \%$ solvent A. The absorbance was monitored at $229 \mathrm{~nm}$ and the column temperature was maintained at $50{ }^{\circ} \mathrm{C}$. The rate constants were calculated using Euler's method. During folding of $\mathrm{N}^{*}$ at low concentration of aromatic disulfides $\mathbf{3}$, one intermediate was observed. To collect the folding intermediate, $2 \mathrm{~mL}$ of a folding mixture containing $30 \mu \mathrm{M}$ of $\mathrm{N}^{*}$ was prepared. At $1 \mathrm{~min}$, the folding mixture was quenched with $5 \%$ by volume of formic acid to the folding to maximize the amount of target intermediate. The acid quenched folding mixture was injected manually onto a Vydac C18 semi-preparative column. A linear gradient with a flow rate of $3 \mathrm{~mL} / \mathrm{min}$ was used: $0 \mathrm{~min}, 90 \%$ solvent $\mathrm{A} ; 15 \mathrm{~min}, 75 \%$ solvent $A ; 35$ min, $73 \%$ solvent $A ; 50$ min, $72 \%$ solvent $A ; 100$ min, $65 \%$ solvent A. The absorbance was monitored at $280 \mathrm{~nm}$ and the column temperature was maintained at $50{ }^{\circ} \mathrm{C}$. The folding intermediates were collected and analyzed by ESI-TOF. 


\subsubsection{Kinetic study of oxidative folding of kinetic trap N' with aromatic disulfides 1,2 and 3}

\subsubsection{Folding of $\mathbf{N}^{\prime}$ with aromatic disulfide 1}

Pure N' was refolded with lower concentrations of aromatic disulfide 1 than $\mathrm{N}^{*}$ because $\mathrm{N}^{\prime}$ was more reactive than $\mathrm{N}^{*}$. Aromatic disulfide 1 was dissolved in deoxygenated bis-tris propane buffer. The $\mathrm{pH}$ of the resulting solution was adjusted to 7.3 by addition of $1 \mathrm{M} \mathrm{KOH}$. The obtained buffer was equilibrated at $25^{\circ} \mathrm{C}$ for $10 \mathrm{~min}$. The folding reaction was conducted under argon at $25^{\circ} \mathrm{C}$. At specific time points, a $300 \mu \mathrm{L}$ aliquot was removed from the folding mixture and quenched by addition of $15 \mu \mathrm{L}$ formic acid. The resulting acid quenched mixtures were analyzed on a Vydac C18 analytical column. The absorbance was monitored at $229 \mathrm{~nm}$ and the column temperature was maintained at $50{ }^{\circ} \mathrm{C}$. A linear gradient with a flow rate of $1 \mathrm{~mL} / \mathrm{min}$ was used: $0 \mathrm{~min}, 90 \%$ solvent $\mathrm{A} ; 15$ min, $75 \%$ solvent $A ; 35$ min, $73 \%$ solvent $A ; 50$ min, $72 \%$ solvent $A ; 70$ min, $69 \%$ solvent A. The rate constants were calculated using Euler's method.

\subsubsection{Folding of $\mathrm{N}^{\prime}$ with aromatic disulfide 2}

The reaction of pure $\mathrm{N}^{\prime}$ with aromatic disulfide $\mathbf{2}$ was conducted in bis-tris propane buffer at $\mathrm{pH}$ 7.3. Pure $\mathrm{N}^{\prime}$ dissolved in $0.01 \mathrm{~N} \mathrm{HCl}$ was refolded at a concentration of $30 \mu \mathrm{M}$. The folding reaction was conducted under argon at $25{ }^{\circ} \mathrm{C}$. At specific time points, $300 \mu \mathrm{L}$ aliquots of the folding mixture were removed and quenched with $15 \mu \mathrm{L}$ of phosphoric acid. The acid quenched folding mixtures were analyzed on a Vydac C18 analytical column. A linear gradient with a flow rate of $1 \mathrm{~mL} / \mathrm{min}$ was used: $0 \mathrm{~min}, 90 \%$ solvent $\mathrm{A} ; 15 \mathrm{~min}, 75 \%$ 
solvent $A ; 35$ min, $73 \%$ solvent $A ; 50$ min, $72 \%$ solvent $A ; 70$ min, $69 \%$ solvent $A$. The absorbance was monitored at $229 \mathrm{~nm}$ and the column temperature was maintained at $50{ }^{\circ} \mathrm{C}$. The rate constants were calculated using Euler's method.

\subsubsection{Folding of $\mathbf{N}^{\prime}$ with aromatic disulfide 3}

Pure $\mathrm{N}^{\prime}$ dissolved in $0.01 \mathrm{~N} \mathrm{HCl}$ was refolded in the presence of bis-tris propane buffer containing aromatic disulfide 3 at $\mathrm{pH}$ 7.3. The folding reaction was conducted under argon at $25{ }^{\circ} \mathrm{C}$. At specific time points, $300 \mu \mathrm{L}$ aliquots of the folding mixture were removed and quenched by addition of $15 \mu \mathrm{L}$ of formic acid. The acid quenched folding mixtures were analyzed on a Vydac C18 analytical column. A linear gradient with a flow rate of $1 \mathrm{~mL} / \mathrm{min}$ was used: $0 \mathrm{~min}, 90 \%$ solvent $A ; 15$ min, $75 \%$ solvent $A ; 35$ min, $73 \%$ solvent $A ; 50$ min, $72 \%$ solvent $A$; $70 \mathrm{~min}, 69 \%$ solvent $\mathrm{A}$. The absorbance was monitored at $229 \mathrm{~nm}$ and the column temperature was maintained at $50{ }^{\circ} \mathrm{C}$. The rate constants were calculated using Euler's method.

\subsubsection{Oxidative folding of reduced BPTI with aromatic disulfides 1, 2 and 3}

Pure reduced $\mathrm{BPTI}$ dissolved in $0.01 \mathrm{~N} \mathrm{HCl}$ was refolded in the presence

of bis-tris propane buffer containing aromatic disulfides $\mathbf{1}, \mathbf{2}$, and $\mathbf{3}$ at $\mathrm{pH} 7.3$. All reactions were carried out under argon at $25^{\circ} \mathrm{C}$. At specific time points, a $300 \mu \mathrm{L}$ aliquot was removed from the folding mixture and quenched by addition of $15 \mu \mathrm{L}$ of formic acid. The acid quenched samples were stored in a refrigerator prior to RP-HPLC analysis. The analysis of folding mixtures was performed on a RPHPLC using a Vydac C18 analytical column. The column temperature was maintained at $50{ }^{\circ} \mathrm{C}$ and the injection volume was $100 \mu \mathrm{L}$. The absorbance was 
monitored at $229 \mathrm{~nm}$. A flow rate of $1 \mathrm{~mL} / \mathrm{min}$ and a linear gradient was used: 0 min, $90 \%$ solvent $A ; 15$ min, $75 \%$ solvent $A ; 35$ min, $73 \%$ solvent $A ; 50$ min, $72 \%$ solvent $A ; 110$ min, $70 \%$ solvent $A$.

\subsection{Results and discussion}

\subsubsection{Kinetic study of oxidative folding of kinetic trap $\mathrm{N}^{*}$ with aromatic} disulfides 1,2 , and 3

\subsubsection{Folding of $\mathrm{N}^{*}$ with aromatic disulfide 1}

The reaction of $\mathrm{N}^{*}$ with low concentration of aromatic disulfide 1 produced exclusively native protein (Fig. 5.2). No intermediate was observed during the folding reaction. When folding was conducted at higher concentrations of aromatic disulfide 1, precipitation was observed during acid quenching. To improve the solubility of aromatic disulfide 1 at lower $\mathrm{pH}$ during quenching, DMF was pre-mixed with formic acid as a co-solvent. During the RP-HPLC analysis, the aromatic disulfide 1 was observed to elute between native protein and $\mathrm{N}^{*}$. Acid quenched folding mixture was purified on a G-25 pipette column to remove the aromatic disulfide 1, as the retention time of the aromatic disulfide may overlap with that of the protein folding intermediates. Surprisingly, only native protein was observed when $\mathrm{N}^{*}$ was refolded with $20 \mathrm{mM}$ aromatic disulfide 1 (Fig. $5.3)$. 


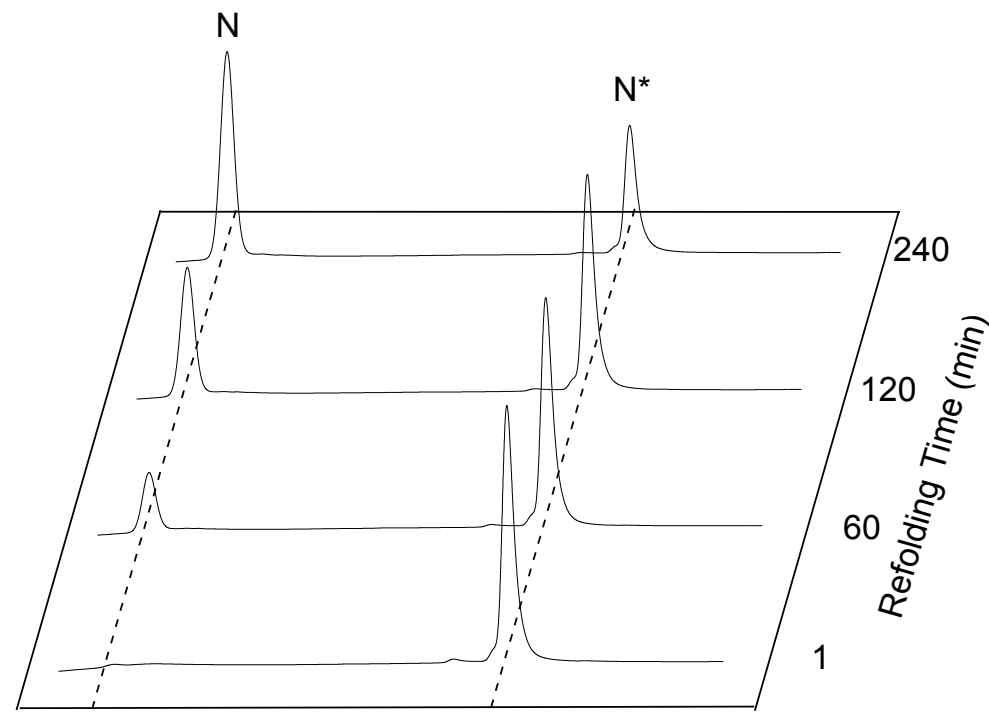

Retention Time ( $\mathrm{min})$

Fig. 5.2 Folding of $\mathrm{N}^{*}$ with $0.25 \mathrm{mM}$ aromatic disulfide 1

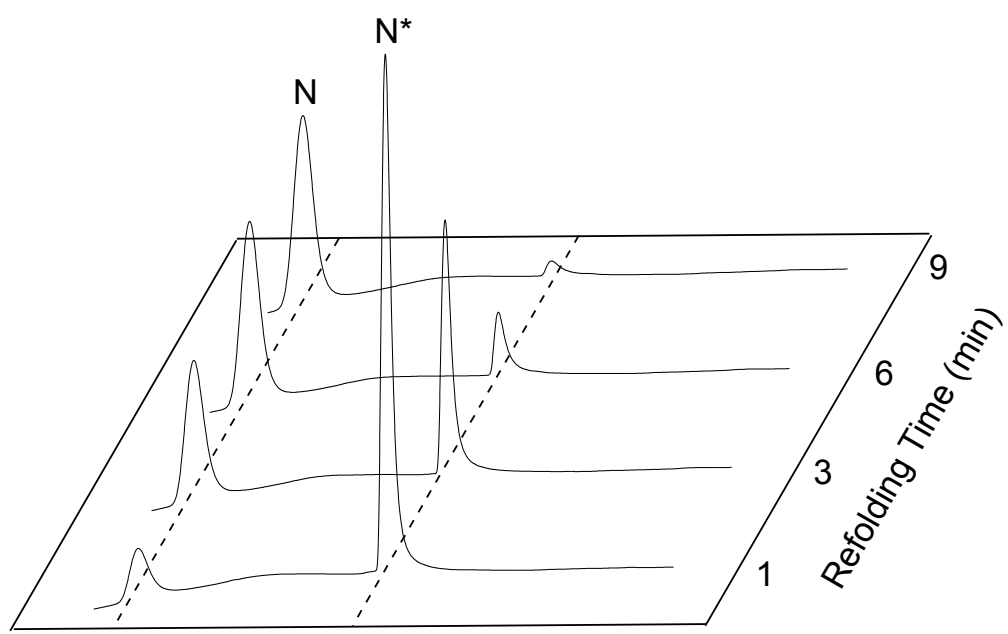

Retention Time (min)

Fig. 5.3 Folding of $\mathrm{N}^{*}$ with $20 \mathrm{mM}$ aromatic disulfide 1

The folding rate of $\mathrm{N}^{*}$ to $\mathrm{N}$ was calculated to be $17 \mathrm{M}^{-1} \mathrm{~min}^{-1}$. The folding rate of $\mathrm{N}^{*}$ was linearly dependent on the concentration of aromatic disulfide 1 indicating that $\mathrm{N}^{*}$ folded to $\mathrm{N}$ via a growth type pathway instead of a rearrangement type pathway. Folding of $\mathrm{N}^{*}$ via a rearrangement type pathway 
would be inefficient because of its kinetic stability. The conversion of $\mathrm{N}^{*}$ to $\mathrm{N}$ without forming intermediates indicated that the formation of mixed disulfide between $\mathrm{N}^{*}$ and aromatic disulfide 1 was much slower than the rearrangement of mixed disulfide to native protein. The intramolecular rearrangement of singly mixed disulfide was much faster than reaction of the remaining cysteine thiol in $\mathrm{N}^{*}(\mathrm{SAr})$ with ArSSAr. The thiols in $\mathrm{N}^{*}$ remained hindered under its oxidative folding with aromatic disulfide 1. The native-like structure inhibited the oxidation of the two cysteine thiols in $\mathrm{N}^{*}$. Folding of $\mathrm{N}^{*}$ was improved by using aromatic disulfide 1 compared with GSSG. The folding rate was slow at low concentration of aromatic disulfide 1 while folding at high concentration caused precipitation during quenching unless DMF was added.

\subsubsection{Folding of $\mathrm{N}^{*}$ with aromatic disulfide 2}

Oxidative folding of $\mathrm{N}^{*}$ with aromatic disulfide 2 produced predominantly $\mathrm{N}$ (Fig. 5.4). Besides native protein, two intermediates were detected during folding (Fig. 5.5). The intermediate close to $\mathrm{N}^{*}$ in terms of retention time quickly reached steady state. The concentration of the intermediate decreased as the reaction progressed, and was absent at the end of the reaction. On the basis of the kinetic property of the intermediate, the intermediate observed at early folding times was assumed to be a singly mixed disulfide. The other intermediate was only observed at the later stages of folding and its concentration increased with folding time. The intermediate remained as a kinetic trap and was proposed to be

doubly mixed disulfide. The reaction of $\mathrm{N}^{*}$ with aromatic disulfide $\mathbf{2}$ indicated that $\mathrm{N}^{*}$ fold to $\mathrm{N}$ via a growth type pathway because the reaction rate of $\mathrm{N}^{*}$ was 
linearly dependent upon the concentration of aromatic disulfide. In order to further confirm the folding pathway of the $\mathrm{N}^{*}$ in the presence of aromatic disulfide 2, the two intermediates were isolated and characterized by mass spectroscopy. Previously, Ms. Shweta M. Mandumula obtained the mass spectrum for the doubly mixed disulfide, $\mathrm{N}^{*}(\mathrm{SAr})_{2} \cdot{ }^{106}$

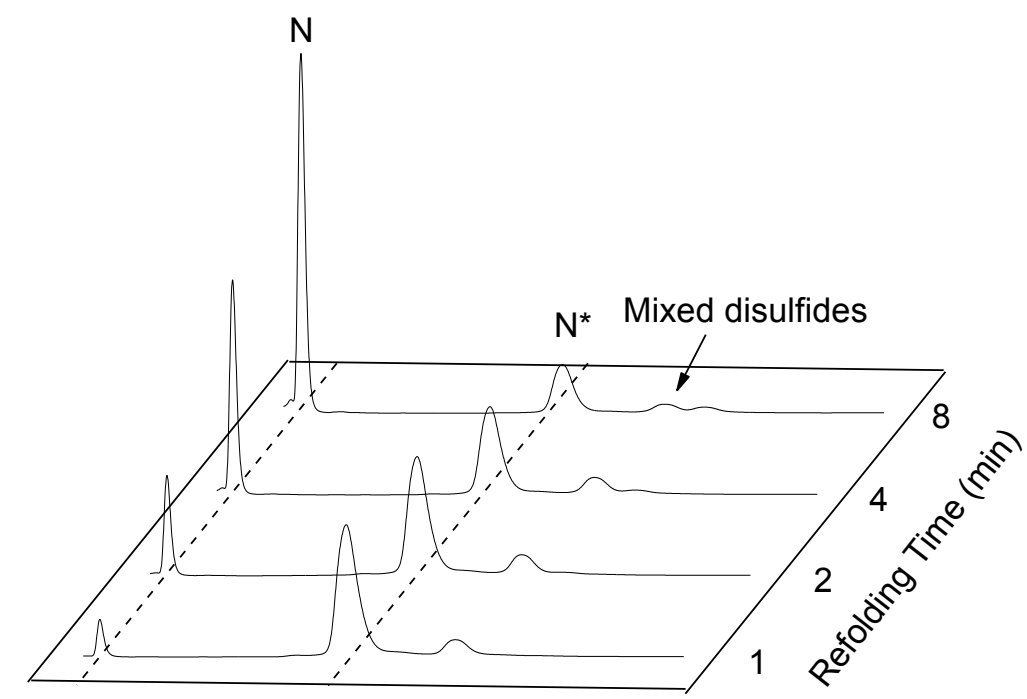

Retention Time (min)

Fig. 5.4 Folding of $\mathrm{N}^{*}$ with $0.25 \mathrm{mM}$ aromatic disulfide 2

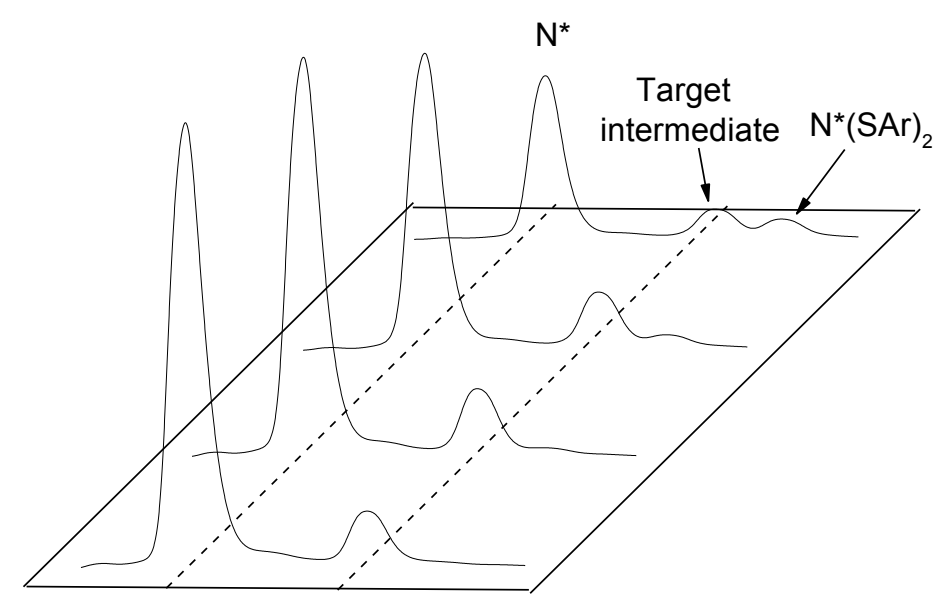

Fig. 5.5 Two intermediates observed during reaction of $\mathrm{N}^{*}$ with $0.25 \mathrm{mM}$ aromatic disulfide 2 
Herein, I separated and examined the singly mixed disulfide intermediate. Reaction of $\mathrm{N}^{*}$ with $0.25 \mathrm{mM}$ aromatic disulfide 2 was quenched after 1 min to obtain the maximum amount of singly mixed disulfide and to minimize the amount of doubly mixed disulfide. The intermediate was purified and subsequently analyzed by mass spectroscopy (Fig. 5.6).

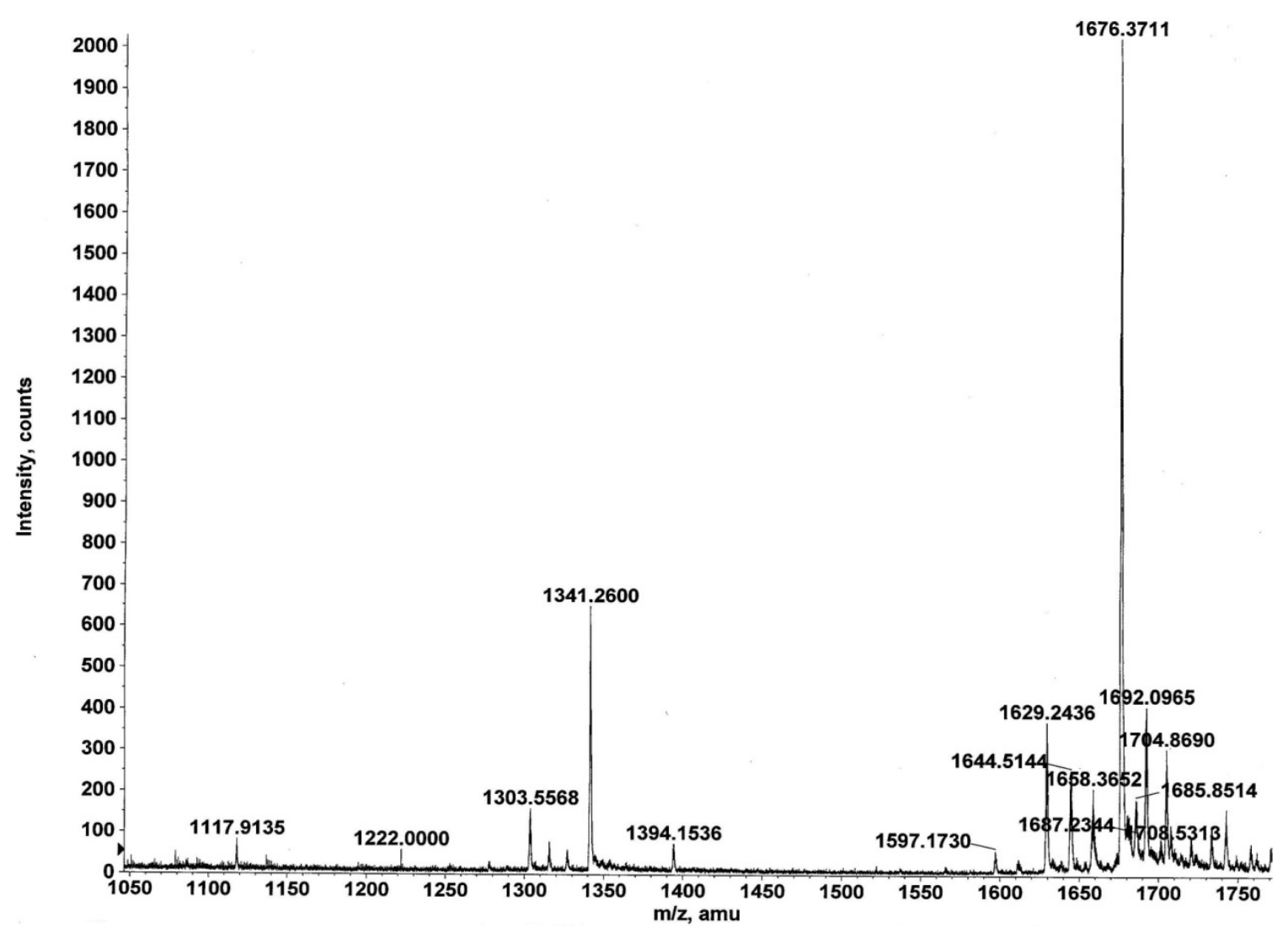

Fig. 5.6 Mass spectrum of $\mathrm{N}^{*}(\mathrm{SAr})$ formed during the reaction of $\mathrm{N}^{*}$ with aromatic disulfide 2

The experimental and theoretical mass results of the target intermediate are summarized in Table 2. The experimental values matched with the theoretical ones confirming that the target intermediate was the singly mixed disulfide. Formation of singly mixed disulfide indicated that the thiol in $\mathrm{N}^{*}$ could 
be oxidized. The singly mixed disulfide was oxidized to doubly mixed disulfide by reaction of the other thiol in $\mathrm{N}^{*}(\mathrm{SAr})$ with the aromatic disulfide. The doubly mixed disulfide intermediate, $\mathrm{N}^{*}(\mathrm{SAr})_{2}$, remained as a kinetic trap in the absence of a reducing reagent because it lacks a free thiol. The conversion of $\mathrm{N}^{*}(\mathrm{SAr})$ to $\mathrm{N}^{*}(\mathrm{SAr})_{2}$ was slow because only a small amount of $\mathrm{N}^{*}(\mathrm{SAr})_{2}$ was observed. Singly mixed disulfide $\mathrm{N}^{*}(\mathrm{SAr})$ still remained as a hindered system preventing the reaction of the remaining cysteine thiol with aromatic disulfide $\mathbf{2}$. The folding rate of $\mathrm{N}^{*}$ was improved using aromatic disulfide 2 but the formation of the doubly mixed disulfide $\mathrm{N}^{*}(\mathrm{SAr})_{2}$ was a drawback.

Table 2. Mass results of singly mixed disulfide $\mathrm{N}^{*}(\mathrm{SAr})$ formed with aromatic disulfide 2

\begin{tabular}{cccc}
\hline Charges on & Theoretical $\mathrm{m} / \mathbf{z}$ & Experimental $\mathbf{m} / \mathbf{z}$ & $\begin{array}{c}\text { Mass error } \\
(\mathrm{ppm})\end{array}$ \\
\hline $\mathrm{N}^{*}(\mathrm{SAr})+4 \mathrm{H}^{+}$ & 1676.3800 & 1676.3711 & 5 \\
$\mathrm{~N}^{*}(\mathrm{SAr})+5 \mathrm{H}^{+}$ & 1341.3040 & 1341.2600 & 33 \\
$\mathrm{~N}^{*}(\mathrm{SAr})+6 \mathrm{H}^{+}$ & 1117.9200 & 1117.9135 & 6 \\
\hline
\end{tabular}

\subsubsection{Folding of $\mathrm{N}^{*}$ with aromatic disulfide 3}

Oxidative folding of $\mathrm{N}^{*}$ was performed in the presence of different concentrations of aromatic disulfide 3. Additional peaks were observed in the HPLC chromatogram. The formation of additional peaks was attributed to the presence of different counter ions for the quaternary ammonium ion. Examination of acid quenched folding mixture after $1 \mathrm{~h}$ could minimize the additional peaks because formate became the major counter ion. The reaction of $\mathrm{N}^{*}$ with 0.125 
$\mathrm{mM}$ aromatic disulfide 3 produced exclusively native protein (Fig. 5.7). However, there was a transitory intermediate that had a retention time between native protein and $\mathrm{N}^{*}$. The intermediate was likely to be singly mixed disulfide $\mathrm{N}^{*}(\mathrm{SAr})$ on the basis of its kinetic feature.

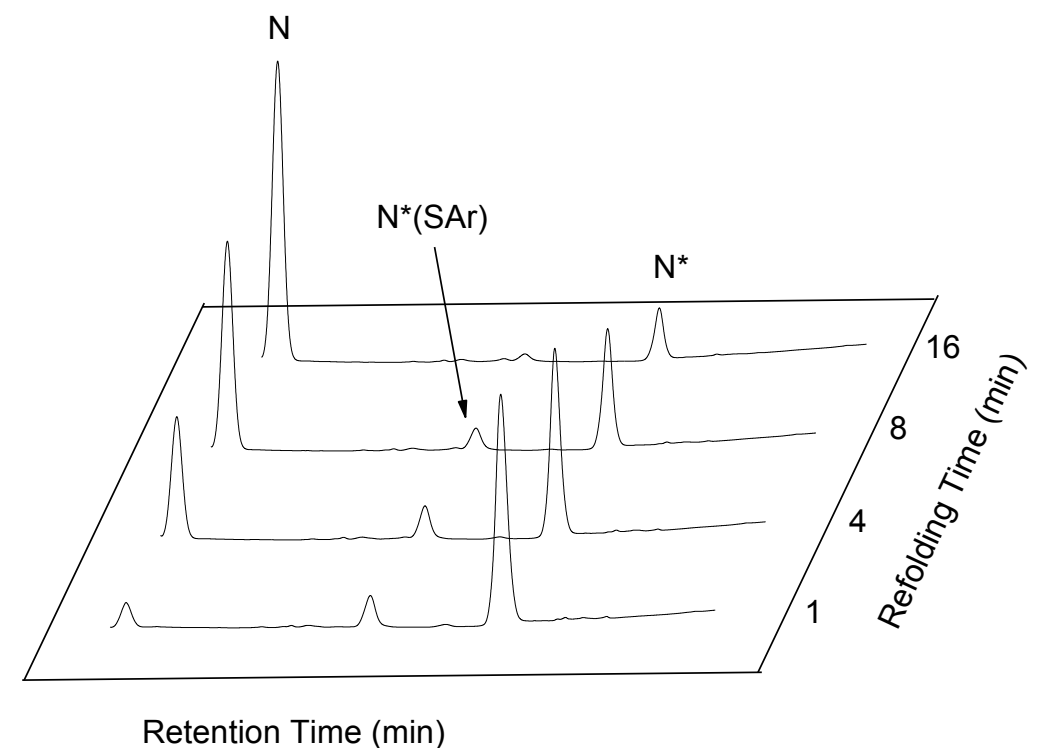

Fig. 5.7 Oxidative folding of $\mathrm{N}^{*}$ with $0.125 \mathrm{mM}$ aromatic disulfide 3

To examine the intermediate, reaction of $\mathrm{N}^{*}$ with $0.25 \mathrm{mM}$ aromatic disulfide 3 was quenched after 1 min to maximize the amount of target intermediate. The intermediate was separated and analyzed by mass spectroscopy (Table 3 and Fig. 5.8).

Table 3 . Mass results of singly mixed disulfide $\mathrm{N}^{*}(\mathrm{SAr})$ formed with 3

\begin{tabular}{cccc}
\hline Charges on $\mathrm{N}^{*}(\mathrm{SAr})$ & Theoretical $\mathrm{m} / \mathbf{z}$ & Experimental $\mathbf{~ m / z}$ & $\begin{array}{c}\text { Mass error } \\
(\mathrm{ppm})\end{array}$ \\
\hline $\mathrm{N}^{*}(\mathrm{SAr})+4 \mathrm{H}^{+}$ & 1339.5614 & 1339.5478 & 10 \\
$\mathrm{~N}^{*}(\mathrm{SAr})+5 \mathrm{H}^{+}$ & 1116.4678 & 1116.4026 & 58 \\
$\mathrm{~N}^{*}(\mathrm{SAr})+6 \mathrm{H}^{+}$ & 957.1153 & 957.0706 & 47 \\
\hline
\end{tabular}




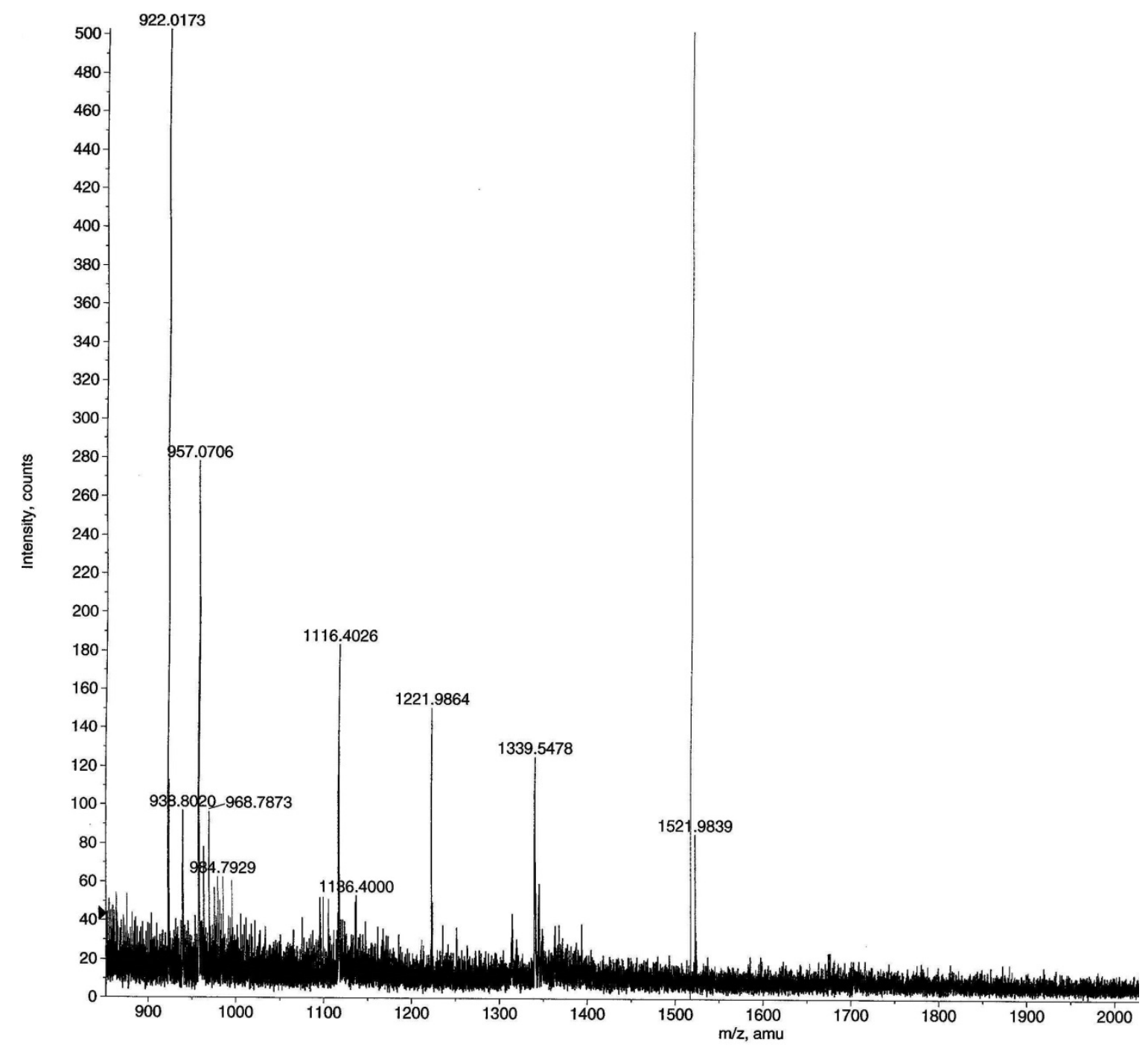

Fig. 5.8 Mass spectrum of singly mixed disulfide formed during the reaction of $\mathrm{N}^{*}$ with aromatic disulfide 3 .

Folding of $\mathrm{N}^{*}$ with three aromatic disulfides, 1, 2, and 3 indicated that $\mathrm{N}^{*}$ was converted to $\mathrm{N}$ via a growth type pathway (Fig. 5.9). The rate of formation of the singly mixed disulfide $\mathrm{N}^{*}(\mathrm{SAr})$ is determined by the reaction of cysteine thiol in $\mathrm{N}^{*}$ with $\operatorname{ArSSAr},\left(k_{1}{ }^{*}\left[\mathrm{~N}^{*}\right]^{*}[\operatorname{ArSSAr}]\right)$. Intermediate $\mathrm{N}^{*}(\mathrm{SAr})$ can be oxidized further to doubly mixed disulfide $\mathrm{N}^{*}(\mathrm{SAr})_{2}$ at a rate of $k_{2}{ }^{*}\left[\mathrm{~N}^{*}(\mathrm{SAr})\right]^{*}[\mathrm{ArSSAr}]$ and can rearrange to native protein at a rate of $k_{3}{ }^{*}\left[\mathrm{~N}^{*}(\mathrm{SAr})\right]$. The partitioning of the 
two folding pathways, $\mathrm{N}$ and $\mathrm{N}^{*}(\mathrm{SAr})_{2}$ is depend on the ration of $k_{3}$ to $k_{2}{ }^{*}$ [ArSSAr]. The rate constants, $k_{1}$ and $k_{2}$ are second order because both reactions involves aromatic disulfide. Rate constant $k_{3}$ is first order because $\mathrm{N}^{*}(\mathrm{SAr})$ folds to $\mathrm{N}$ via an intramolecular rearrangement type pathway.

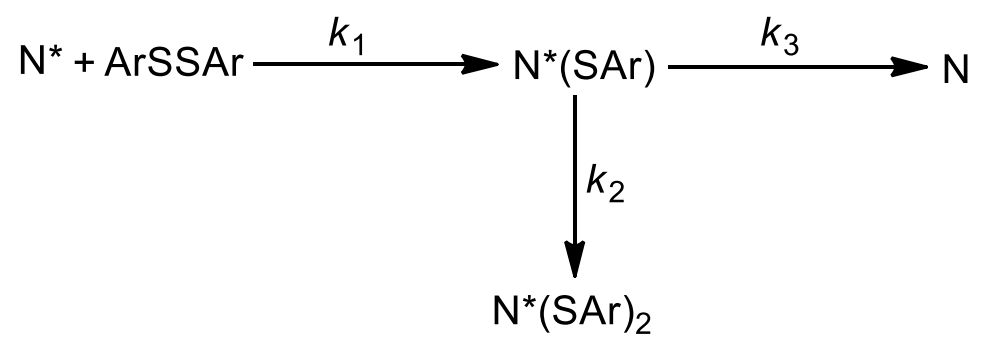

Fig. 5.9 Folding of $\mathrm{N}^{*}$ with aromatic disulfide via a growth type pathway, $\operatorname{ArSSAr}$ refers to aromatic disulfide 1, 2 and 3

Oxidative folding of $\mathrm{N}^{*}$ with the three aromatic disulfides were compared with GSSG and the rate constants are summarized in Table X. Folding of $\mathrm{N}^{*}$ with aromatic disulfide 1 produced exclusively native protein. The rate constant $k_{1}$ (17 $\mathrm{M}^{-1} \mathrm{~min}^{-1}$ ) was determined on the basis of $\mathrm{N}^{*}$ disappearance using a pseudo first order assumption. Because no intermediate was detected during folding of $\mathrm{N}^{*}$ with aromatic disulfide 1 , the $k_{2}$ and $k_{3}$ were not determined. The rate constants with aromatic disulfide $\mathbf{2}$ and $\mathbf{3}$ were determined by fitting the kinetic scheme illustrated in Fig. 5.9 using Euler's method with a time step of $0.1 \mathrm{~s}$. Folding of $\mathrm{N}^{*}$ with low concentration of aromatic disulfide $\mathbf{3}$ only produced singly mixed disulfide and native protein. The rate constant $k_{2}$ was determined by folding of $\mathrm{N}^{*}$ with $5 \mathrm{mM}$ of aromatic disulfide 3 , which produced $\mathrm{N}^{*}(\mathrm{SAr})_{2}$ predominantly. The folding rate of $\mathrm{N}^{*}$ with aromatic disulfides 1, 2 and $\mathbf{3}$ was improved dramatically compared with GSSG because the corresponding thiols of the aromatic disulfides 
have lower $\mathrm{pK}_{\mathrm{a}}$ values. The lower $\mathrm{pK}_{\mathrm{a}}$ makes the thiolate a better leaving group during rearrangement of mixed disulfide.

Table 4. Kinetics of oxidative folding of $\mathrm{N}^{*}$ with disulfides at $\mathrm{pH} 7.3$

\begin{tabular}{ccccc}
\hline Disulfides & $\begin{array}{c}\mathrm{pK}_{\mathrm{a}} \text { of } \\
\text { corresponding thiol }\end{array}$ & $k_{1}\left(\mathrm{M}^{-1} \mathrm{~min}^{-1}\right)$ & $k_{2}\left(\mathrm{M}^{-1} \mathrm{~min}^{-1}\right)$ & $k_{3}\left(\mathrm{~min}^{-1}\right)$ \\
\hline GSSG & 8.7 & 0.13 & $\mathrm{~N} / \mathrm{A}$ & 0.11 \\
$\mathbf{1}$ & 6.6 & 17 & $\mathrm{~N} / \mathrm{A}$ & $\mathrm{N} / \mathrm{A}$ \\
$\mathbf{2}$ & 5.7 & 740 & 160 & 1.2 \\
$\mathbf{3}$ & 5.5 & 1200 & 35 & 1.0 \\
\hline
\end{tabular}

The folding rate of $\mathrm{N}^{*}$ with aromatic disulfide 1 was 100 times faster than that with GSSG. No disulfide intermediate was observed even though $\mathrm{N}^{*}$ was folded at $20 \mathrm{mM}$ aromatic disulfide 1 . The folding results indicated that intramolecular rearrangement of $\mathrm{N}^{*}(\mathrm{SAr})$ to $\mathrm{N}$ was much faster than the conversion of $\mathrm{N}^{*}$ to $\mathrm{N}^{*}(\mathrm{SAr})$ and $\mathrm{N}^{*}(\mathrm{SAr})$ to $\mathrm{N}^{*}(\mathrm{SAr})_{2}$ during folding of $\mathrm{N}^{*}$ with aromatic disulfide 1. Examination of protein folding at high concentration of aromatic disulfide $\mathbf{1}$ is more difficult because of precipitation during acid quenching. The solubility of aromatic disulfide 1 is poor at low $\mathrm{pH}$.

Two intermediates, $\mathrm{N}^{*}(\mathrm{SAr})$ and $\mathrm{N}^{*}(\mathrm{SAr})_{2}$ were observed when $\mathrm{N}^{*}$ was refolded with aromatic disulfide 2 . The rate constants $k_{1}$ was almost 5 times larger than $k_{2}$, which indicated that oxidation of the first thiol in $\mathrm{N}^{*}$ was easier than the oxidation of the thiol in $\mathrm{N}^{*}(\mathrm{SAr})$. The formation of the mixed disulfide does not expose the remaining cysteine thiol in $\mathrm{N}^{*}$ to exogenous disulfides. The 
rearrangement rate of $N^{*}(S A r)$ to $N$ equals the oxidation rate of $N^{*}(S A r)$ to $\mathrm{N}^{*}(\mathrm{SAr})_{2}$ at $7.5 \mathrm{mM}$ aromatic disulfide 2. Thus, folding of $\mathrm{N}^{*}$ with low concentration of aromatic disulfide $\mathbf{2}$ favors the formation of native protein.

Singly mixed disulfide was detected when $\mathrm{N}^{*}$ was refolded with low aromatic disulfide $\mathbf{3}$. In contrast to aromatic disulfide $\mathbf{2}$, no doubly mixed disulfide was observed at low concentrations of 3 . The rearrangement rate of $\mathrm{N}^{*}(\mathrm{SAr})$ to $\mathrm{N}$ becomes equal to the oxidation rate of $\mathrm{N}^{*}(\mathrm{SAr})$ to $\mathrm{N}^{*}(\mathrm{SAr})_{2}$ at $28 \mathrm{mM}$ aromatic disulfide 3 . Singly mixed disulfide $\mathrm{N}^{*}(\mathrm{SAr})$ preferred rearrangement to $\mathrm{N}$ rather than being oxidized to $\mathrm{N}^{*}(\mathrm{SAr})_{2}$ with low concentration of 3 . Folding of $\mathrm{N}^{*}$ at low concentration aromatic disulfide 3 produced predominantly $\mathrm{N}$.

\subsubsection{Kinetic study of oxidative folding of kinetic trap $N^{\prime}$ with aromatic disulfides 1,2 and 3}

\subsubsection{Folding of $\mathrm{N}^{\prime}$ with aromatic disulfide 1}

Pure N' was refolded with $0.125,0.25$ and $1 \mathrm{mM}$ aromatic disulfide 1 . The folding rate was dependent upon the concentration of 1 , which indicated that $\mathrm{N}^{\prime}$ folded via a growth type pathway. Reaction of $\mathrm{N}^{\prime}$ with 0.125 and $0.25 \mathrm{mM}$ aromatic disulfide 1 produced mainly native protein. A minor peak was observed when $\mathrm{N}^{\prime}$ was folded at $1 \mathrm{mM}$ aromatic disulfide 1 . The peak overlapped with the aromatic disulfide peak, which made its isolation difficult. The folding mixture is expected to be purified by gel filtration to remove the disulfide 1 . If the peak remains after filtration, a further analysis of the minor peak needs to be performed using mass spectroscopy. Interestingly, folding of $\mathrm{N}^{*}$ and $\mathrm{N}^{\prime}$ with aromatic disulfide 1 produced predominantly native protein. It seems that folding 
of $\mathrm{N}^{*}$ is slow at low concentrations of aromatic disulfide 1 compared with the rearrangement of mixed disulfide intermediates.

\subsubsection{Folding of $\mathbf{N}^{\prime}$ with aromatic disulfide 2}

Reaction of N' with aromatic disulfide $\mathbf{2}$ produced two intermediates which were proposed to be $\mathrm{N}^{\prime}(\mathrm{SAr})$ and $\mathrm{N}^{\prime}(\mathrm{SAr})_{2}$. The folding reaction was so fast that reaction of $\mathrm{N}^{\prime}$ with $0.125 \mathrm{mM}$ aromatic disulfide 2 completed within 2 min. The oxidation rate of the remaining cysteine thiol in $\mathrm{N}^{\prime}(\mathrm{SAr})$ was almost the same as the reaction rate of $\mathrm{N}^{\prime}$ to $\mathrm{N}^{\prime}(\mathrm{SAr})$. Reaction of $\mathrm{N}^{\prime}$ with aromatic disulfide 2 produced doubly mixed disulfide $\mathrm{N}^{\prime}(\mathrm{SAr})_{2}$ within $30 \mathrm{~s}$.

\subsubsection{Folding of $\mathrm{N}^{\prime}$ with aromatic disulfide 3}

Folding of $\mathrm{N}^{\prime}$ with aromatic disulfide $\mathbf{3}$ was so fast that $\mathrm{N}^{\prime}$ was oxidized completely within $15 \mathrm{~s}$. Two intermediates were observed and were proposed to be singly mixed disulfide $\mathrm{N}^{\prime}(\mathrm{SAr})$ and doubly mixed disulfide $\mathrm{N}^{\prime}(\mathrm{SAr})_{2}$. After $1 \mathrm{~min}$, folding produced $20 \% \mathrm{~N}$ and $80 \%$ doubly mixed disulfide $\mathrm{N}^{\prime}(\mathrm{SAr})_{2}$. Folding of $\mathrm{N}^{\prime}$ with only aromatic disulfide 3 became inefficient because large amount of doubly mixed disulfide was produced.

\subsubsection{Oxidative folding of reduced BPTI with aromatic disulfides 1,2 , and 3}

Pure reduced BPTI $(R)$ was refolded with aromatic disulfides 1 to examine the folding efficiency. Surprisingly, reaction of $\mathrm{R}$ with $0.25 \mathrm{mM}$ aromatic disulfide 1 produced mainly native protein (Fig. 5.10). Only a limited number of intermediates were observed. Most of the protein was converted to native protein at $6 \mathrm{~h}$. Oxidative folding of reduced BPTI to native protein was fast with aromatic disulfide 1 in the first $6 \mathrm{~h}$. The concentration of total protein from reaction of $\mathrm{R}$ 
with aromatic disulfide 1 was found to be lower at $24 \mathrm{~h}$ than folding of reduced BPTI with GSSG and GSH under the same folding condition. Folding of reduced using aromatic disulfide 1 only had $70 \%$ recovery. Loss of protein was likely to be caused by protein precipitation or undetected intermediates. However, folding with aromatic disulfide $\mathbf{1}$ is still encouraging because no kinetic trap was observed. Improving the solubility of aromatic disulfide 1 will enhance its application for the folding of disulfide containing proteins.

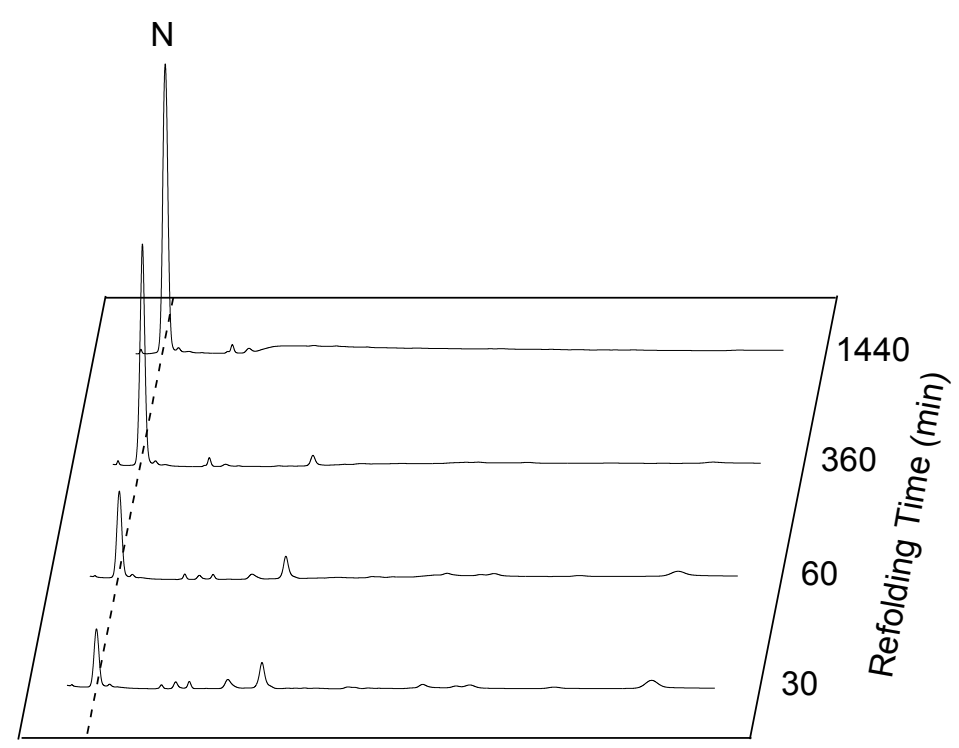

Retention Time (min)

Fig. 5.10 Oxidative folding of reduced BPTI with $0.25 \mathrm{mM}$ aromatic disulfide 1 at $\mathrm{pH} 7.3$

Reduced BPTI was refolded in the presence of $0.25 \mathrm{mM}$ aromatic disulfide 2 without thiol. Folding was monitored for the first 40 min to examine early folding intermediates because folding of reduced BPTI with aromatic disulfide 2 was expected to be fast. Reaction of $\mathrm{R}$ with aromatic disulfide $\mathbf{2}$ was fast and multiple peaks were observed after $1 \mathrm{~min}$. Most folding intermediates might be mixed 
disulfide without thiol because all peaks remained almost constant for the first 40 min. If the intermediates contained free thiol, rearrangement of the intermediates would occur resulting in a decrease in the amount of those particular folding intermediates. Rapid oxidation of thiols in reduced BPTI produced many kinetic traps, which hampered the formation of native disulfide bonds via rearrangement and oxidation. To destabilize the kinetic traps, a redox buffer containing aromatic thiol $\mathbf{5}$ and aromatic disulfide $\mathbf{2}$ was used to fold reduced BPTI. However, there was no significant decrease in the folding intermediates compared with folding by disulfide $\mathbf{2}$ only. Addition of thiol $\mathbf{5}$ didn't reduce the mixed disulfide intermediates. Folding of reduced BPTI with aromatic disulfide $\mathbf{3}$ also produced several folding intermediates. It appears that the more reactive aromatic disulfides tend to react with protein thiols rapidly resulting in the formation of mixed disulfide intermediates, which have no free thiol and remain as kinetic traps.

\subsection{Conclusion}

Folding of kinetic traps, $\mathrm{N}^{*}$ and $\mathrm{N}^{\prime}$, with aromatic disulfides was fast compared with GSSG. Formation of doubly mixed disulfides hampered the conversion of kinetic traps to native protein. Folding of reduced BPTI with aromatic disulfides produced several folding intermediates, which were very stable in a short reaction time. 


\section{Chapter 6}

\section{Conclusions and future research}

Disulfide intermediates formed during oxidative folding of reduced BPTI with GSSG and GSH were investigated. The reaction rate constants of disulfide intermediates with GSSG and GSH were determined and incorporated into a folding model. The best folding condition was explored by changing the concentrations of GSSG and GSH in terms of refolding time. Folding of reduced BPTI under the resulting best condition was examined. As a result, folding produced $93 \%$ native protein in $12 \mathrm{~h}$. Compared with reported folding results, folding of BPTI under the changing concentrations of GSSG and GSH condition is efficient.

The oxidative folding of the two kinetic traps, $\mathrm{N}^{*}$ and $\mathrm{N}^{\prime}$, and the reduced BPTI with three aromatic disulfides (1, 2 and $\mathbf{3})$ was studied. Folding proceeded via a growth type pathway towards native protein. The overall folding rate with aromatic disulfides was faster than folding with traditional disulfide, GSSG. However, a significant amount of doubly mixed disulfide, $\mathrm{N}^{\prime}(\mathrm{SAr})_{2}$ was observed during folding with $\mathrm{N}$ '. In addition, an initial folding of reduced BPTI with aromatic disulfides $\mathbf{2}$ and $\mathbf{3}$ indicated that thiols in reduced BPTI were rapidly oxidized to mixed disulfide intermediates.

Herein, I propose to fold reduced BPTI with different combinations of aromatic disulfides and thiols concentration. Aromatic disulfides are expected to oxidize the thiols to mixed disulfide intermediates, which may or may not rearrange to from native disulfide bond. If the mixed disulfide intermediates do 
not rearrange, they will stay as kinetic traps. Therefore, addition of aromatic thiols is expected to reduce the undesired intermediates and mixed disulfide intermediates. The best folding conditions involving aromatic disulfides and thiols are expected to fold reduced BPTI faster than folding with GSSG and GSH.

Kinetic traps formed during reaction of reduced BPTI with aromatic disulfides and thiols will be reacted with aromatic disulfides and thiols separately to determine the rate constants. The obtained rate constants will be used to model the folding of reduced BPTI with aromatic disulfides and thiols. The best folding condition for reduced BPTI is expected to be explored and will be examined with aromatic disulfides and thiols. The best aromatic disulfide and thiol will be used as paradigms to design other disulfides and thiols for folding of disulfide containing proteins. 


\section{References}

1. Voet, D., Voet, J. G., and Pratt, C. W. (2012) Fundamentals of Biochemistry: Life at the Molecular Level, 4th ed., Wiley.

2. McLachlan, A. D. (1972) Protein Structure and Function, Annu. Rev. Phys. Chem. 23, 165-192.

3. Anfinsen, C. B. (1972) The formation and stabilization of protein structure, Biochem. J. 128, 737-749.

4. Vendruscolo, M., Zurdo, J., MacPhee, C. E., and Dobson, C. M. (2003) Protein folding and misfolding: a paradigm of self-assembly and regulation in complex biological systems, Philos. Trans. R. Soc. Lond. Ser. A 361, 1205-1222.

5. Thornton, J. M. (1981) Disulphide bridges in globular proteins, J. Mol. Biol. $151,261-287$.

6. Anfinsen, C. B. (1973) Principles that Govern the Folding of Protein Chains, Science 181, 223-230.

7. Hartl, F. U., and Hayer-Hartl, M. (2009) Converging concepts of protein folding in vitro and in vivo, Nat. Struct. Mol. Biol. 16, 574-581.

8. Dobson, C. M. (1999) Protein misfolding, evolution and disease, Trends Biochem. Sci. 24, 329-332.

9. Huang, C., Jr., Lin, H., and Yang, X. (2012) Industrial production of recombinant therapeutics in Escherichia coli and its recent advancements, J. Ind. Microbiol. Biotechnol. 39, 383-399.

10. Kamionka, M. (2011) Engineering of Therapeutic Proteins Production in Escherichia coli, Curr. Pharm. Biotechnol. 12, 268-274.

11. Baneyx, F. (1999) Recombinant protein expression in Escherichia coli, Curr. Opin. Biotechnol. 10, 411-421.

12. Clark, E. D. B. (2001) Protein refolding for industrial processes, Curr. Opin. Biotechnol. 12, 202-207.

13. De Bernardez Clark, E. (1998) Refolding of recombinant proteins, Curr. Opin. Biotechnol. 9, 157-163.

14. Taylor, G., Hoare, M., Gray, D. R., and Marston, F. A. O. (1986) Size and Density of Protein Inclusion Bodies, Nat. Biotechnol. 4, 553-557. 
15. Rudolph, R., and Lilie, H. (1996) In vitro folding of inclusion body proteins, FASEB J. 10, 49-56.

16. Carrell, R. W., and Lomas, D. A. (1997) Conformational disease, Lancet 350, 134-138.

17. Kelly, J. W. (1996) Alternative conformations of amyloidogenic proteins govern their behavior, Curr. Opin. Struct. Biol. 6, 11-17.

18. Thomas, P. J., Qu, B.-H., and Pedersen, P. L. (1995) Defective protein folding as a basis of human disease, Trends Biochem. Sci. 20, 456-459.

19. Soto, C. (1999) Alzheimer's and prion disease as disorders of protein conformation: implications for the design of novel therapeutic approaches, J. Mol. Med. 77, 412-418.

20. Carrell, R. W., and Gooptu, B. (1998) Conformational changes and disease - serpins, prions and Alzheimer's, Curr. Opin. Struct. Biol. 8, 799-809.

21. Soto, C. (2001) Protein misfolding and disease; protein refolding and therapy, FEBS Lett. 498, 204-207.

22. Dill, K. A., Ozkan, S. B., Shell, M. S., and Weikl, T. R. (2008) The Protein Folding Problem, Annu. Rev. Biophys. 37, 289-316.

23. Baldwin, R. L. (2008) The Search for Folding Intermediates and the Mechanism of Protein Folding, Annu. Rev. Biophys. 37, 1-21.

24. Chang, J.-Y. (2011) Diverse Pathways of Oxidative Folding of Disulfide Proteins: Underlying Causes and Folding Models, Biochemistry 50, 34143431.

25. Neri, D., Billeter, M., Wider, G., and Wuthrich, K. (1992) NMR determination of residual structure in a urea-denatured protein, the 434repressor, Science 257, 1559-1563.

26. Yi, Q., Scalley-Kim, M. L., Alm, E. J., and Baker, D. (2000) NMR characterization of residual structure in the denatured state of protein $\mathrm{L}, J$. Mol. Biol. 299, 1341-1351.

27. McCarney, E. R., Kohn, J. E., and Plaxco, K. W. (2005) Is There or Isn't There? The Case for (and Against) Residual Structure in Chemically Denatured Proteins, Crit. Rev. Biochem. Mol. Biol. 40, 181-189. 
28. Shortle, D., and Abeygunawardana, C. (1993) NMR analysis of the residual structure in the denatured state of an unusual mutant of staphylococcal nuclease, Structure (London, England : 1993) 1, 121-134.

29. Hammack, B. N., Smith, C. R., and Bowler, B. E. (2001) Denatured state thermodynamics: residual structure, chain stiffness and scaling factors, $J$. Mol. Biol. 311, 1091-1104.

30. Gorovits, B. M., Seale, J. W., and Horowitz, P. M. (1995) Residual Structure in Urea-Denatured Chaperonin GroEL, Biochemistry 34, 1392813933.

31. Shortle, D., and Ackerman, M. S. (2001) Persistence of Native-Like Topology in a Denatured Protein in 8 M Urea, Science 293, 487-489.

32. Narayan, M., Welker, E., Wedemeyer, W. J., and Scheraga, H. A. (2000) Oxidative Folding of Proteins, Acc. Chem. Res. 33, 805-812.

33. Welker, E., Narayan, M., Wedemeyer, W. J., and Scheraga, H. A. (2001) Structural determinants of oxidative folding in proteins, Proc. Natl. Acad. Sci. U. S. A. 98, 2312-2316.

34. Poland, D. C., and Scheraga, H. A. (1965) Statistical mechanics of noncovalent bonds in polyamino acids. VIII. Covalent loops in proteins, Biopolymers 3, 379-399.

35. Pace, C. N., Grimsley, G. R., Thomson, J. A., and Barnett, B. J. (1988) Conformational stability and activity of ribonuclease $T_{1}$ with zero, one, and two intact disulfide bonds, J. Biol. Chem. 263, 11820-11825.

36. Creighton, T. E. (1974) Intermediates in the refolding of reduced pancreatic trypsin inhibitor, J. Mol. Biol. 87, 579-602.

37. Creighton, T. E. (1974) The single-disulphide intermediates in the refolding of reduced pancreatic trypsin inhibitor, J. Mol. Biol. 87, 603-624.

38. Weissman, J., and Kim, P. (1991) Reexamination of the folding of BPTI: predominance of native intermediates, Science 253, 1386-1393.

39. Huggins, C., Tapley, D. F., and Jensen, E. V. (1951) SulphydrylDisulphide Relationships in the Induction of Gels in Proteins by Urea, Nature 167, 592-593.

40. Gilbert, H. F. (1990) Molecular and Cellular Aspects of Thiol-Disulfide Exchange, In Adv. Enzymol. Relat. Areas Mol. Biol., pp 69-172, John Wiley \& Sons, Inc. 
41. Wedemeyer, W. J., Welker, E., Narayan, M., and Scheraga, H. A. (2000) Disulfide Bonds and Protein Folding, Biochemistry 39, 4207-4216.

42. Konishi, Y., Ooi, T., and Scheraga, H. A. (1981) Regeneration of ribonuclease $A$ from the reduced protein. Isolation and identification of intermediates and equilibrium treatment, Biochemistry 20, 3945-3955.

43. Hwang, C., Sinskey, A., and Lodish, H. (1992) Oxidized redox state of glutathione in the endoplasmic reticulum, Science 257, 1496-1502.

44. Cleland, W. W. (1964) Dithiothreitol, a New Protective Reagent for SH Groups, Biochemistry 3, 480-482.

45. Rothwarf, D. M., and Scheraga, H. A. (1993) Regeneration of bovine pancreatic ribonuclease A. 1. Steady-state distribution, Biochemistry 32, 2671-2679.

46. Rothwarf, D. M., and Scheraga, H. A. (1993) Regeneration of bovine pancreatic ribonuclease A. 2. Kinetics of regeneration, Biochemistry 32, 2680-2689.

47. Rothwarf, D. M., and Scheraga, H. A. (1993) Regeneration of bovine pancreatic ribonuclease A. 3. Dependence on the nature of the redox reagent, Biochemistry 32, 2690-2697.

48. Rothwarf, D. M., and Scheraga, H. A. (1993) Regeneration of bovine pancreatic ribonuclease A. 4. Temperature dependence of the regeneration rate, Biochemistry 32, 2698-2703.

49. Konishi, Y., Ooi, T., and Scheraga, H. A. (1982) Regeneration of ribonuclease $A$ from the reduced protein. 1. Rate-limiting steps, Biochemistry 21, 4734-4740.

50. Konishi, Y., Ooi, T., and Scheraga, H. A. (1982) Regeneration of ribonuclease $A$ from the reduced protein. 2. Energetic analysis, Biochemistry 21, 4741-4748.

51. Konishi, Y., Ooi, T., and Scheraga, H. A. (1982) Regeneration of RNase A from the reduced protein: models of regeneration pathways, Proc. Natl. Acad. Sci. U. S. A. 79, 5734-5738.

52. Talluri, S., Rothwarf, D. M., and Scheraga, H. A. (1994) Structural Characterization of a Three-Disulfide Intermediate of Ribonuclease a Involved in both the Folding and Unfolding Pathways, Biochemistry 33, 10437-10449. 
53. Shimotakahara, S., Ríos, C. B., Laity, J. H., Zimmerman, D. E., Scheraga, H. A., and Montelione, G. T. (1997) NMR Structural Analysis of an Analog of an Intermediate Formed in the Rate-Determining Step of One Pathway in the Oxidative Folding of Bovine Pancreatic Ribonuclease A: Automated Analysis of ${ }^{1} \mathrm{H},{ }^{13} \mathrm{C}$, and ${ }^{15} \mathrm{~N}$ Resonance Assignments for Wild-Type and [C65S, C72S] Mutant Forms, Biochemistry 36, 6915-6929.

54. Laity, J. H., Lester, C. C., Shimotakahara, S., Zimmerman, D. E., Montelione, G. T., and Scheraga, H. A. (1997) Structural Characterization of an Analog of the Major Rate-Determining Disulfide Folding Intermediate of Bovine Pancreatic Ribonuclease A, Biochemistry 36, 12683-12699.

55. Pearson, M. A., Karplus, P. A., Dodge, R. W., Laity, J. H., and Scheraga, H. A. (1998) Crystal structures of two mutants that have implications for the folding of bovine pancreatic ribonuclease A, Protein Sci. 7, 1255-1258.

56. Rothwarf, D. M., Li, Y.-J., and Scheraga, H. A. (1998) Regeneration of Bovine Pancreatic Ribonuclease A: Identification of Two Nativelike ThreeDisulfide Intermediates Involved in Separate Pathways, Biochemistry 37, 3760-3766.

57. Rothwarf, D. M., Li, Y.-J., and Scheraga, H. A. (1998) Regeneration of Bovine Pancreatic Ribonuclease A: Detailed Kinetic Analysis of Two Independent Folding Pathways, Biochemistry 37, 3767-3776.

58. Creighton, T. E., and Goldenberg, D. P. (1984) Kinetic role of a metastable native-like two-disulphide species in the folding transition of bovine pancreatic trypsin inhibitor, J. Mol. Biol. 179, 497-526.

59. Weissman, J. S., and Kim, P. S. (1995) A kinetic explanation for the rearrangement pathway of BPTI folding, Nat. Struct. Mol. Biol. 2, 11231130.

60. Weissman, J. S., and Kim, P. S. (1993) Efficient catalysis of disulphide bond rearrangements by protein disulphide isomerase, Nature $365,185-$ 188.

61. Dadlez, M., and Kim, P. S. (1996) Rapid Formation of the Native 14-38 Disulfide Bond in the Early Stages of BPTI Folding, Biochemistry 35, 16153-16164.

62. Creighton, T. E. (1974) Renaturation of the reduced bovine pancreatic trypsin inhibitor, J. Mol. Biol. 87, 563-577. 
63. Weissman, J. S., and Kim, P. S. (1992) Kinetic role of nonnative species in the folding of bovine pancreatic trypsin inhibitor, Proc. Natl. Acad. Sci. U. S. A. $89,9900-9904$.

64. Kibria, F. M., and Lees, W. J. (2008) Balancing Conformational and Oxidative Kinetic Traps during the Folding of Bovine Pancreatic Trypsin Inhibitor (BPTI) with Glutathione and Glutathione Disulfide, J. Am. Chem. Soc. $130,796-797$.

65. Berndt, K. D., Güntert, P., Orbons, L. P. M., and Wüthrich, K. (1992) Determination of a high-quality nuclear magnetic resonance solution structure of the bovine pancreatic trypsin inhibitor and comparison with three crystal structures, J. Mol. Biol. 227, 757-775.

66. Wlodawer, A., Nachman, J., Gilliland, G. L., Gallagher, W., and Woodward, C. (1987) Structure of form III crystals of bovine pancreatic trypsin inhibitor, J. Mol. Biol. 198, 469-480.

67. Miachel Hanson, W., Beeser, S. A., Oas, T. G., and Goldenberg, D. P. (2003) Identification of a Residue Critical for Maintaining the Functional Conformation of BPTI, J. Mol. Biol. 333, 425-441.

68. Bulaj, G., and Goldenberg, D. P. (2001) Ф-Values for BPTI folding intermediates and implications for transition state analysis, Nat. Struct. Mol. Biol. 8, 326-330.

69. Lee, B., and Richards, F. M. (1971) The interpretation of protein structures: Estimation of static accessibility, J. Mol. Biol. 55, 379-400.

70. Deisenhofer, J., and Steigemann, W. (1975) Crystallographic refinement of the structure of bovine pancreatic trypsin inhibitor at $1.5 \AA$ resolution, Acta Crystallogr. B 31, 238-250.

71. Creighton, T. E. (1978) Experimental studies of protein folding and unfolding, Prog. Biophys. Mol. Biol. 33, 231-297.

72. Creighton, T. E. (1977) Conformational restrictions on the pathway of folding and unfolding of the pancreatic trypsin inhibitor, J. Mol. Biol. 113, 275-293.

73. Creighton, T. (1992) The disulfide folding pathway of BPTI, Science 256, 111-112.

74. Weissman, J. S., and Kim, P. S. (1992) Response: The disulfide folding pathway of BPTI, Science 256, 112-114. 
75. Goldenberg, D. P. (1988) Kinetic analysis of the folding and unfolding of a mutant form of bovine pancreatic trypsin inhibitor lacking the cysteine-14 and -38 thiols, Biochemistry 27, 2481-2489.

76. Marks, C., Naderi, H., Kosen, P., Kuntz, I., and Anderson, S. (1987) Mutants of bovine pancreatic trypsin inhibitor lacking cysteines 14 and 38 can fold properly, Science 235, 1370-1373.

77. Scheraga, H. A., Konishi, Y., and Ooi, T. (1984) Multiple pathways for regenerating ribonuclease A, Adv. Biophys. 18, 21-41.

78. Zapun, A., and Creighton, T. E. (1994) Effects of DsbA on the Disulfide Folding of Bovine Pancreatic Trypsin Inhibitor and a-Lactalbumin, Biochemistry 33, 5202-5211.

79. Weissman, J. S., and Kim, P. S. (1992) The pro region of BPTI facilitates folding, Cell 71, 841-851.

80. States, D. J., Dobson, C. M., Karplus, M., and Creighton, T. E. (1984) A new two-disulphide intermediate in the refolding of reduced bovine pancreatic trypsin inhibitor, J. Mol. Biol. 174, 411-418.

81. Bass, R., Ruddock, L. W., Klappa, P., and Freedman, R. B. (2004) A Major Fraction of Endoplasmic Reticulum-located Glutathione Is Present as Mixed Disulfides with Protein, J. Biol. Chem. 279, 5257-5262.

82. Beld, J., Woycechowsky, K. J., and Hilvert, D. (2007) Selenoglutathione: Efficient Oxidative Protein Folding by a Diselenide, Biochemistry 46, 53825390.

83. Beld, J., Woycechowsky, K. J., and Hilvert, D. (2008) Catalysis of Oxidative Protein Folding by Small-Molecule Diselenides, Biochemistry 47, 6985-6987.

84. Beld, J., Woycechowsky, K. J., and Hilvert, D. (2010) Diselenides as universal oxidative folding catalysts of diverse proteins, J. Biotechnol. 150, 481-489.

85. Bachrach, S. M., Demoin, D. W., Luk, M., and Miller, J. V. (2004) Nucleophilic Attack at Selenium in Diselenides and Selenosulfides. A Computational Study, J. Phys. Chem. A 108, 4040-4046.

86. Steinmann, D., Nauser, T., and Koppenol, W. H. (2010) Selenium and Sulfur in Exchange Reactions: A Comparative Study, J. Org. Chem. 75, 6696-6699. 
87. Metanis, N., Foletti, C., Beld, J., and Hilvert, D. (2011) SelenoglutathioneMediated Rescue of Kinetically Trapped Intermediates in Oxidative Protein Folding, Isr. J. Chem. 51, 953-959.

88. Freedman, R. B., Hirst, T. R., and Tuite, M. F. (1994) Protein disulphide isomerase: building bridges in protein folding, Trends Biochem. Sci. 19, 331-336.

89. Ellgaard, L., and Ruddock, L. W. (2005) The human protein disulphide isomerase family: substrate interactions and functional properties, EMBO Rep. 6, 28-32.

90. Goldberger, R. F., Epstein, C. J., and Anfinsen, C. B. (1963) Acceleration of Reactivation of Reduced Bovine Pancreatic Ribonuclease by a Microsomal System from Rat Liver, J. Biol. Chem. 238, 628-635.

91. Venetianer, P., and Straub, F. B. (1963) The enzymic reactivation of reduced ribonuclease, Biochim. Biophys. Acta 67, 166-168.

92. Ferrari, D. M., and Söling, H. D. (1999) The protein disulphide-isomerase family: unravelling a string of folds, Biochem. J. 339, 1-10.

93. Wilkinson, B., and Gilbert, H. F. (2004) Protein disulfide isomerase, Biochim. Biophys. Acta 1699, 35-44.

94. Edman, J. C., Ellis, L., Blacher, R. W., Roth, R. A., and Rutter, W. J. (1985) Sequence of protein disulphide isomerase and implications of its relationship to thioredoxin, Nature 317, 267-270.

95. Hawkins, H. C., and Freedman, R. B. (1991) The reactivities and ionization properties of the active-site dithiol groups of mammalian protein disulphide-isomerase, Biochem. J. 275, 335-339.

96. Darby, N., and Creighton, T. E. (1995) Characterization of the active site cysteine residues of the thioredoxin-like domains of protein disulfide isomerase, Biochemistry 34, 16770-16780.

97. Creighton, T. E., Hillson, D. A., and Freedman, R. B. (1980) Catalysis by protein-disulphide isomerase of the unfolding and refolding of proteins with disulphide bonds, J. Mol. Biol. 142, 43-62.

98. Zapun, A., Creighton, T. E., Rowling, P. J. E., and Freedman, R. B. (1992) Folding in vitro of bovine pancreatic trypsin inhibitor in the presence of proteins of the endoplasmic reticulum, Proteins 14, 10-15. 
99. Kaji, E. H., and Lodish, H. F. (1993) In vitro unfolding of retinol-binding protein by dithiothreitol. Endoplasmic reticulum-associated factors, J. Biol. Chem. 268, 22195-22202.

100. Gough, J. D., Williams, R. H., Donofrio, A. E., and Lees, W. J. (2002) Folding Disulfide-Containing Proteins Faster with an Aromatic Thiol, J. Am. Chem. Soc. 124, 3885-3892.

101. Gough, J. D., Gargano, J. M., Donofrio, A. E., and Lees, W. J. (2003) Aromatic Thiol pKa Effects on the Folding Rate of a Disulfide Containing Protein, Biochemistry 42, 11787-11797.

102. Gough, J. D., and Lees, W. J. (2005) Effects of redox buffer properties on the folding of a disulfide-containing protein: dependence upon $\mathrm{pH}$, thiol $\mathrm{pK}_{\mathrm{a}}$, and thiol concentration, J. Biotechnol. 115, 279-290.

103. Madar, D. J., Patel, A. S., and Lees, W. J. (2009) Comparison of the oxidative folding of lysozyme at a high protein concentration using aromatic thiols versus glutathione, J. Biotechnol. 142, 214-219.

104. Gurbhele-Tupkar, M. C., Perez, L. R., Silva, Y., and Lees, W. J. (2008) Rate enhancement of the oxidative folding of lysozyme by the use of aromatic thiol containing redox buffers, Biorg. Med. Chem. 16, 2579-2590.

105. Patel, A. S., and Lees, W. J. (2012) Oxidative folding of lysozyme with aromatic dithiols, and aliphatic and aromatic monothiols, Biorg. Med. Chem. 20, 1020-1028.

106. Mandumula, S. M. (2009) Investigating the direct conversion of a kinetic trap to native protein during the folding of BPTI, Florida International University.

107. Zhang, J.-X., and Goldenberg, D. P. (1997) Mutational analysis of the BPTI folding pathway: I. Effects of aromatic $\rightarrow$ leucine substitutions on the distribution of folding intermediates, Protein Sci. 6, 1549-1562.

108. Lees, W. J. (2008) Small-molecule catalysts of oxidative protein folding, Curr. Opin. Chem. Biol. 12, 740-745. 
VITA

YINGSONG WANG

Born, Shaanxi, China

2003-2007

B.S., Chemistry and Materials Science

Shaanxi Normal University

Shaanxi, China

2007-2008

Laboratory assistant

Shaanxi Normal University

Shaanxi, China

$2009-2013$

Doctoral Candidate

Florida International University

Miami, Florida

Teaching Assistant

Florida International University

Miami, Florida

\section{PUBLICATIONS AND PRESENTATIONS}

Zhang, L.; Bai, C.; Wang, Y.; Jiang, Y.; Hu, M.; Li, S.; Zhai, Q. Biotechnol. Lett. 2009, 31, 1269.

Jiang, Y.; Feng, Y.; Wang, Y.; Lu, J.; Hu, M.; Li, S. Chem.-Biol. Interact. 2008, $171,325$.

Zhi, L.; Jiang, Y.; Wang, Y.; Hu, M.; Li, S.; Ma, Y. Biotechnol. Prog. 2007, 23, 729.

Lu, J.; Jiang, Y.; Hu, M.; Li, S.; Wang, Y. Chin. J. Chem. 2006, 24, 350.

Wang, Y., and Lees, W. Investigating Oxidative Folding Pathways during the Folding of Bovine Pancreatic Trypsin Inhibitor (BPTI) 2013, 245 ${ }^{\text {th }}$ ACS National Meeting 